\title{
Modelled exposure to motor vehicle generated noise at schools and early childhood centres.
}

By

Allan Schori

\begin{abstract}
A thesis
submitted to the Victoria University of Wellington

in fulfilment of the requirements for the degree of

Master of Geographic Information Science

Victoria University of Wellington

2021
\end{abstract}

Page 1 of 182 


\section{Abstract}

Motor vehicle generated noise pollution places a significant burden on the health and wellbeing of people in many urban areas and children have been identified as a particularly vulnerable group. Despite this, little is known about the extent of exposure to noise at schools and early childhood centres (ECCs), areas where children spend much of their time. To examine traffic generated noise levels at schools and ECCs, this study used the Common Noise Assessment Methods in Europe and validated the results against volunteered geographic noise measurements, using the Wellington Territorial Authority as a case study area. We examined the relationship of modelled noise values with socio-demographic variables of schools and ECCs. In addition, we assessed the relationship between modelled noise values and land use and proximity to busy roads to assess their use as proxy measures of noise. For the case study area, we found $57.7 \%$ of ECCs and $41.0 \%$ of schools exceeded the 2018 World Health Organization Environmental Noise Guidelines (53dB) and noise levels at schools and ECCs were higher compared to background levels. Schools with a higher proportion of international students, privately run ECCs, and ECCs located in the central city experienced particularly high noise levels. Compared to volunteered in situ noise measurements, our model performed reasonably: $81 \%$ of model values within $15 \mathrm{~dB}$ of a volunteered measurement. While we found the proxy noise measurement 'distance to busy roads' explained $2 \%$ of the modelled noise levels in this study. Compared to proxy measures of noise, the modelled noise levels enhanced our understanding of noise level exposure. Overall, the findings of this research highlight the magnitude and inequalities of traffic generated noise pollution on children, which may be useful for guiding

\section{Page 2 of 182}


policy to mitigate noise pollution around schools and ECCs, such as location planning and identifying areas where ameliorating noise levels is important. 


\section{Acknowledgements}

I would like to thank my supervisors, Mairéad de Róiste and Mirjam Schindler for their guidance and feedback through each stage of the research process and Barry Borman for his public health expertise. I would also like to acknowledge Stephen Haslett and Mathangi Shanthakumar for their advice on statistical methods. Finally, I thank Michael Craig for his efforts editing and proof reading. 


\section{Contents}

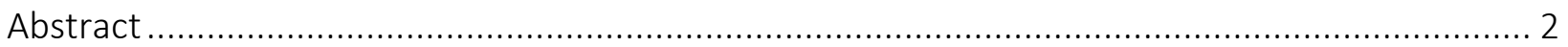

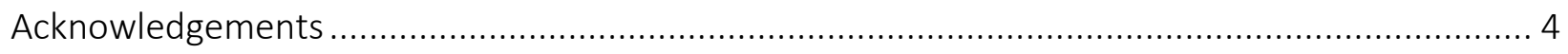

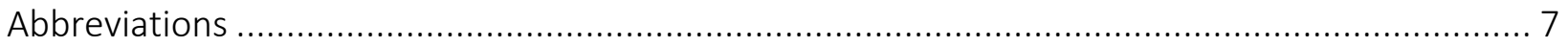

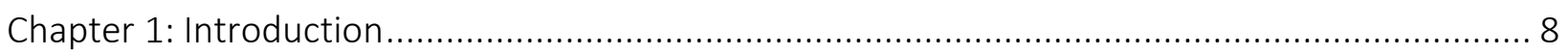

1.1 Current understanding of noise levels at schools and ECCs ..................................... 11

1.2 Noise levels at schools and ECCs in New Zealand ................................................ 13

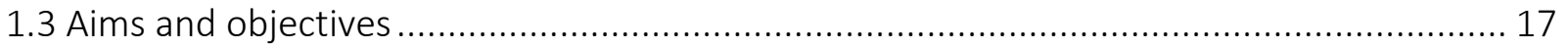

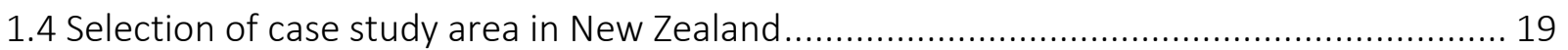

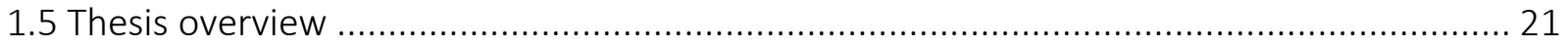

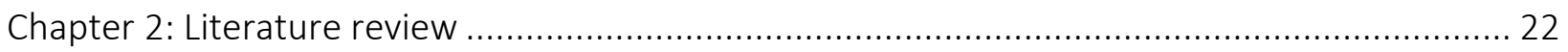

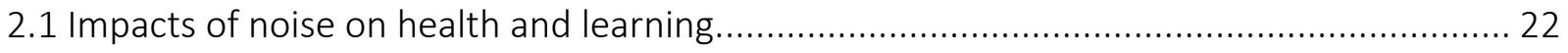

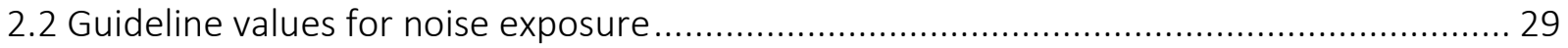

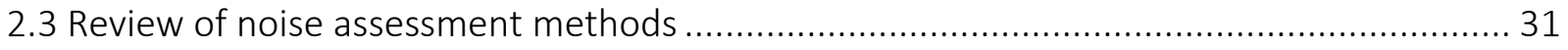

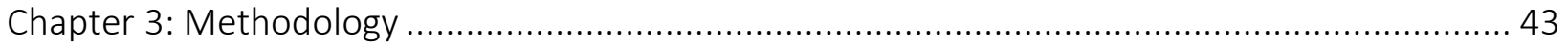

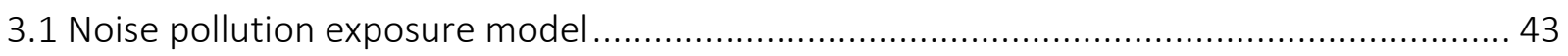

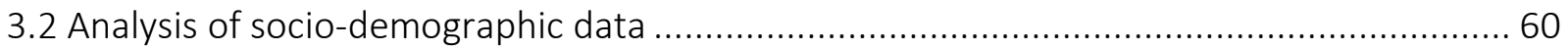

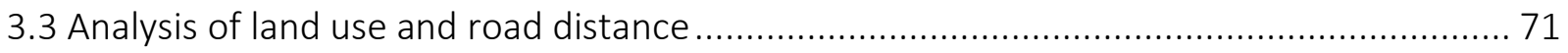

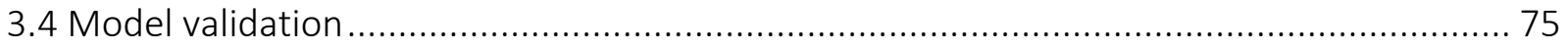

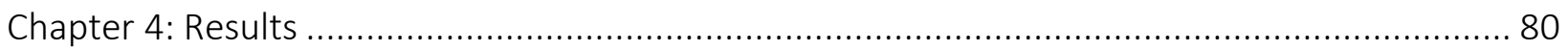

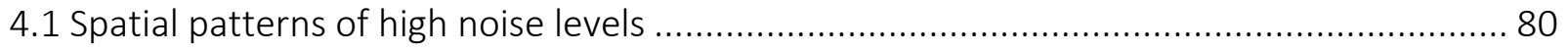

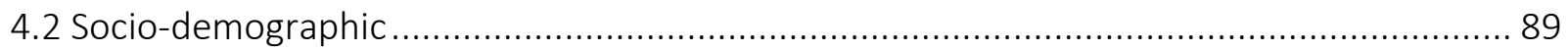




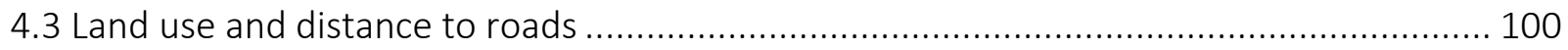

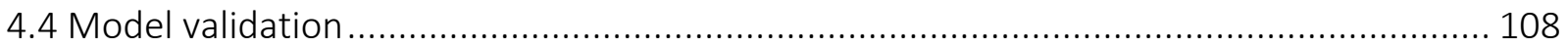

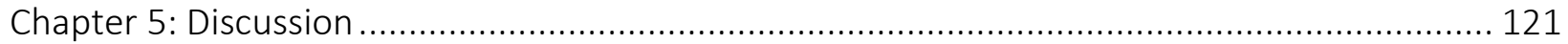

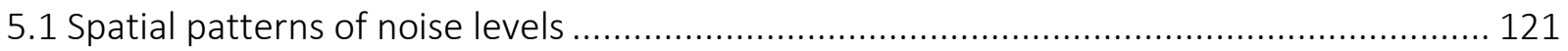

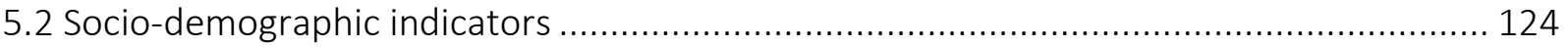

5.3 Noise levels by land use and proximity to roads ................................................... 150

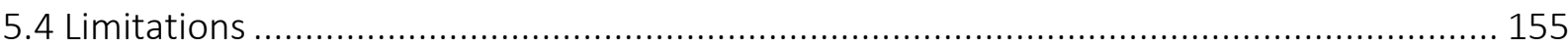

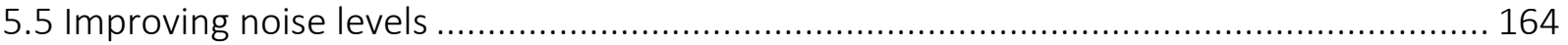

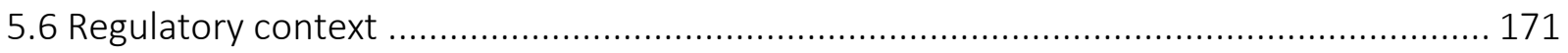

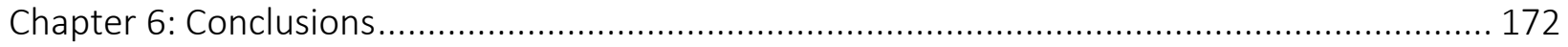

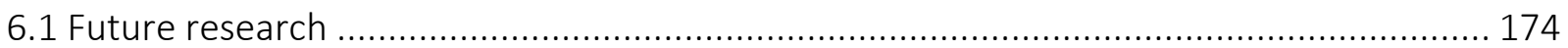

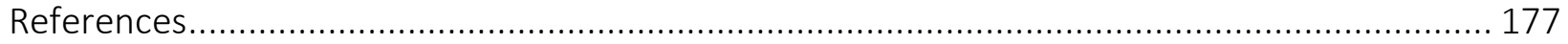

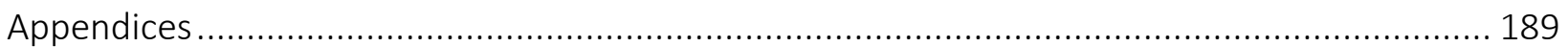

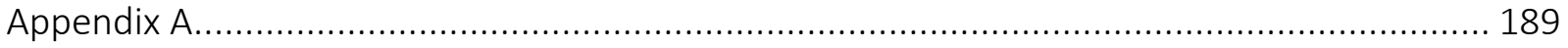

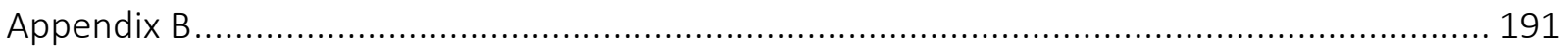




\section{Abbreviations}

\begin{tabular}{cl}
\hline Abbreviation & Meaning or description \\
\hline ARPHS & Auckland Regional Public Health Service \\
AWS & Automatic Weather Station \\
CBD & Central Business District \\
CDC & Centers for Disease Control and Prevention \\
CDHB & Canterbury District Health Board \\
CNOSSOS-EU & Common Noise Assessment Methods \\
DEM & Digital Elevation Model \\
ECC & Early Childhood Centre \\
EO & English Only language speaker \\
EQI & Equity Index \\
EV & Electric Vehicle \\
GIS & Geographic Information System \\
ICE & Internal Combustion Engine \\
L2 & English as a second language speaker \\
MELAA & Middle Eastern, Latin American, and African (ethnicity) \\
NIWA & National Institute of Water and Atmospheric Research \\
NZQA & New Zealand Qualifications Authority \\
NZTA & New Zealand Transport Agency, Waka Kotahi \\
OECD & Organisation for Economic Co-operation and Development \\
SAT & Standard Attainment Tests \\
SMA & Stone Mastic Asphalt \\
SUV & Sport Utility Vehicle \\
VGI & Volunteered Geographic Information \\
WHO & World Health Organization \\
&
\end{tabular}




\section{Chapter 1: Introduction}

Accessible transport provides access to many services that contribute to improved health and wellbeing, including employment opportunities (Gurley \& Bruce, 2005), healthcare (Wang, McLafferty, Escamilla, \& Luo, 2008), nutrition (Walker, Keane, \& Burke, 2010), and social participation (Lucas, 2012). Car use has grown in tandem with income globally (Dargay, Gately, \& Sommer, 2007) as individuals pursue improved access to resources and services to increase their standard of living. New Zealand, the US, Australia, and Canada, rank as having above average car ownership rates compared to the OECD average, with New Zealand ranking the highest (OECD, 2013). While OECD countries have made efforts to introduce cleaner, more fuel-efficient vehicles, these efforts have been largely offset by growth in vehicle numbers and use (OECD, 2013).

Having a high car-use society and increasing numbers of vehicles on our roads comes with environment and health costs. Motor vehicles inflict physical injuries, emit harmful gasses and particulate matter, and create noise, with human costs related to road safety (CDC, 2016), air pollution (Kim et al., 2004), and noise pollution (Stansfeld \& Clark, 2015). The spread of these costs flowing onto the population is likely not even and children are a particularly vulnerable group. In the US, unintentional injury was the leading cause of death for people aged 1-44 years (CDC, 2016a). Of unintentional injury to young people aged 5-24 years, the leading cause was motor vehicle traffic accidents. In children aged 1-4 years, motor vehicle traffic accidents were second only to unintentional drownings (CDC, 2016b). Similarly, children are at greater risk to health impacts from air pollution compared to the general population; they spend more time

\section{Page 8 of 182}


playing outdoors, where air pollution from traffic is greater, have higher breathing rates, narrower airways, and developing lungs and immune systems (Houston, Ong, Wu, \& Winer, 2006). Children have also been identified as a vulnerable group to noise pollution (Stansfeld \& Clark, 2015). Noise pollution affects children's ability to learn (World Health Organization, 2018) at schools and children are more vulnerable to the effects of sleep disturbance (Stansfeld \& Clark, 2015).

The impacts of physical injuries due to motor vehicle traffic crashes on children's health are often dramatic and have received much attention in the scientific community, for example, Kingham, Sabel, and Bartie (2011); Warsh, Rothman, Slater, Steverango, and Howard (2009). As a result, authorities have made efforts to improve safety, for example launching road traffic safety education campaigns at schools in Europe and Australasia (Dragutinovic \& Twisk, 2006) and modifying speeds around schools when children are present (New Zealand Transport Agency, 2011). In contrast, the impacts of noise and air pollution on children are thought to be insidious; exposure during childhood may pose little immediate risk but likely increases risk of disease later in life (Gauderman et al., 2004; Stansfeld \& Clark, 2015). For noise pollution particularly, despite children being a vulnerable group, most research has concentrated on the adult age group (Stansfeld \& Clark, 2015), when health issues eventuate. While it is important to recognise all health impacts on children associated with spending time near busy roads (i.e., injury, and exposure to air and noise pollution), this study focuses on developing an understanding of the exposure of children to noise pollution, an area which is comparatively less understood.

\section{Page 9 of 182}


High traffic volumes tend to synchronise with when children are at schools and early childhood centres (ECCs), peaking during weekdays and daytime hours (NZTA, 2018). Therefore, ECCs and schools are key locations, capturing the location of children at times where high traffic volumes likely heighten exposure to noise pollution. This study therefore focuses on exposure to noise pollution at schools and ECCs. 


\subsection{Current understanding of noise levels at schools and ECCs}

Studies to assess noise levels at schools and ECCs have predominantly used manually collected noise data. In the United Kingdom and Spain, Shield and Dockrell (2004), and Sanz, García, and García (1993), each captured noise measurements inside classrooms and on external classroom façades. In New Zealand, McLaren (2008) attached wearable noise meters to children. Such manual collection has been useful for examining the impacts of noise levels on children, including academic performance (Sanz et al., 1993; Shield \& Dockrell, 2008), and the effects of classroom features such as double glazing, building age (Shield \& Dockrell, 2004), and soft wall and roof surfaces (McLaren, 2008) on noise levels. These methods can produce results of high accuracy, for example, attaching wearable noise meters to children allows the measurement of noise level experienced at the individual level (McLaren, 2008). However, such methods do not lend themselves well to scaling up to assess exposure to noise pollution over many schools or ECCs at regional or national scales. Many of these studies include only several schools or ECCs and a limited number of classrooms (Sanz et al., 1993; Shield \& Dockrell, 2004; Yee Choi \& McPherson, 2005).

To assess noise levels at schools and ECCs at larger scales, researchers have used an indicator measure of noise pollution, proximity to busy roads (Amram, Abernethy, Brauer, Davies, \& Allen, 2011). This indicator has also been used to assess exposure to air pollution (Appatova, Ryan, LeMasters, \& Grinshpun, 2008; Chakraborty \& Zandbergen, 2007; Green, Smorodinsky, Kim, McLaughlin, \& Ostro, 2004; Wu \& Batterman, 2006). While convenient and relatively easy to execute, proximity to busy roads remains an indicator of noise levels and does not directly

\section{Page 11 of 182}


account for other variables, such as speed, road gradient, road surface, traffic volume, or interactions between barriers in the environment such as fences and buildings, all of which influence actual road noise levels experienced at the building level (Kephalopoulos, Paviotti, \& Anfosso-Lédée, 2012). As richer spatial data about roads and the environment becomes more abundant, newer methods of assessing noise which account for more variables have become possible using Geographic Information Systems (GIS). Some of these methods include statistical noise models (Aguilera et al., 2015), crowdsourced noise models (Maisonneuve, Stevens, Niessen, \& Steels, 2009), and numerical noise models (Kephalopoulos et al., 2012). Like manually collected noise methods, modelling noise levels yield quantifiable noise values. Quantifiable noise values are advantageous over indicators, enabling the evaluation of noise levels against guideline values which can be directly linked to health outcomes (World Health Organization, 2018). Quantifiable noise values also enable comparisons between measured noise values, which can provide information on how well a model has performed. 


\subsection{Noise levels at schools and ECCs in New Zealand}

The location of schools relative to busy roads as an indicator for noise and air pollution is well studied in North American cities. Across ten Canadian cities, $16.3 \%$ of schools were located within 75m of 'major roads' (expressways, highways, and main roads) (Amram et al., 2011), in the state of California, $9.5 \%$ of schools were located within $150 \mathrm{~m}$ of roads carrying at least 25,000 vehicles per day (Green et al., 2004), and in Detroit, Michigan 4.9\% of schools were within 150 m of a road carrying 50,000 vehicles per day (Wu \& Batterman, 2006). Despite motor vehicle ownership rates in New Zealand being the highest among OECD countries (OECD, 2013) and continuing to grow on a per capita basis (Annual Fleet Statistics, 2016), to our knowledge there have been no studies examining the proximity of schools or ECCs to busy roads, nor noise levels in New Zealand. Given the similarities between New Zealand's and North America's reliance on cars as a form of transport (OECD, 2013), proximity to busy roads and elevated road noise levels, is likely an issue of equal or greater magnitude in New Zealand.

In addition to high vehicle use, planning restrictions in New Zealand cities may lead schools and ECCs to open in higher traffic, commercial areas. Urban design in New Zealand is primarily shaped by local government district plans, which describe where different activities are permitted. If an activity goes against the district plan, local government may issue resource consent to permit the activity (Wellington City Council, n.d.-a). Often local councils granting resource consent for ECCs in residential areas meet strong opposition from locals. The media has reported on complaints to councils about planned ECCs due to noise generation, the destruction of street character, increased traffic, and reduced parking (Neale, 2018; Sparks, 2016, 2017).

\section{Page 13 of 182}


Residents succeeding in preventing ECCs from opening in quiet residential areas, may push ECCs into noisier, heavily trafficked commercial areas. The Canterbury District Health Board (CDHB), has also been critical of the locations of ECCs, citing local council planning restrictions in residential areas as a reason for encouraging centres to open in inappropriate locations (Canterbury District Health Board, 2017). In addition to planning restrictions, desires for increased prominence of street-side advertising and convenience for parents may further encourage schools and ECCs to locate near busy roads (Hodgson, 1981). Regardless of the drivers, any force pushing ECCs into inappropriate locations would likely mean children are inadvertently exposed to heightened noise levels, with risks to health. Due to a lack of understanding of where schools and ECCs are located within the soundscapes of urban areas, it is not yet known how often ECCs, or schools are in areas with elevated noise levels.

In New Zealand, little research exists to guide local and state government decisions about restricting the proximity of ECCS and schools to busy roads. Regardless, various health agencies have begun to release guideline information for locating new ECCs with respect to roads, albeit these guidelines are unenforceable.

The Canterbury District Health Board (CDHB) set out an information pack for new ECCs with recommendations for centres. Though the sources for these recommended actions were not present, CDHB states new ECCs should not be located within:

- 100 m of a motorway

- 20 m of a road traversed by 10,000 or more vehicles per day 
- 5 m of a 'busy' intersection, 'major' road, railway, or industrial area.

- $\quad$ Any location exceeding World Health Organization (WHO) Noise Guidelines

- $\quad$ Locations exceeding Ministry for the Environment Ambient Air Quality guidelines

(Canterbury District Health Board, 2017)

The Auckland Regional Public Health Service (ARPHS) also has guidelines for noise: not exceeding $55 \mathrm{~dB}$ for the school and outdoor playground environment from any external sources (such as traffic) during playtime (Auckland Regional Public Health Service, 2013).

Waka Kotahi, New Zealand's Transport Agency (NZTA), has signalled that exposure to transport noise is not well understood in New Zealand and its impact on health is underappreciated (Wild et al., 2021).

Studies overseas have revealed differences between proximity to roads and several sociodemographic features of schools. Across North American cities, Hispanic and Black children (Chakraborty \& Zandbergen, 2007), non-white children (Green et al., 2004), children receiving subsidised school lunches (Green et al., 2004), and schools located in lower income neighbourhoods (Amram et al., 2011) tend to be located within closer proximity of busy roads. This pattern of vulnerable socio-demographic groups being located near busy roads and therefore potentially higher noise levels is important to explore for New Zealand. In New Zealand, providing equitable health outcomes is a government priority, with the government having a duty under the Treaty of Waitangi to ensure Māori have equal or better health

\section{Page 15 of 182}


outcomes compared to non-Māori (Ministry of Health, 2014). Māori and Pacific people often fall behind in many aspects of health (Walsh \& Grey, 2019). It is therefore important to understand if some socio-demographic groups are exposed to higher noise levels than others in New Zealand.

New Zealand's high reliance on motor vehicles, planning restrictions which may disfavour locating schools and ECCs in quiet suburban areas, and potential for differences in exposure to noise levels between socio-demographic groups make it a valuable region to study. 


\subsection{Aims and objectives}

Schools and ECCs are particularly important locations to understand noise levels due to children's vulnerability to the damaging effects of noise pollution, and the potential for sociodemographic differences. Advances in GIS methods to model noise and richer road and environmental data offer an opportunity to improve our understanding of traffic noise at schools and ECCs compared to indicator measures previously used.

Given this, there is a need to i) better understand exposure to noise pollution in school and ECC environments, ii) assess whether there are socio-demographic differences in exposure to noise pollution, and iii) assess the role land use and proximity to roads plays in explaining noise pollution. These three points give rise to the research question and objectives of this study, outlined below.

\section{Research question}

- How does exposure to noise pollution at schools and ECCs vary by their spatial and sociodemographic characteristics?

To answer the research question above, the following three objectives must be met:

\section{Objectives:}

- Model noise levels to identify schools and ECCs located in areas of high traffic-generated noise pollution, relative to health guidelines and background levels.

- Examine the relationship between socio-demographic indicators of schools and ECCs and exposure to noise pollution.

\section{Page 17 of 182}


- Examine the relationship between noise levels and land use and busy roads.

Increasing knowledge around the level of exposure to noise levels and whether sociodemographic differences exist would be of interest for groups involved in the health and education sectors and would enable those making decisions about urban planning to design urban areas which minimise the effects of noise pollution on children. 


\subsection{Selection of case study area in New Zealand}

To assess whether noise pollution varies between schools and ECCs of different sociodemographic characteristics, we chose a case study area with a varied road scape and considerable sample size of schools and ECCs. Wellington City, as defined by the territorial authority boundary (Figure 1), is a moderately sized city (pop. 190,000) with a dense Central Business District (CBD). Its road scape is varied, characterised by quiet suburban roads, busier roads nearer the $\mathrm{CBD}$ and areas adjacent to highways with traffic volumes bolstered by commuters from satellite towns (Hutt City and Porirua City). Wellington City contains 82 schools and 167 ECCs. Bordered by commuter towns, and with a monocentric layout, Wellington is also representative of many other cities in New Zealand (e.g., Christchurch, Dunedin). 

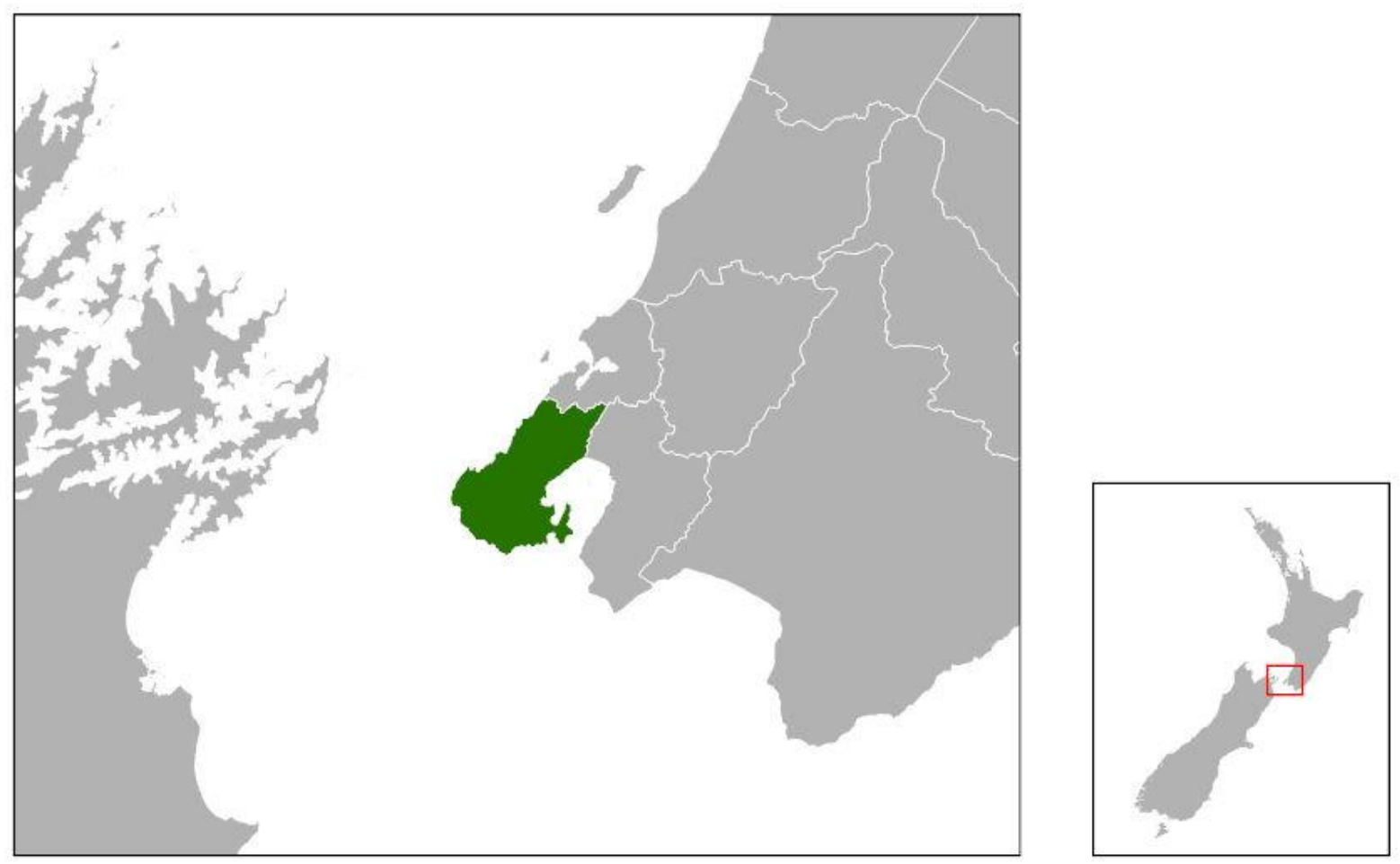

Figure 1: Location of the Wellington City Territorial Authority within New Zealand

Page 20 of 182 


\subsection{Thesis overview}

In Chapter 2, we examine the impact of noise on children's health through literature review, examine threshold noise values and their relationship with health, and review and justify the selection of a GIS method to model noise pollution for this study.

Chapter 3 describes the data and methods used to evaluate traffic noise in the case study area, and the statistical analyses used to assess the relationship between traffic noise and sociodemographic variables, land use and distance to roads. We also describe how the model output is validated against in situ volunteered noise measurements.

The results for the study, including spatial patterns of noise pollution, socio-demographic, land use, distance to roads, and model validation, are presented in Chapter 4.

In Chapter 5, we discuss the findings of the research and examine their significance in a regulatory context, how we might improve noise levels, and the limitations of the study, including those arising from the model validation.

Chapter 6 summarises the main conclusions of the study and identifies future areas of research. 


\section{Chapter 2: Literature review}

In this chapter we assess the health impacts of noise on children at ECCs and schools, justify the threshold noise values in relation to health impacts, and review noise assessment methods to model noise levels for this study.

\subsection{Impacts of noise on health and learning}

Excessive noise levels place a considerable burden on both children's health, wellbeing, and learning. In New Zealand, an estimated 60 people die each year due to the aggregated effects of traffic noise pollution (Briggs, Mason, \& Borman, 2015), and children have been identified as a group particularly vulnerable to some of the effects of noise, specifically in the school environment (Berglund, Lindvall, \& Schwela, 1999). In 2018, the World Health Organization released Environmental noise guidelines for the European Region and identified the following outcomes relating to exposure to environmental noise:

- Adverse birth outcomes

- Annoyance

- Cardiovascular disease

- Cognitive impairment

- $\quad$ Effects on sleep

- Hearing impairment

- Metabolic outcomes

- Quality of life, metal health and wellbeing 
(World Health Organization, 2018)

Many of these health risks associated with exposure to excessive noise do not occur in isolation. Often there are strong linkages between health and wellbeing issues, for example, stress and diabetes are linked to cardiovascular disease (World Health Organization, 2018). They also occur across different temporal scales. The effects of traffic noise on communication are immediate; oral comprehension is disrupted during the periods of elevated noise. While others, such as hearing impairment relate to long term exposure to elevated noise levels. In this section we explore the impacts of road traffic noise on human health and wellbeing, focusing on the relevance for schools and ECCs.

\section{Adverse birth outcomes}

The World Health Organization recognises adverse birth outcomes as a possible effect of exposure to high noise levels (World Health Organization, 2018). One study found some evidence for reductions in birth weights (Passchier-Vermeer \& Passchier, 2000). For most children at schools and ECCs, adverse birth outcomes are not relevant. However, for teen parent units, adverse birth outcomes due to high noise levels may be of concern. There is one such unit in the Wellington Territorial Authority.

\section{Annoyance}

'Noisiness' is the general term used to describe how humans perceive noises based on a combination of qualities such as sound level, sound level distribution, frequency spectrum, single noise events, variations, familiarity, and predictability (Berglund et al., 1999). Noisiness is a

\section{Page 23 of 182}


subjective measure; different people can perceive some sounds as pleasant, and others as annoying. For example, rainfall sounds, bird sounds, and church bells can often enhance a soundscape, while noises such as construction and road noise are often perceived as annoying (Jeon, Lee, You, \& Kang, 2010). Because noisiness is tied to psychological experience, there is not a predictable relationship between qualities of noise (Berglund et al., 1999). Two sounds of equal noise level might not be perceived as having the same noisiness, though in general, for sounds perceived as annoying, the louder the sound the more annoyance is generated (Jeon et al., 2010). While annoyance in itself is psychosomatic, it is considered a causal pathway to cardiovascular disease (World Health Organization, 2018), it may also be a driver for poor cognitive performance (Andringa \& Lanser, 2013) and have negative effects on sleep quality (Kim et al., 2012).

\section{Cardiovascular health}

Traffic noise is most commonly associated with cardiovascular problems in adults. Increases in blood pressure and risk of ischemic heart disease have been observed in adults exposed to high levels of road noise (Passchier-Vermeer \& Passchier, 2000). However, in school environments, high systolic and diastolic blood pressures has been reported in children exposed to high levels of traffic noise (Passchier-Vermeer \& Passchier, 2000). Similarly, children in early childhood centre environments with higher noise levels also recorded higher blood pressure compared to children in quieter environments (Passchier-Vermeer \& Passchier, 2000). While cardiovascular risk is small for children, the life time consequences of elevated blood pressure in childhood is currently unknown (Stansfeld \& Clark, 2015).

\section{Page 24 of 182}


Cardiovascular disease has many causal pathways which are linked to noise levels including metabolic outcomes, sleep, and mental health and wellbeing (World Health Organization, 2018).

\section{Cognitive impairment}

The WHO identifies reading and oral comprehension, short and long-term memory deficits, attention deficits, and executive function deficits (working memory) as cognitive impairments associated with exposure to elevated noise levels (World Health Organization, 2018). These impairments are important to consider in school and ECC environments because of their effect on education. Education is strongly linked with better outcomes later in life, including higher starting wages and better income trajectories which is in turn linked to health, through better access to healthcare and lowered stress (Lynch, 2006).

At higher noise levels, students have difficulty differentiating between different sounds within words (Nelson, Kohnert, Sabur, \& Shaw, 2005). Poor speech perception between students and teachers means knowledge and new ideas are not communicated between students and teachers, thus impacting children's ability to learn and their educational outcomes. Hearing impaired children and children who do not have the same native language as the main language in which classes are taught, are particularly impacted by speech perception issues at elevated noise levels. For these groups of children, speech perception begins to decline at lower noise levels (Hétu, Truchon-Gagnon, \& Bilodeau, 1990; Nelson et al., 2005).

Noise in classrooms not only affects the communication of ideas between students and teachers, but also the concentration and attention of the individual (Hétu et al., 1990). Exposure to noise

\section{Page 25 of 182}


interferes with the encoding stage of memory and inner dialog (Hygge, 2003; Poulton, 1978), resulting in lack of attention in the classroom, slowness in learning to read and helplessness behaviour (Hétu et al., 1990). Children afflicted by anxiety tend to exhibit the greatest decreases in attention with higher classroom noise levels (Hétu et al., 1990).

In classrooms, the impact on learning should be considered, as well as the impact of teachers' ability to teach with loud background noises. Road traffic noise can create environments which teachers consider unsatisfactory and detrimental to their ability to teach (Hétu et al., 1990; Sargent, Gidman, Humphreys, \& Utley, 1980). Interruptions from loud bursts of noise, such as vehicle horns or emergency service sirens, cause disruptions which contribute to significant losses in classroom teaching time (Weinstein, 1979).

\section{Effects on sleep}

Sleep is important for the recovery and repair of many of the body's organs and systems, including the brain and cardiovascular system (Passchier-Vermeer \& Passchier, 2000). Elevated night-time noise affects many aspects of sleep, including leading to multiple awakenings, changes to cardiovascular systems (e.g. heart rate), hormone levels, affecting self-rated sleep quality and mood the following day (Passchier-Vermeer \& Passchier, 2000).

For older, school-aged children, the effects of traffic noise on sleep are not relevant in the school environment as sleep does not take place during school hours. However, for young children (ECC age), sleep cycles are broken into nocturnal sleep and daytime napping. Like night-time traffic noise for adults and older children, daytime traffic noise could also disrupt naptime in ECCs.

\section{Page 26 of 182}




\section{Hearing impairment}

Damage to hearing can occur from both short-term exposure to periods of very high noise levels (e.g., horns and sirens) and chronic exposure to elevated noise levels (e.g., traffic noise). Exposure to very high levels of noise can damage the ear drum and other structures within the ear. Chronic exposure to elevated noise levels cause the loss of the fine hair structures in the inner ear (Berglund \& Lindvall, 1995). Hearing impairments are socially disabling, affecting one's ability to understand speech and communicate with others. Hearing impaired people may be excluded from social situations resulting in isolation and loneliness, and poorer performance at work (Passchier-Vermeer \& Passchier, 2000; World Health Organization, 2020). Animal studies suggest younger children may be particularly sensitive to hearing impairment from high noiselevels, more so than adults (Passchier-Vermeer \& Passchier, 2000).

\section{Metabolic outcomes}

Long-term noise exposure may be associated with the development of type 2 diabetes (Dzhambov, 2015) and obesity (Oftedal et al., 2015). Noise can stimulate hypothalamic-pituitaryadrenal hormones which can decrease insulin production and decrease insulin sensitivity, leading to type 2 diabetes. Reactions to noise induced stress also induce behavioural changes, such as excessive consumption of food (Passchier-Vermeer \& Passchier, 2000), which can contribute to obesity and the risk of developing type 2 diabetes. Chronic sleep deprivation is a causal pathway to poor metabolic health outcomes, increasing both fasting glucose levels and appetite (Dzhambov, 2015).

\section{Page 27 of 182}


Quality of life, mental health, and wellbeing

Elevated noise levels may result in an increased release of stress hormones for children, which may affect mental health and wellbeing. In one study, the stress hormones epinephrine and norepinephrine levels rose significantly in children living beneath a newly designated flight path (Passchier-Vermeer \& Passchier, 2000). 


\subsection{Guideline values for noise exposure}

It is clear from the different dimensions explored earlier in this chapter that noise has many impacts on learning and health and noise may be negatively impacting children at schools and ECCs. Guideline values are an important component needed to assess exposure to excessive noise levels. Guideline values provide a noise level, above which many of the aforementioned health risks begin to have substantial effects. Agreed guideline values are often set with the general population in mind. Vulnerable populations, such as the elderly, deaf, young children and foreign language listeners may be affected at lower guideline values (Berglund \& Lindvall, 1995). Guideline values can also vary widely depending on the time of day and the health risk of interest. For example, it is generally considered that there is negligible risk of hearing loss for short term noise exposure below $75 \mathrm{~dB}$, while noticeable effects on sleep occur at noise levels as low as 30dB (Berglund \& Lindvall, 1995). Similarly, for annoyance, many people are only affected at noise levels above $55 \mathrm{~dB}$ during the day, dropping to $45-50 \mathrm{~dB}$ at night time.

In consideration of some of these variations, guideline values are often grouped by broad categories for night time activities and daytime activities. For school and ECC environments, noise levels of below $55 \mathrm{~dB}$ outside have been proposed as generally safe, while a limit of $35 \mathrm{~dB}$ inside has been suggested to facilitate conversation along with $30 \mathrm{~dB}$ in sleeping rooms in ECCs to facilitate an undisturbed sleep (Berglund \& Lindvall, 1995). While there a numerous proposed threshold noise values, in this study we will use the 2018 WHO Environmental Noise Guidelines (World Health Organization, 2018). The 2018 WHO Environmental Noise Guidelines use the most up to date evidence to justify threshold noise levels for the general population, and were the

\section{Page 29 of 182}


guidelines used by New Zealand's transport agency, Waka Kotahi at the time of this study (Wild et al., 2021). The WHO guidelines for environmental noise provide two guideline values: $45 \mathrm{~dB}$ for night time noise levels and 53dB for daytime noise levels. 


\subsection{Review of noise assessment methods}

To assess the extent to which noise is an issue for schools and ECCs, we require an assessment of noise exposure for schools, ECCs and background levels within the Wellington Territorial Authority. This section examines the available methods to assess noise levels, compares the advantages and disadvantages of each method, and justifies the selection of a noise model most suitable for this research. We consider several factors when selecting the most suitable model for this study including spatial resolution, model performance and costs (e.g., monetary, time, and computing power).

Spatial resolution is an important factor; an assessment of noise to the building-level resolution is required to estimate the noise exposure for individual schools and ECCs. Buildings are a good indication of where children spend time within schools and ECCs, especially for noise sensitive activities, such as learning and sleeping. Model performance is also important, the closer the model reflects real world noise levels, the more useful the conclusions can be drawn from the output. Though, while complex models can produce results which accurately reflect the real world, they may be computationally expensive with diminishing returns. Following the 'Garbage In, Garbage Out' principle (McCarthy \& Ratcliffe, 2005), the limits of output accuracy may be reached by the accuracy of the data supplied into the model, rather than the model itself.

Costs for models can be monetary or relate to time or computing power. Original data required for some models is both time and monetarily expensive to collect, but costs can be minimised by 
using data already available. Other monetary costs, such as licensing of proprietary software and computing power, are also a consideration.

\section{Noise model types}

Methods to spatially model noise pollution most commonly involve either statistical or numerical models. Statistical models use a sample of noise measurements in the environment fitted to predictor variables to model levels across a greater area (Aguilera et al., 2015; Ragettli et al., 2016; Xie, Liu, \& Chen, 2011). Numerical models use physical and experimentally derived laws to model the level of noise produced at a source and the propagation of this noise through the environment. Crowd sourcing noise measurements is a novel method to assess exposure to noise (Maisonneuve et al., 2009). However, crowd sourcing methods have thus far resulted in outputs of relatively sparse data coverage (Dutta, Pramanick, \& Roy, 2017). In future, limitations may be overcome with statistical or numerical propagation techniques, but the field is currently not well developed (Dutta et al., 2017). As crowd sourced noise measurements cannot yet provide adequate data coverage, we will only consider the more established statistical and numerical models for this research.

\section{Statistical models}

Notable studies using statistical noise models include Aguilera et al. (2015), Ragettli et al. (2016), and Xie et al. (2011). Common noise predictor variables are population density, building density, road length, and green space. The outputs for these studies are of limited spatial resolution and therefore limited use for areas of high noise variability, including most urban areas. It is unlikely

\section{Page 32 of 182}


that these models can provide an assessment of noise levels at the building resolution. Statistical models also rely on a sample of in situ noise levels in the environment to train the model. Not only is this data time and monetarily expensive to collect, but samples of noise include noise generated by all sources in the environment. The outputs are therefore unable to differentiate between noise produced by road traffic and noise produced by other sources, such as rail or airways (Aguilera et al., 2015). Differentiating traffic noise from other sources is important for the impacts of annoyance, as annoyance relates to qualities of noise other than noise levels. For example, loud bird calls or church bells (if perceived as pleasant), may have less impact on annoyance compared to loud traffic noise. Due to the limited spatial resolution, costs, and inability to differentiate noise sources, statistical models are less suitable for modelling traffic noise for this study.

\section{Numerical models}

Numerical models, in contrast, do not rely on in situ noise measurements. An estimate of the level of noise at any given point in space is made by applying physical and experimentally derived laws to data about characteristics of the road and surrounding environment. Figure 2, gives a schematic of the function of a numerical model for a source point.

\section{Page 33 of 182}




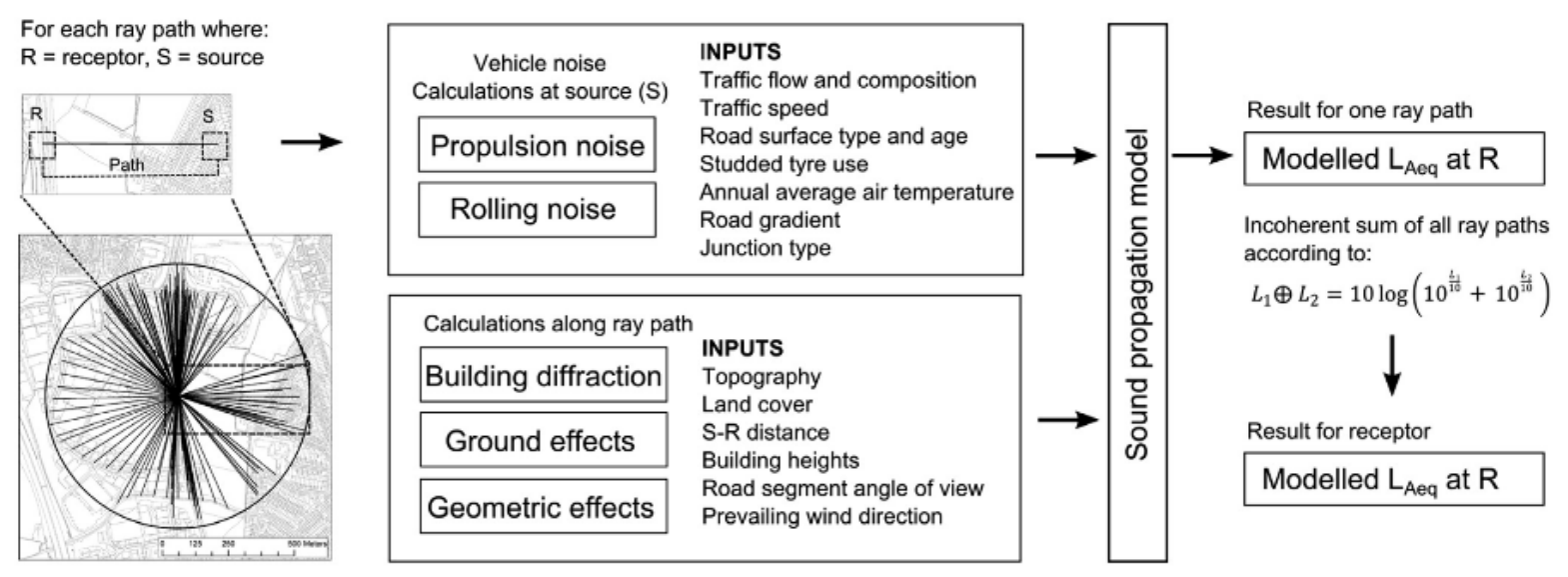

Reprinted from Environmental Pollution, 206, D.W. Morley,K. de Hoogh,D. Fecht,F. Fabbri,M. Bell,P.S. Goodman,P. Elliott,S. Hodgson,A.L. Hansell,J. Gulliver, International scale implementation of the CNOSSOS-EU road traffic noise prediction model for epidemiological studies,10., Copyright (2015), with permission from Elsevier.

Figure 2: Schematic workflow of a numerical noise model, CNOSSOS-EU

Source: Morley et al. (2015)

A road is divided into a series of source points (S) from where noise is generated. These source points contain attribute information about the road, which is required to calculate the noise generated. In general, noise generated at the source point is divided into two types: rolling noise and propulsion noise. Rolling noise is the noise generated through the interaction of the tyre with the road surface and mostly depends on the traffic flow and road surface type, but is also modified by other factors (Poulikakosa et al., 2016). Propulsion noise is noise emitted by the vehicle's engine, including the fans, gears and exhaust and is mostly dependent on the engine configuration (i.e. vehicle class; light, heavy vehicles), as well as the load placed on the engine through slope or speed, is also modified by other factors (Poulikakosa et al., 2016). 
Receiver points $(R)$ are points for which a noise level is being calculated (e.g., a building façade). Receiver points are paired with multiple source points. Lines (rays) are constructed to connect receiver-source point pairs. This raytracing simulates how noise waves travel from the source point through the environment to the receiver point. Raytracing also accounts for environmental variables which modify how the noise propagates in the environment. Modifying factors include noise barriers (e.g., fences, buildings), which block noise, cause diffraction (bending of noise waves around a barrier) or reflection. Other modifying factors include land cover, which modify how much noise energy is absorbed by the surface type, for example, grass absorbs more sound energy than concrete, and climate: wind direction and temperature. The models iterate raytracing for each source point-receiver point combination within a specified maximum ray length. The noise energy at each receiver point is calculated by summing each of the ray traces paired with the receiver point.

Source points in numerical models are also noise-source specific. A different set of physical and experimentally derived laws exist to calculate noise generated from different sources. For example, the generation of noise from railways can be estimated by laws in relation to how the track base, rail head roughness, locomotive type (electric, diesel) and other properties, interact and produce noise (Kephalopoulos et al., 2012). Road noise, for example, can be estimated by the interaction between different properties, such as vehicle type and road surface (Kephalopoulos et al., 2012).

Numerical models using propagation techniques can create outputs of higher accuracy and with finer spatial resolution compared to statistical models, so are likely to perform better in urban 
areas which have high spatial noise variability. Data for numerical models is also often preexisting as it is used for other applications, e.g. road traffic counts are used for traffic management, road safety and surface renewal decisions (Christchurch City Council, n.d.), but are used for numerical noise models as well. Therefore, given the finer spatial resolution, ability to isolate road noise and minimisation of data costs, a numerical noise model is advantageous for this study.

There are many numerical models (Table 1 ), these numerical models typically follow the same general setup described earlier (Figure 2) but differ by which variables are incorporated in the noise calculation and how each of these variables interact through different experimentally derived laws. Generally, these specifications are defined by a noise assessment standard which is established by a panel of noise experts.

\section{Noise assessment standards}

Noise assessment standards ('standards') specify which physical properties are incorporated in the noise calculation and the experimentally derived laws. There is currently no ISO (International Organization for Standardization) standard for modelling noise pollution. Instead, numerous standards have been developed and adopted in various regions of the world (Table 1). In New Zealand, Australia, and the United Kingdom, the CoRTN standard (Department of Transport Welsh Office, 1988) is the most broadly used standard, adopted by both the NZTA and Ministry of Transport in New Zealand (Standards New Zealand, 2010), widely in Australia (Peng, Kessissoglou, \& Parnell, 2017) and the United Kingdom where it originated.

\section{Page 36 of 182}




\begin{tabular}{|c|c|}
\hline Standard & Region \\
\hline Nord 2000 Road & Scandinavia \\
\hline RVS 3.02/4.02 & Austria \\
\hline NMPB - Routes, Guide de Bruit 1996 and 2008 & France \\
\hline RLS 90 & Germany \\
\hline Calculation of Road Traffic Noise (CoTRN) & Great Britain \\
\hline ASJ - Model B 1998 and 2003 & Japan \\
\hline TNM & United States \\
\hline ASJ - Model 2008 & - \\
\hline DIN 18005 & Germany \\
\hline Statens Planverk 48 & Scandinavia \\
\hline Calculation of Road Traffic Noise & Scandinavia \\
\hline StL-86, StL-9/StL 97 & Switzerland \\
\hline Federal Highway Model & United States \\
\hline VBUS & Germany \\
\hline
\end{tabular}


TNM (FHWA) 1998

HJ 2.4 - 2009

Russian Road Model

CNOSSOS-EU
United States

China

Russia

European Union

Source: (SoundPlan, n.d.)

When reviewing different standards, Rajakumara and Gowda (2008) cautioned that standards tend to be designed to meet the requirements of government regulations or other design specifications. No current model fits a 'theoretically ideal model', and different weaknesses and errors exist within all the standards assessed. Hence, while the CoRTN standard is most widely used in New Zealand, it may not necessarily be the best performing standard for every use.

Selecting the best performing standard to use in a study is difficult. Studies have attempted to compare the performance of different standards de Lisle (2016) ran models to the Calculation of Road Traffic Noise (CoRTN), Acoustical Society of Japan-Road Traffic Noise (ASJ RTN), and Noise Propagation Computation Method Including Meteorological Effects (NMPB) standards for the same region and compared the over or under prediction of various standards to 39 in situ measurements. The CoRTN standard drew criticism, with de Lisle (2016) arguing that the standard is antiquated and many of the simplifications that allow for hand calculations mean

\section{Page 38 of 182}


developments of complex algorithms are absent. In many cases, this leads to over-predictions (de Lisle, 2016).

Peng, Parnell, and Kessissoglou (2019) examined the performance of the CoRTN, Traffic Noise Model (TNM) and Common Noise Assessment Methods in Europe (CNOSSOS-EU) standards for two locations in Sydney, Australia. The methodology, identical to de Lisle (2016), compared outputs from each standard to in situ measurements. However, errors in this study were likely smaller since noise levels were sampled coincidentally with the traffic data feeding into the models. The study found all three standards performed similarly in the urban arterial road setting (-0.3dB deviation from measured), but the CoRTN standard performed poorly $(-0.7 \mathrm{~dB}$ deviation from measured) in the interstate freight route setting compared to CNSSOS-EU $(-0.6 \mathrm{~dB}$ deviation from measured) and TNM (-0.2dB deviation from measured).

Although some standards performed better than others, the performance was site-specific, making it difficult to rank standards (de Lisle, 2016; Peng et al., 2019). In both studies, the CoRTN standard performed poorly and drew criticism for being overly simplistic.

The selection of the best performing standard is also constrained by data availability for the study area. Most standards require certain data resolutions, both spatial and temporal. To meet the standard, data must be collected to the resolutions specified. Collecting original data to fit a best performing model for individual studies would be resource and time expensive. For this reason, models often rely on using data primarily collected by local agencies as part of a wider traffic monitoring for traffic management and making resurfacing decisions (Christchurch City

\section{Page 39 of 182}


Council, n.d.). Most standards are driven by local regulators (Rajakumara \& Gowda, 2008), and therefore regions are typically locked into their local standard. In a New Zealand setting, the CoRTN standard is the most frequently used, but has drawn some criticism, such as poorer performance on interstate type roads Peng et al. (2019), and sometimes high over prediction (de Lisle, 2016), possibly due to the absence of many recently developed algorithms in the model (de Lisle, 2016).

While most standards were designed as country-specific standards, the CNOSOSS-EU standard was designed as an international standard between EU member states (Kephalopoulos et al., 2012). After the development of CNOSOSS-EU, (Morley et al., 2015) investigated implementation with different data resolutions which would allow international comparisons. The study used Leicester, England as the study area. The study deployed the CNOSOSS-EU standard across datasets of multiple resolutions to simulate the use of different regional data. Unlike the rest of the European Union, the United Kingdom typically uses the CoRTN standard, for example, (Gulliver et al., 2015). Morley et al. (2015) successfully implementing CNOSOSS-EU in a typically CORTN region suggests that CNOSOSS-EU could be implemented internationally and importantly in a region where CoRTN is broadly used such as New Zealand. The study also compared CNSOSS-EU performance to that of CoRTN. The overall performance of the two models was statistically similar.

In this study, we will employ the CNOSOSS-EU model because of criticisms of the CoRTN model, and similar or better performance of CNOSOSS-EU compared to CORTN.

\section{Page $\mathbf{4 0}$ of 182}




\section{CNOSSOS-EU standard}

The CNOSSOS-EU standard was developed by a panel of 150 noise experts, primarily supported by the European Environment Agency and World Health Organization. The purpose was to develop a common standard for European Union member states to map noise levels, for the purpose of assessing exposure for public health (Kephalopoulos et al., 2012).

Implementing standards in a Geographic Information System (GIS) No official tool was released with the CNOSOSS-EU to implement the standard; however, such a tool has been suggested for future development. In place of an official tool, both opensource and proprietary GIS tools have been developed to implement the standard.

Proprietary software options include SoundPlan (SoundPlan, n.d.) and CadNaA (Computer Aided Noise Abatement) (DataKustik, n.d.). Opensource options include OpeNoise; a QGIS plugin developed by Agenzia Regionale per la Protezione Ambientale (ARPA, English: The Regional Agency for the Protection of the Environment), Piedmont Italy (Environmental Protection Agency of Piedmont Italy, 2019a). Other studies have implemented the standard using tailored PostGIS/PostGreSQL applications (Morley et al., 2015).

All tools (SoundPlan, CadNaA, OpeNoise, and the tailored PostGIS/PostGreSQL applications) were developed in accordance with the framework in the CNOSSOS-EU standard. To minimise costs, in this study we used the opensource software, OpeNoise (Environmental Protection Agency of Piedmont Italy, 2019a).

\section{Page 41 of 182}




\section{Chapter 3: Methodology}

In this chapter, we describe the data and methods required to model noise levels across the Wellington Territorial Authority, examine noise levels by school and ECC socio-demographic characteristics, examine noise levels by land use and distance to roads, and assess the validity of the noise model against volunteered noise measurements.

\subsection{Noise pollution exposure model}

In section 2.3, we justified the selection of the Common Noise Assessment Methods in Europe (CNOSSOS-EU) as the most suitable standard to model noise levels for this study. This section now describes the implementation of the CNOSSOS-EU standard to model noise to the buildinglevel for the Wellington Territorial Authority. The standard was implemented using OpeNoise (version 1.3) in QGIS v3.3.1-Noosa, released on GitHub, October 2019 (Environmental Protection Agency of Piedmont Italy, 2019b). 


\section{Spatial noise model data}

A summary of the spatial data needed to implement the CNSOSS-EU standard for the study area is presented in Table 2. Each of these data and their use within the model are explained further below.

Table 2: Data used to model road noise for given schools and ECCS using the CNOSSOS-EU standard in OpeNoise

\begin{tabular}{|c|c|c|c|c|c|}
\hline Name & Usage & Geometry & Attribute variables & Year of data & Source \\
\hline Building outlines & $\begin{array}{l}\text { Noise barriers, Building } \\
\text { receptors. }\end{array}$ & Polygons & Building ID & 2019 & $\begin{array}{r}\text { Land } \\
\text { Information } \\
\text { New Zealand } \\
\text { (2019) }\end{array}$ \\
\hline \multirow{4}{*}{ Roads } & \multirow{4}{*}{$\begin{array}{l}\text { Calculation of rolling and } \\
\text { propulsion noise }\end{array}$} & \multirow{4}{*}{ Lines } & $\begin{array}{l}\text { Slope (percent). } \\
\text { Derived from } \\
\text { digital elevation } \\
\text { model. }\end{array}$ & 2013-2014 & $\begin{array}{r}\text { Land } \\
\text { Information } \\
\text { New Zealand } \\
\text { (2017) }\end{array}$ \\
\hline & & & $\begin{array}{l}\text { Heavy traffic rate } \\
\text { (vehicles per hour) }\end{array}$ & $\begin{array}{r}\text { Varies by } \\
\text { road } \\
\text { segment }\end{array}$ & NZTA (2019) \\
\hline & & & $\begin{array}{l}\text { Light traffic rate } \\
\text { (vehicles per hour) }\end{array}$ & $\begin{array}{r}\text { Varies by } \\
\text { road } \\
\text { segment }\end{array}$ & NZTA (2019) \\
\hline & & & $\begin{array}{l}\text { Vehicle velocity } \\
(\mathrm{km} / \mathrm{h}) \text {. Derived } \\
\text { from posted speed } \\
\text { limit. }\end{array}$ & $\begin{array}{r}2019 \text { (year } \\
\text { data } \\
\text { extracted) }\end{array}$ & $\begin{array}{r}\text { OpenStreetMap } \\
\text { (2019) }\end{array}$ \\
\hline Temperature & Correction of rolling noise & Point & $\begin{array}{l}\text { Temperature } \\
\text { (degrees Celsius). }\end{array}$ & $\begin{array}{r}\text { Annual } \\
\text { average } \\
\text { (1981 to } \\
2010)\end{array}$ & NIWA (n.d.) \\
\hline
\end{tabular}

\section{Page 43 of 182}




\section{Building outlines}

Use: Noise receptors for which noise levels are modelled. Noise barriers.

Description: Building outlines are derived from building rooftops produced by LINZ (Land Information New Zealand) using manual and automated processing of aerial imagery. Buildings with an area greater than 10 square metres are captured in this process, this includes approximately up to the size of larger garages and sheds (LINZ, n.d.).

Limitations: The data were published in 2019, however, temporal capture is dependent on aerial imagery which is collected every 'few years' and non-simultaneously. Very recently constructed buildings may not be included.

\section{Roads}

Use: Spatial road data was used to generate source points in the model. Attribute data was used to calculate rolling and propulsion noise.

Description: Road geometry was sourced from the National Road Centreline dataset via NZTA (NZTA, 2019). The dataset combines road information from the Department of Conservation, local councils, NZTA, and the private sector. Attribute variables listed in Table 2 were extracted from NZTA (traffic rates), LINZ (slope), and OpenStreetMap (vehicle speed) and appended to the National Road Centrelines dataset.

Limitations: Road data are at least updated quarterly (NZTA, 2019). Newly constructed roads, at most, 3 months from the date of extraction (i.e., May 2019), are not included in the study. This

\section{Page 44 of 182}


3-month delay is unlikely to have a significant impact on the study as the number of new roads is likely relatively small.

\section{Temperature}

Use: Rolling noise levels are moderated by temperature. Higher temperatures decrease rolling noise as rubber tyres become more malleable, while at lower temperatures tyres are more rigid and generate more noise. Temperature is therefore used as a rolling noise calculation correction factor.

Description: Average annual temperature $\left(12.9^{\circ} \mathrm{C}\right) 1981-2010$ for Kelburn automatic weather station (NIWA, n.d.). Kelburn is a suburb located approximately centrally within the Wellington Territorial Authority, Figure 3.

Limitations: We used the average annual temperature for Kelburn; however, temperature varies on both temporal and spatial scales. Owing to its proximity to the coast, these variations are moderated in Wellington. Diurnal temperature range is small $\left(5.9^{\circ} \mathrm{C}\right)$, and extreme high (above $25^{\circ} \mathrm{C}$ ) and low temperatures (below $0^{\circ} \mathrm{C}$ ) are rare (Chappell, 2014). Spatially, the mean temperature in the Wellington Territorial Authority ranges from about $12^{\circ} \mathrm{C}$ to $14{ }^{\circ} \mathrm{C}$ (Chappell, 2014). Both spatially and temporally, the temperature is often close to the Kelburn automatic weather station mean. 


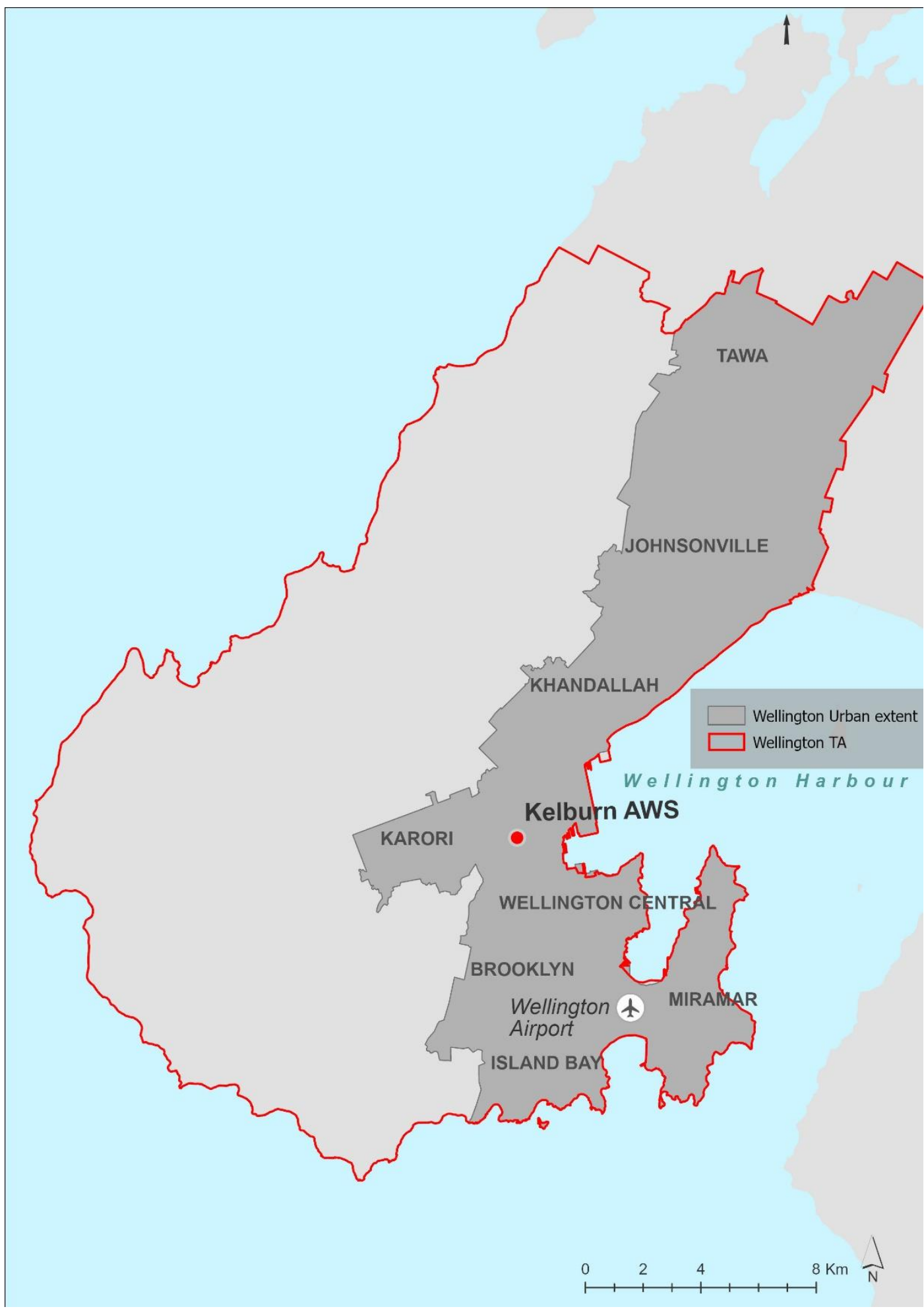

Figure 3: Location of Kelburn automatic weather station (AWS) 


\section{Model implementation}

In the real-world, the source of traffic noise pollution are individual vehicles. However, to simplify this real-world phenomenon and enable modelling using CNOSSOS-EU through OpeNoise, individual cars were aggregated to linear features representing the flow of vehicles along road segments. The National Road Centreline Dataset (Table 2) was split into segments no greater than 100 metres in length. Smaller segments ensure road characteristics (slope, speed, and vehicle count etc.) do not vary significantly within each segment. The flow of vehicles within a segment is principally described by three factors: vehicle category, vehicle speed, and vehicle count. CNOSSOS-EU uses these three variables to calculate rolling and propulsion noise. This is described in the Factors affecting noise emissions at the source section.

Environmental corrections are later applied to the rolling and propulsion noise components, then summed to give the total noise energy emitted from a given road segment. Several environmental correction variables were used to correct the model, affecting rolling or propulsion noise. Each of these factors, their effect, and how they were calculated, are explained in the Environmental corrections section of this chapter. Some factors which contribute to noise modification were not applicable to this study (e.g., studded tyres), these are also discussed.

Once the total noise energy is calculated by summing the propulsion and rolling noise components and applying the environmental corrections, the model propagates noise paths into the environment to the receiver points (i.e., building façades) and noise levels are assigned to buildings. This propagation process and assigning of noise levels to buildings is described in the Propagation of noise section of this chapter.

\section{Page 47 of 182}




\section{Factors affecting noise emissions at the source}

This section describes the factors used to calculate rolling and propulsion noise emissions at the source (i.e., road centreline).

\section{Vehicle speed}

Traffic noise increases with speed due to an increased tyre-road interaction and a greater load placed on the driveline (engine, exhaust, fans) (Kephalopoulos et al., 2012). Ideally, vehicle speed should be set to the average vehicle speed as this is the best estimate of the actual speed vehicles are travelling; however, the CNOSSOS-EU standard acknowledges that the posted speed limit may be used in place (Kephalopoulos et al., 2012). For Wellington, data on the average vehicle speed was not available. In place, the posted speed limit was extracted from OpenStreetMap (Table 2) and joined to the National Road Centreline dataset (Table 2). If the speed limit was unavailable in OpenStreetMap, the road speed was set to the default speed limit for New Zealand urban areas, $50 \mathrm{~km} / \mathrm{h}$ (Ministry of Transport, 2017). Using the maximum speed limit will result in an overestimation of the speed travelled by vehicles and over prediction of noise levels if vehicles travel slower than the speed limit, or an under estimation of the speed and under prediction of noise levels if vehicles travel faster than the speed limit.

\section{Vehicle category}

Larger, heavier vehicles generate more noise, including aerodynamic interaction (rolling noise), and engine noise (propulsion noise) (Kephalopoulos et al., 2012). These differences are large, especially at high speeds, for example, at motorway speeds one truck generates approximately the same acoustic energy as 10 cars (Waka Kotahi, 2014).

\section{Page 48 of 182}


The CNOSSOS-EU standard separates vehicles into four categories (Table 3). However, the National Road Centreline dataset (Table 2) used in this study separates traffic counts into just two categories: total vehicles, and heavy vehicles (Table 3). We assigned NZTA heavy vehicles to the CNOSSOS-EU category 3, while the remainder were assigned as CNOSSOS-EU category 1 motor vehicles. Combined, light and heavy categories made $98.9 \%$ of the vehicle kilometres travelled in Quarter 22019 (Ministry of Transport, n.d.), so miscategorisation is assumed to be minimal.

Table 3: CNOSSOS-EU standardised vehicle classes

\begin{tabular}{|c|c|c|c|c|}
\hline CNOSSOS-EU Category & $\begin{array}{l}\text { CNOSSOS-EU } \\
\text { Description }\end{array}$ & CNOSSOS-EU Examples & $\begin{array}{l}\text { NZTA equivalent } \\
\text { used }\end{array}$ & $\begin{array}{l}\text { Used in this } \\
\text { study }\end{array}$ \\
\hline Category 1 & Light motor vehicles & $\begin{array}{l}\text { Passenger cars, SUVs } \\
\text { (sport utility vehicles), } \\
\text { caravans, small delivery } \\
\text { vans }\end{array}$ & $\begin{array}{l}\text { NZTA' Light } \\
\text { vehicles.' }\end{array}$ & $\checkmark$ \\
\hline Category 2 & Medium-heavy vehicles & $\begin{array}{l}\text { Delivery vans, touring } \\
\text { cars, large delivery vans }\end{array}$ & Not used & $x$ \\
\hline Category 3 & Heavy vehicles & Buses, trucks & $\begin{array}{l}\text { NZTA' Heavy } \\
\text { vehicles.' }\end{array}$ & $\checkmark$ \\
\hline Category 4 & Powered two-wheelers & Motorcycles, mopeds & Not used & $x$ \\
\hline
\end{tabular}

Source: Adapted from Kephalopoulos et al. (2012) 


\section{Vehicle count}

Higher traffic counts mean more individual vehicle pass-bys for a given road segment, which generates greater propulsion and rolling noise.

Traffic count data was collected by NZTA automatic traffic recorders and obtained through the National Road Centreline dataset (Table 2). The heavy traffic count and total traffic count were provided in the dataset. Light traffic counts were calculated by subtracting the heavy count from the total.

\section{Environmental corrections}

This section describes the environmental corrections applied to road noise levels calculated at the source (i.e., road centreline).

\section{Acceleration/deceleration}

Acceleration and deceleration can affect noise emissions, especially around intersections where vehicles decelerate to enter the intersection and accelerate to exit. Acceleration involves changes in speed and engine load, both important factors in noise generation. However, acceleration is complex and multifactorial. Acceleration depends on individual vehicle behaviour, time of day, traffic conditions, and road design features, e.g., speed bumps and intersections. CNOSSOS-EU notes that often the uncertainty around acceleration is greater than the effect on noise (Kephalopoulos et al., 2012). For this reason, the effect of acceleration and deceleration is disregarded in the model. Disregarding acceleration and deceleration around intersections, we

\section{Page 50 of 182}


assume vehicles travel at the same speed as the adjacent sections of roads, resulting in some overestimation of rolling noise, but underestimation of propulsion noise.

\section{Temperature}

Increased temperature decreases rolling noise. CNOSSOS-EU uses a correction factor of $0.08 \mathrm{~dB} /$

${ }^{\circ} \mathrm{C}$ variance from the reference conditions of $20^{\circ} \mathrm{C}$. This is consistent with other studies which found empirical evidence for correction factors of $0.06 \mathrm{~dB} /{ }^{\circ} \mathrm{C}$ (Bueno, Luong, Viñuela, Terán, \& Paje, 2011) and $0.1-0.06 \mathrm{~dB} /{ }^{\circ} \mathrm{C}$ (Anfosso-Lédée \& Pichaud, 2007).

The temperature variable in this study was set to $12.9^{\circ} \mathrm{C}$. This is the $1981-2010$ mean temperature for Kelburn, automatic weather station (NIWA, n.d.).

\section{Studded tyres}

Studded tyres increase the emission of rolling noise and can be corrected for under the CNOSSOS-EU standard. However, in New Zealand, winter tyres are uncommon and, where used, must be studless (NZTA, 2009). Studded tyres were excluded from the model in this study.

\section{Road surface}

Surface type can vary noise emission by up to $15 \mathrm{~dB}(\mathrm{~A})$ on a single pass-by (Kephalopoulos et al., 2012). There is no universal reference for assessing the acoustic properties of road surfaces, and the descriptors provided in the National Road Centreline data (Appendix A) could not be mapped to the descriptors set by European standard CNOSSOS-EU (Appendix B) and road surface condition data for roads in Wellington was not publicly available or unknown.

\section{Page 51 of 182}


As a result, all road surfaces were set to the reference road surface conditions; dense asphaltic concrete and stone mastic asphalt with an age of 2-7 years.

Dense asphaltic concrete (or similar) is used in about $10 \%$ of roads in New Zealand, mainly highways, with the vast majority, 89\%, using chip seal (Waka Kotahi, 2014). Chip seal has a rougher surface texture compared to dense asphaltic concrete, generating more rolling noise, particularly at higher speeds (Waka Kotahi, 2014). Most high-speed roads in Wellington are motorways and are likely dense asphaltic concrete. Urban streets will most likely be chip seal or SMA (stone mastic asphalt) all with an unknown age. Using the reference road surface will lead to an under prediction of noise output on chip seal roads. However, any under prediction will be limited by the typically low speeds on urban streets.

Road surfaces tend to become louder over time, with more vibration and noise generated as the surface deteriorates (Waka Kotahi, 2014); however, the age and condition of roads in Wellington is not publicly available and, in many cases, unknown. As a result, segments of road which are newer or in better condition than the reference road surface will over-predict noise levels, and segments of road which are older or in poorer condition than the reference road surface will under-model noise levels. 


\section{Gradient}

Higher road gradients lead to higher engine loads, which generate more propulsion noise.

Vehicles also tend to be lower geared on steeper gradients. Low geared vehicles increase engine speed, leading to higher propulsion emissions (Kephalopoulos et al., 2012).

For the case study area, road slope was calculated using a $1 \mathrm{~m}$ resolution DEM (Digital Elevation Model) raster provided by LINZ (Table 2). The slope was calculated along 10m segments of the National Road Centreline dataset by taking the elevation changes between the start and endpoint of each $10 \mathrm{~m}$ segment and converting to degrees (Equation 1).

road gradient $(\%)=100 \frac{\text { rise }}{\text { run }}$

Where:

rise is equal to elevation end $_{-}$evelation $_{\text {start }}$

run is equal to 10 metres, representing 10 intervals between source points

Equation 1: Calculation to convert road changes in DEM elevation to road gradient

The mean slope value was then calculated and joined to the $100 \mathrm{~m}$ National Road Centreline Dataset road segments. 
Standard slope tools, e.g., ArcGIS Slope (Spatial Analyst) are unsuitable for calculating slope along a road surface. Built-in slope tools calculate the slope angle of the terrain surface, which is often not equivalent to the slope of the road. In areas of steep terrain, roads often cut terrain at an angle to lessen the slope to make it manageable for road users.

The gradient also affects vehicle speed; which would affect propulsion and rolling noise; however, vehicle speed is already accounted for outside of the gradient correction as one of the traffic flow variables.

\section{Propagation of noise to buildings}

OpeNoise uses road to building façade propagation paths to determine noise levels using CNOSSOS-EU standards. To do this, the linear feature representing the flow of traffic along each $100 \mathrm{~m}$ segment of road was broken down into noise emission point features, every ten metres.

Receptor points were created for the façades of every building. One receiver point was created for the midpoint of each exterior building face.

Propagation paths were then traced from each road source point to façade receiver point. Buildings were also treated as barriers, blocking, or modifying propagation paths. CNOSSOS-EU allows for paths to be traced up to $2000 \mathrm{~m}$ (Kephalopoulos et al., 2012). However, long trace distances increases the computational power needed to run the model. Shorter propagation paths have the most influence on the noise at a receptor, as noise energy diminishes with propagation path length. Most buildings are within $50 \mathrm{~m}$ of a roadside in urban areas. Buildings further than $50 \mathrm{~m}$ are less likely to experience elevated levels of noise pollution and are also

\section{Page 54 of 182}


likely to have some barrier (other buildings, trees etc.) blocking noise propagation paths. The maximum propagation path distance for this study was therefore set to $50 \mathrm{~m}$. To ensure accurate modelling for buildings near the case study area boundary, source points and barriers located 50 m outside of the case study area were included in the model.

CNOSSOS-EU describes four sets of propagation paths which may be considered. Type 1 paths; direct/straight-line paths, type 2 paths; paths reflected off barriers, type 3 paths; paths refracted around barriers, and type 4 paths; a combination of reflected and refracted paths (Kephalopoulos et al., 2012). The OpeNoise tool allows for type 1 and type 2 paths to be traced. Figure 4 shows an example of the direct propagation path from source points (road) to building facades, while Figure 5 shows an example of a diffracted propagation path around a building façade. 


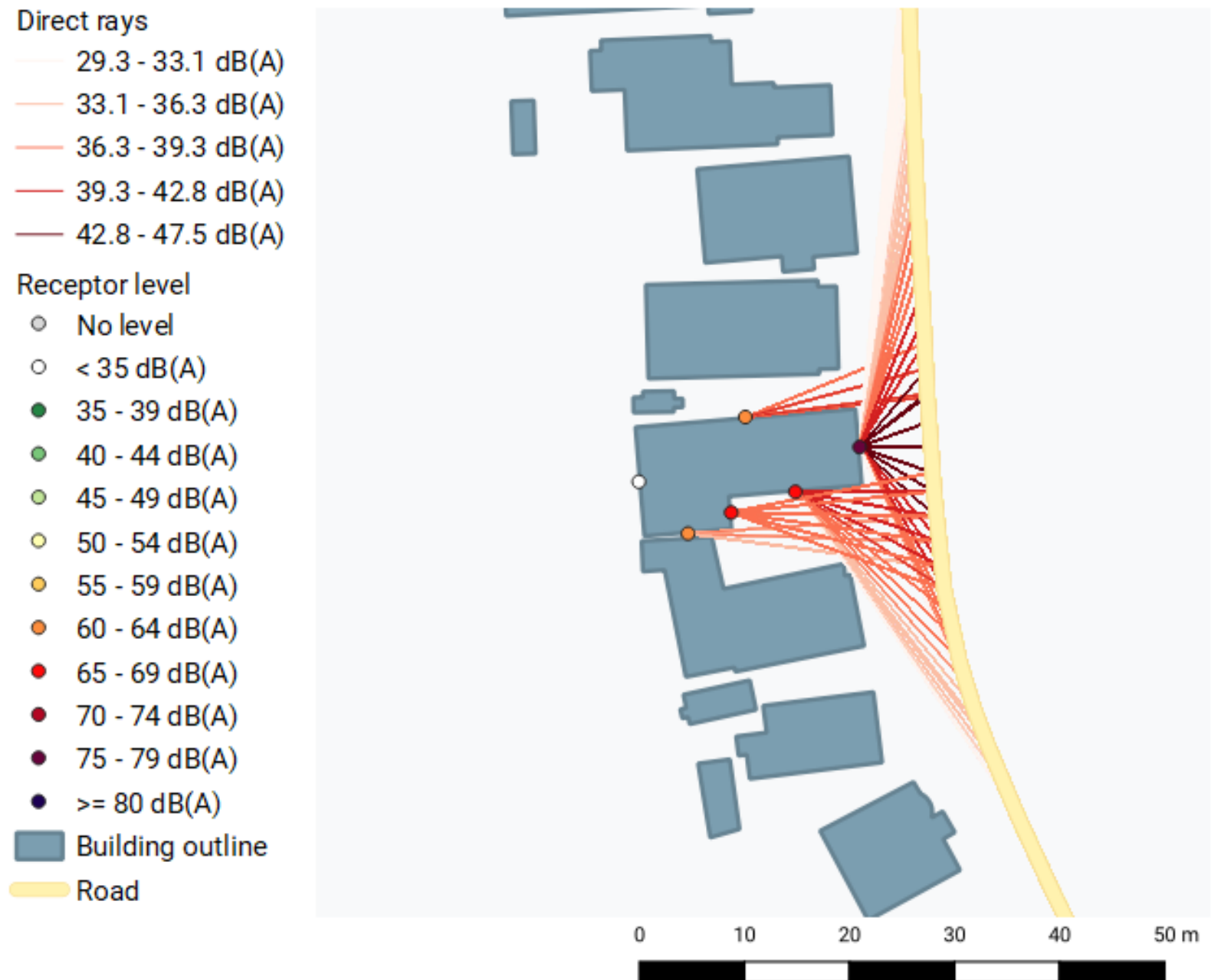

Figure 4: An example of direct rays output for a building in Wellington

Source: Author's own 


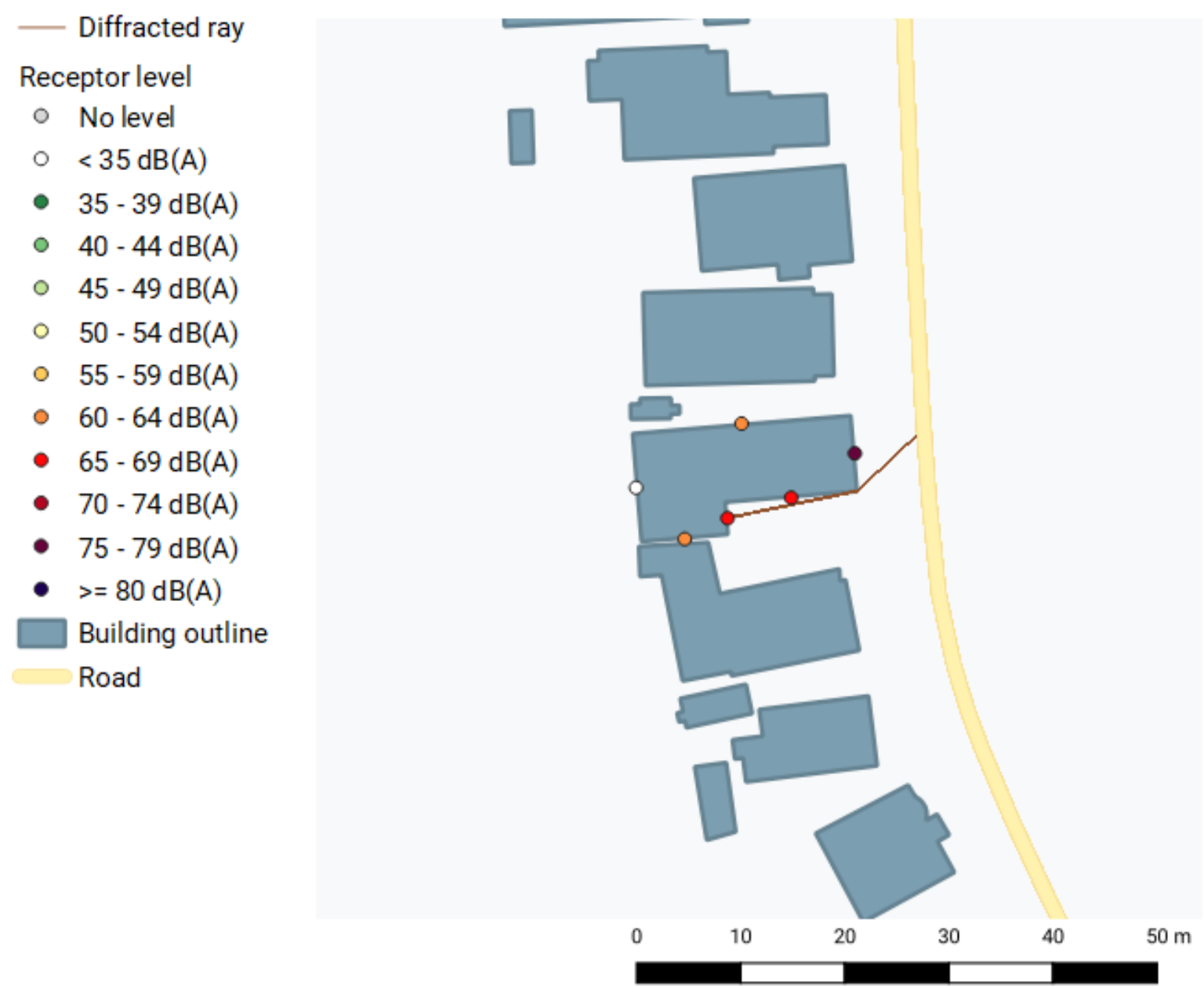

Figure 5: An example of a diffracted ray for the same building in as Figure 4

Source: Author's own 
The noise level at the building receiver point is calculated by summing the noise energy from each propagation path.

\section{Tunnels}

We assigned tunnels propagation path lengths of $0 \mathrm{~m}$, effectively excluding them from noise calculations. This assumes noise did not propagate through the ground surface above tunnels. While noise may build-up in a tunnel, concerns lie within this noise radiating from tunnel exits (Takagi, Miyake, Yamamoto, \& Tachibana, 2000), rather than the vibrations travelling through the surface above the tunnel.

Finally, the noise level for a given building is determined by the average noise level of all façades. 


\subsection{Analysis of socio-demographic data}

In section 3.1, we described the methods used to determine road traffic noise levels at the building-level across the Wellington Territorial Authority. We now describe the methods to assign building-level noise data to schools and ECCs, and the statistical analyses used to compare the noise levels of schools and ECCs by socio-demographic variables.

\section{School and ECC data}

School and ECC location and demographic data were sourced from the Education Counts database (Education Counts, n.d.), a database administered by the Ministry of Education. The database is updated on a continual basis for schools. New schools are added as required, and the school roll is updated by individual schools every time a student unenrolls or is enrolled at a school. For ECCs, data are updated with an annual census. Data was extracted from the Education Counts database on 13 May 2019, providing data current to the extraction date for schools and covering the 2018 ECC census. Data contained school or ECC location (latitude and longitude), decile (schools) or equity index (ECCs), roll size, ethnic breakdown of students, and facility type.

School decile is determined by the proportion of students drawn from low socio-economic communities and was developed for resource allocation (education.govt.nz, n.d.-b). Under the school decile system, low socio-economic communities are defined by an aggregated measure of: household income and crowding, parent education level, occupation, and income support benefits (education.govt.nz, n.d.-b). Aggregated indices are advantageous over single factor measures of deprivation (e.g. income) as they capture the multifaceted nature of socio-

\section{Page 59 of 182}


economic deprivation which can cover aspects of life from housing, transportation, recreation, family, and workplace (Pampalon, Hamel, Gamache, \& Raymond, 2009). The New Zealand school decile system only considers students drawn from low socioeconomic communities (i.e. decile 1 schools are the $10 \%$ of schools with the greatest proportion of students drawn from low socio-economic communities (education.govt.nz, n.d.-b), it does not represent the complete deprivation-mix of students attending the school, a point which has drawn criticism (Vester, 2018). However, the school decile system is commonly used as a measure of deprivation in health research in New Zealand (Maher, Wilson, \& Signal, 2005; Yelavich et al., 2008). Overseas, other single proxy measures of student deprivation such as neighbourhood income (Amram et al., 2011), and the proportion of students receiving subsidised canteen lunches (Green et al., 2004) appear more common. Although the school decile system fails to collect the complete deprivation mix of schools, it does capture multiple aspects of deprivation including from income work and home, so was preferred over a single proxy measure for this study.

For ECCs, an equity index (Education Counts, n.d.) is used to assess deprivation for funding. The measure is similar to school decile, aggregating households with low incomes, crowded households, parents receiving social security benefits, parents working low skill occupations, and parents without a qualification (education.govt.nz, n.d.-a). The data is provided as quintiles.

Ethnicity is collected as multiple response. A given student may identify as both European and Māori and will appear in both the European and Māori total, but only once in the overall school roll. For ECCs, this was broken down into Māori, Pacific, Asian, European/Pākehā, and Other.

\section{Page 60 of 182}


Data for schools gave an additional ethnicity option: Middle Eastern, Latin American, and African (MELAA). For ECCs, ethnicity data were updated at the 2018 ECC census.

School roll sizes are updated by schools as students enrol, change schools, graduate, or leave the school system. School roll size may differ from the Ministry of Education's other formal roll collections. For ECCs, roll sizes were updated at the 2018 ECC census.

Location data was provided for each school and ECC as a latitude and longitude (WGS 84).

ECCs differ by facility type by institution type and authority (ownership model). Facility types define the type of activities taking place on campuses, often driven by age and need. Table 4 describes these facility types. In Wellington, five different institution types were present: Education and Care Service, Free Kindergarten, Homebased Network, Playcentre, and Te Kōhanga Reo. Homebased Networks were not included due to a lack of spatial data; individual home locations are not provided by the Ministry of Education for privacy reasons.

ECCs also differ by ownership structure; either privately owned or community based. Community-based ECCs such as playcentres are parent/caregiver-led, with time volunteered to look after children. Conversely, privately owned ECCs do not rely on parents/caregivers and may be run on a for-profit basis.

The 137 ECC facilities included in the study comprised of 93 (67.9\%) Education and Care Services, 27 (19.7\%) Free Kindergartens, 11 (8.0\%) Playcentres, and 6 (4.4\%) Te Kōhanga Reo.

\section{Page 61 of 182}


Table 4: School and ECC facility types

Facility type

ECC

Education and Care Service

Free Kindergarten

Homebased Network

Playcentre

Te Kōhanga Reo
Description

All day options, flexible hour sessions, children aged birth to 5 years old.

All day options, children aged 2 to 5 years old

Care provided at educators or child's home, children aged birth to 5 years old

Care is always provided by parents and family members, children aged birth to 5 years old

Māori immersion, children aged birth to 5 years old

\section{Schools}

\begin{tabular}{|c|c|}
\hline Activity Centre & For students at risk of low outcomes \\
\hline Composite & School year $1-10$ \\
\hline Contributing & School year $1-6$ \\
\hline Full Primary & School year $1-8$ \\
\hline Intermediate & School year $7 \& 8$ \\
\hline Secondary & School year $9-15$ \\
\hline Special School & High needs students \\
\hline Teen Parent Unit & School for students who are parents or pregnant \\
\hline
\end{tabular}

To assess the impacts of excessive noise levels on learning we require a measure of student achievement. For this study, student achievement was limited to students completing the 
National Certificate of Educational Achievement (NCEA) qualifications and quantified by school university entrance (UE) rates. UE is awarded to students achieving NCEA level 3 and meeting requirements for literacy and numeracy, among others. UE signifies a high level of academic performance and has been a measure of success used by the Ministry of Education (Ministry of Education, 2011). New Zealand schools occasionally offer Cambridge International Examinations or International Baccalaureate. Students completing these examinations can achieve UE, however, are not included in the NCEA UE rate for schools. We used 2015 UE rates supplied by New Zealand Qualifications Authority (NZQA). 2015 UE data was the most recent available, and was obtained via data.govt.nz on July 32020 (New Zealand Qualification Authority, 2015).

\section{Assigning noise levels to schools and ECCs}

Noise levels were assigned to schools and ECCs by allocating building footprints to individual schools and ECCs, and then calculating a noise level of a school or ECC based on the assigned buildings.

Buildings were assigned to schools and ECCs by performing an intersecting spatial join (ArcGIS Pro v2.6.0, ESRI) between:

1. Property parcels (Land Information New Zealand, 2020) to school or ECC points (Education Counts, n.d.).

2. Property parcels to building outlines (Land Information New Zealand, 2019).

\section{Page 63 of 182}


At each step, joins were manually verified for validity and manual corrections were completed where errors were detected. Corrected errors and solutions were:

- Error: Buildings adjacent to a school or ECC boundaries had footprints erroneously crossing into school or ECC boundaries.

Solution: the false attribution of the building to a school or ECC was removed.

- Error: School or ECC point location not matching to the property boundary (e.g., located on the roadside).

Solution: the location of the school or ECC point was altered, such that it crossed the land parcel. The school/ECC to land parcel join was repeated.

- Error: The school boundary comprised of multiple land parcels.

Solution: The additional land parcels were assigned to the relevant school or ECC. The school/ECC to land parcel join was repeated.

Once buildings were assigned to schools and ECC, the average noise level for each school and ECC was calculated. To determine the average noise level experienced for students at each facility, we assume the population of students or children are evenly spaced within the building footprints, this follows similar logic to areametric methods of assigning population to buildings for census tracts (Lwin \& Murayama, 2009). Therefore, a noise level for a school/ECC was defined as the building-size weighted average noise level $(d B)$. This was calculated by taking the 
average noise level for all buildings assigned to a given school or ECC with weights assigned proportional to the building footprint area, i.e., the noise level for buildings with a larger footprint area has a greater influence on the overall mean noise level for a given school or ECC compared to smaller buildings. Limitations of the areametric method assumptions are that it cannot account for multi-storey buildings where the areametric density of students could be much higher, or buildings where students and children do not spend time, such as administration or storage blocks.

\section{Summary of noise level assignment: Early childhood centres (ECCs)}

There were 166 ECCs identified in the Wellington Territorial Authority, enrolling 7,342 children. Data was unavailable for 29 facilities (1,041 children) and 137/166 (82.5\%) facilities and 6,301/7,342 (85.8\%) children remained in the study (Table 5). ECCs with data unavailable comprised of 10 Homebased Networks, 12 Education and Care services, 5 Free kindergarten facilities, and 2 Playcentres. Early childhood education in Homebased Networks is provided in private homes, rather than centres. Location data for these private homes are not publicly available due to privacy concerns, hence all 10 Homebased networks could not be included in the study. There was insufficient data (e.g., traffic counts) to model noise levels for the remaining 19 ECCs excluded from the study.

\section{Summary of noise level assignment: Schools}

There were 82 schools identified in the Wellington Territorial Authority, enrolling 31,588 students. There was insufficient data to model noise levels for 4 schools (1,949 students).

\section{Page 65 of 182}


Schools excluded because of insufficient data to model noise included 1 Full Primary, 1 Secondary, and 2 Intermediate schools. 78/82 (87.8\%) schools and 29,639/31,588 (93.8\%) students remained in the study (Table 5). 
Table 5: Facilities by type in Wellington territorial authority, facility count, in brackets child or student count

\begin{tabular}{|c|c|c|c|}
\hline Facility type & Total count & $\begin{array}{c}\text { Count } \\
\text { excluded }\end{array}$ & $\begin{array}{l}\text { Count } \\
\text { remaining in } \\
\text { study }\end{array}$ \\
\hline \multicolumn{4}{|l|}{ ECC } \\
\hline Education and Care Service & $105(4,610)$ & $12(379)$ & $93(4,231)$ \\
\hline Free Kindergarten & $32(1,811)$ & $5(265)$ & $27(1,546)$ \\
\hline Homebased Network & $10(317)$ & $10(317)$ & $0(0)$ \\
\hline Playcentre & $13(508)$ & $2(80)$ & $11(428)$ \\
\hline Te Kōhanga Reo & $6(96)$ & $0(0)$ & $6(96)$ \\
\hline Total ECC & $166(7,342)$ & $29(1,041)$ & $137(6,301)$ \\
\hline \multicolumn{4}{|l|}{ Schools } \\
\hline Activity Centre & $1(0)$ & $0(0)$ & $1(0)$ \\
\hline Composite & $4(2,103)$ & $0(0)$ & $4(2,103)$ \\
\hline Contributing & $27(7,414)$ & $0(0)$ & $27(7,414)$ \\
\hline Full Primary & $32(7,733)$ & $1(286)$ & $31(7,447)$ \\
\hline Intermediate & $5(2,624)$ & $2(946)$ & $3(1,678)$ \\
\hline Secondary (Year 9-15) & $11(11,692)$ & $1(717)$ & $10(10,975)$ \\
\hline Special School & $1(22)$ & $0(0)$ & $1(22)$ \\
\hline Teen Parent Unit & $1(0)$ & $0(0)$ & $1(0)$ \\
\hline Total schools & $82(31,588)$ & $4(1,949)$ & $78(29,639)$ \\
\hline
\end{tabular}




\section{Summary of noise level assignment: remaining buildings in the Wellington Territorial Authority}

A total of 99,336 buildings were identified in the Wellington Territorial Authority. Of these buildings 10,856 (10.9\%) had insufficient data for modelling (e.g., traffic counts for roads are not provided); 88,480 buildings remained in the study. Of the buildings excluded for insufficient data, 360 were in school campuses and 255 were in ECC facilities.

\section{Statistical analyses}

To produce observational results about the general pattern of noise and distribution of schools and ECCs within the Wellington noisescape, we plotted locations of buildings, ECCs and schools by their respective noise levels. Contextual features, such as main roads, suburb names, and points of interest were added to gauge spatial patterns of noise. The maps, presented in section 4.1, were created in ArcGIS Pro 2.6.0 (ESRI, 2020).

School and ECC socio-demographic data were then analysed to reveal any differences in noise exposure between different groups of children, and to assess relationships between sociodemographic variables and noise levels. For continuous variables (school decile, roll size, university entrance rate), scatter plots were constructed to assess the relationship between noise levels and socio-demographic variables. We used r-squared and Pearson statistics (Pearson, 1900) to assess any correlation between noise levels and socio-demographic factors. For categorical variables (for example, ethnicity and facility type), bar charts and confidence intervals were constructed to assess whether noise levels differed significantly within categorical socio-demographic variables.

\section{Page 68 of 182}


We also assessed whether noise levels for buildings located at schools and ECCs differed significantly from the remaining building stock in the Wellington Territorial Authority. Analyses for building use comparisons were performed using SAS 9.4 (SAS Institute Inc, 2020). Tests for normality of the data were performed using the Shapiro-Wilk test (Shapiro \& Wilk, 1965). Finally, after determining a non-normal distribution of building noise levels, differences in noise levels between ECC, school and other building uses were examined using Kruskal-Wallis (Kruskal \& Wallis, 1952) and Wilcoxon-Mann-Whitney tests (Mann \& Whitney, 1947). All statistical assessments were performed at the $\alpha=0.05$ level of significance. 


\subsection{Analysis of land use and road distance}

In this section we evaluate noise levels by land use and proximity to roads. This will determine whether land use and proximity to busy roads are suitable indicators compared to modelled noise values.

\section{Land use and road data}

Land use data was extracted from the current (2018) Wellington City Council District Plan ('the District Plan') (Wellington City Council, 2018). The District Plan sets out zones permitting different land uses, such as residential, industrial, or undeveloped land. The zones defined in the District Plan are specific, covering 17 individual zones. For this study, we grouped zones into six larger, similar land use areas. The land use areas used in this study along with their District Plan constituents and descriptions are provided in Table 6. Wellington City Council cautions that District Plan zone boundaries do not necessarily align with property boundaries (Wellington City Council, 2018), hence may not align with building outlines for which we modelled noise levels. Road data used were road centrelines and traffic counts. This data was the same as used in noise mode and is described in Table 2.

\section{Page 70 of 182}


Table 6: Land use definitions and District Plan descriptions

\begin{tabular}{|c|c|c|}
\hline Land use & District Plan zone & District Plan description \\
\hline \multirow{2}{*}{$\begin{array}{l}\text { City } \\
\text { centre }\end{array}$} & Central Area & $\begin{array}{l}\text { Most activities can take place in the Central Area including } \\
\text { intensified commercial, intensified residential, political, } \\
\text { recreational, entertainment uses. }\end{array}$ \\
\hline & Centre & $\begin{array}{l}\text { Complements the Central Area. Intensification of } \\
\text { residential and commercial activities encouraged. }\end{array}$ \\
\hline \multirow{2}{*}{ Industrial } & Business 1 & $\begin{array}{l}\text { Employment activities, light industrial, commercial, and } \\
\text { business services, recreational, residential and } \\
\text { entertainment uses, and local community services. }\end{array}$ \\
\hline & Business 2 & Warehousing, manufacturing, and commercial services. \\
\hline \multirow{4}{*}{$\begin{array}{l}\text { Open } \\
\text { space }\end{array}$} & Open Space A & Recreation: developed. E.g., sports fields. \\
\hline & Open Space B & Recreation: Generally unbuilt, natural state. \\
\hline & Open Space C & Town belt: Historic, social, cultural importance. \\
\hline & Conservation & $\begin{array}{l}\text { Open space requiring protection. E.g., native bush } \\
\text { remnants, wetlands }\end{array}$ \\
\hline $\begin{array}{l}\text { Inner } \\
\text { residential }\end{array}$ & Inner Residential & Residential area adjacent to the central city. \\
\hline $\begin{array}{l}\text { Outer } \\
\text { residential }\end{array}$ & Outer Residential & Suburban neighbourhoods. \\
\hline Other & Sea & Sea. \\
\hline
\end{tabular}




\begin{tabular}{|l|l|l|}
\hline & $\begin{array}{l}\text { Institutional } \\
\text { Precinct }\end{array}$ & $\begin{array}{l}\text { Includes Victoria University, Massey University, and } \\
\text { Wellington Regional Hospital. Intensive development } \\
\text { allowed. }\end{array}$ \\
\cline { 2 - 3 } & $\begin{array}{l}\text { Medium Density } \\
\text { Residential Area }\end{array}$ & Semidetached houses, duplexes, townhouses. \\
\cline { 2 - 3 } & $\begin{array}{l}\text { Urban } \\
\text { Development } \\
\text { Area }\end{array}$ & Undeveloped. Future growth. \\
\cline { 2 - 3 } & Pastoral farming, small settlements. \\
\cline { 2 - 3 } & Airport & Wellington Airport. \\
\cline { 2 - 3 } & Over water & Docks. \\
\hline
\end{tabular}

Source: Wellington City Council (n.d.-b) 
Assigning land use zones to buildings, schools and ECCs

To assign land use to each building, we used the Spatial Join tool (ESRI, 2020). Because building outlines can cross multiple District Plan zones, we used joins on buildings with their geometric centre within a given District Plan zone. For schools and ECCs, we used the point locations provided by Ministry of Education (Education Counts, n.d.) and similarly used the Spatial Join (ESRI, 2020) to assign a land use area to each school and ECC.

\section{Distance from nearest road calculation}

We defined the distance between buildings and roads as the Euclidean (straight-line) distance from building centroids to road centrelines. We calculated distances from each building centroid to all road centrelines and to major roads using the Nearest tool (ESRI, 2020). Major roads were defined as having daily traffic greater than 3,000 vehicles. This matches the NZTA definition for road hierarchies of arterial, regional, high volume, and national routes (Waka Kotahi, n.d.).

Schools and ECCs may comprise of multiple buildings, hence for each school and ECC we give a single mean building to road distance. This was defined as the mean distance of every building centroid located at the school to the road centreline.

To assess the relationship between distance to roads and noise levels, we fitted a linear model between the variables in R-4.1.1(R Core Team, 2021) and calculated $r$-squared values to determine the degree to which distance from roads to buildings explained modelled noise levels.

\section{Page 73 of 182}




\subsection{Model validation}

This section describes how noise levels in this study, modelled using the CNSOSS-EU were compared to volunteered in situ noise measurements from Noise Planet (Bocher, Petit, Picaut, Fortin, \& Guillaume, 2017). Environmental data often has high costs to collect, however volunteer geographic information (VGI) provides a means to access a volume of data which is often otherwise unavailable (Antoniou, Capineri, \& Haklay, 2017). The purpose of the comparison between modelled and volunteered values is to assess model performance, i.e., how closely modelled values match to volunteered noise values, and the identification of outlier areas (areas where the model value differs significantly from the volunteered value). Identifying these outlier areas is useful to identify where the model performed poorly, which can help identify future improvements to the model.

\section{Volunteered noise data}

Volunteered noise data was obtained from Noise Planet (Bocher et al., 2017). Noise Planet collects noise data in the form of volunteered geographic information (VGI). Volunteers download an Android smartphone application which enables them to continuously (i.e., every second) record environmental noise levels, along with time, and location data as they walk any chosen path. All volunteered data are shared and aggregated on the OnoMap spatial data infrastructure and made available for public download as either points, tracks, or a $15 \mathrm{~m}$ hex

mesh at www.noise-planet.org@. The data are processed in accordance with the European Environmental Noise Directive (European Comission, 2002). The directive is consistent with the

\section{Page 74 of 182}


CNSOSS-EU standard (Kephalopoulos et al., 2012) used to model environmental noise in the Wellington Territorial Authority in this study. Volunteered noise levels in the Wellington Territorial Authority comprised 169,998 points of data, partial spatial coverage of the buildings included in this study.

\section{Spatial manipulation of noise data}

We paired modelled data with volunteered data using the Spatial Join tool, ArcGIS Pro version 2.6.0 (ESRI, 2020). Volunteered data were joined to modelled data within a $7.5 \mathrm{~m}$ radius. The 7.5 $\mathrm{m}$ radius is consistent with the $15 \mathrm{~m}$ diameter determined by the hex mesh from Noise Planet (Bocher et al., 2017). Where multiple volunteered points were within a $7.5 \mathrm{~m}$ radius of a building with modelled data, the mean of the volunteered values were paired with a modelled value. Of the 88,480 buildings in the study, $2.7 \%(2,411)$ were matched with volunteered noise level data. The coverage included 6 different land use categories within the Wellington Territorial Authority.

Breaking the model validation down by land use enabled an assessment of the impact land use might have on model performance. Central and industrial areas are more likely affected by sources of noise other than traffic noise, including music, people talking, horns and sirens in central areas (Alías \& Socoró, 2017) and hammers, grinders, drills, and factories in industrial areas (Gupta, Gupta, Jain, \& Gupta, 2018). These additional sources of noise could mean volunteered noise levels are higher than modelled noise levels in central and industrial areas, since the CNSOSS-EU standard used in this study only models traffic noise.

\section{Page 75 of 182}


We stratified the data by land use zones, supplied by Wellington City Council District Plan (Wellington City Council, 2018). We aggregated Wellington City District Plan Zones into 6 similar areas (Table 7) to assess noise model performance. 32 measurements were recorded for buildings in 'Other' areas (Table 7). These land use areas were of insufficient size to assess any of these land use areas further. 
Table 7: Land use definitions for this study as defined as an aggregate of Wellington City Council district plan zones.

$\begin{array}{lrr}\text { Land use area description for } & \text { Wellington City Council district } & \text { Number of buildings with } \\ \text { this study } & \text { plan zones } & \text { matched volunteered: } \\ & & \text { modelled values }\end{array}$

\begin{tabular}{|c|c|c|}
\hline City centre & Centre, Central Area & 439 \\
\hline Inner residential & Inner residential & 354 \\
\hline Outer residential & Outer residential & 1,457 \\
\hline Industrial & Business 1, Business 2 & 60 \\
\hline Open space & $\begin{array}{l}\text { Open Space A, Open Space B, } \\
\text { Open Space C, Conservation }\end{array}$ & 69 \\
\hline Other & $\begin{array}{l}\text { Airport, over water, sea, rural, } \\
\text { Institution precinct, medium } \\
\text { density residential area }\end{array}$ & 32 \\
\hline All & All district plan zones & 2,411 \\
\hline
\end{tabular}


Assessing the relationship between modelled and volunteered noise values

We examined the relationship between volunteered and modelled noise levels using R-studio version 1.1.463 (R Core Team, 2021). We created scatter plots between volunteered and modelled variables for each building and attempted to fit a linear model and calculate R-squared values. During this process, we identified a bias in the collection of volunteered points, which made fitting a linear model problematic. Volunteered points were most often only collected where buildings had high modelled noise values, meaning there was little data at low noise levels. Fitting a linear model without low noise level data is difficult and the result may not necessarily reflect true model performance. To overcome the lack of volunteered data for low noise level areas, we repeated the linear model with the assumption that where volunteered data equalled zero, modelled data would equal $0 \mathrm{~dB}$. The assumption that where volunteered data equalled zero, modelled data equalled zero is reasonable, based on the physical assumptions of the model inputs (i.e., if no cars pass by, then no noise is emitted). Hence, we constrained the linear model to pass through the origin to give a proxy for volunteered low noise levels which are lacking. All analyses were repeated for each of the land categories defined in Table 7. 


\section{Chapter 4: Results}

We modelled motor vehicle traffic noise levels for 88,480 (89.1\%) buildings in the Wellington

Territorial Authority and compared noise levels for ECCs, schools and other buildings. In this

chapter we present the results of the study, strictly speaking for:

1. spatial patterns of noise levels in the Wellington Territorial Authority,

2. differences in noise levels by school and ECC socio-demographic characteristics,

3. the relationship between noise levels and proximity to roads and land use indicator variables,

4. and the results of the model validation.

\subsection{Spatial patterns of high noise levels}

Figure 6 shows the geographic distribution of buildings and corresponding noise levels across the Wellington Territorial Authority. Higher noise levels are typically concentrated in Central Wellington and other smaller suburban centres (e.g., Karori, Johnsonville, Khandallah) or about high-volume roads. Areas of the city which provide no throughways to other areas, typically had the lowest noise levels. This phenomenon was most marked in the outer streets of Karori, Miramar and Island Bay. Figure 7 shows the geographic distribution of ECCs and corresponding noise levels. In general, the ECCs with the highest noise levels are more likely to be in Central Wellington, particularly grouping around high-volume roads. Five of the seven ECCs with the highest noise levels were in Wellington Central. Figure 9 shows the geographic distribution of schools and corresponding noise levels. Similarly to ECCs, schools with the highest noise levels are grouped around Wellington Central and high-volume roads.

\section{Page 79 of 182}


The mean noise level for buildings for ECC and school use was higher compared to the mean noise level for all other building uses in the Wellington Territorial Authority. The mean noise level was $51.8 \mathrm{~dB}$ for all ECC buildings and $49.8 \mathrm{~dB}$ for all school buildings, this compared to $46.7 \mathrm{~dB}$ for all other building uses. The rate of noise exceedance above the $53 \mathrm{~dB}$ WHO standard, was $57.7 \%$ (79 of 137 facilities) for ECCs and 41.0\% (32 of 78 facilities) for schools. For all buildings in the Wellington Territorial Authority, 29.5\% (26,098 of 88,480 buildings) exceeded the standard. 


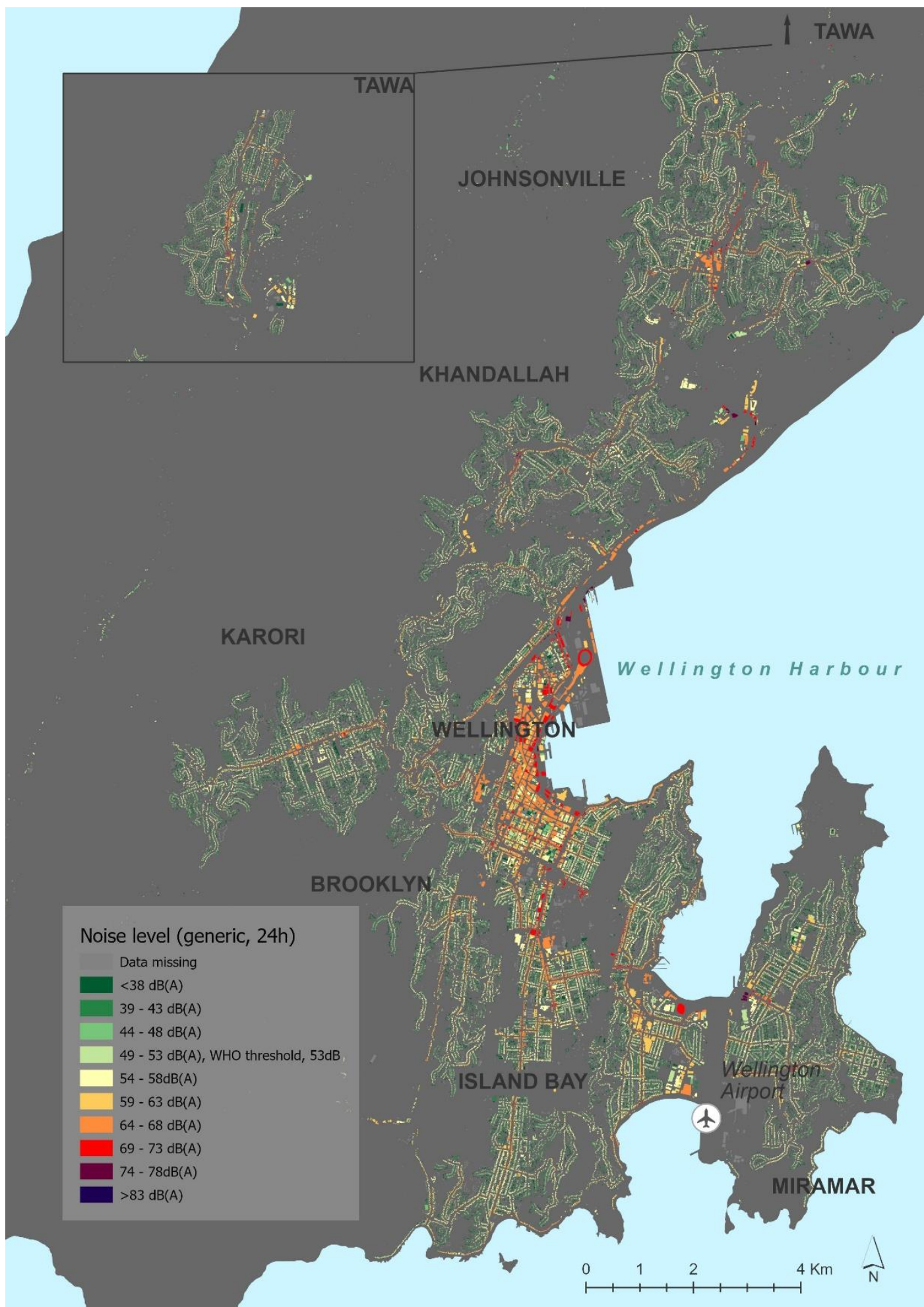

Figure 6: Noise levels modelled for all buildings in Wellington Territorial Authority

Page 81 of 182 


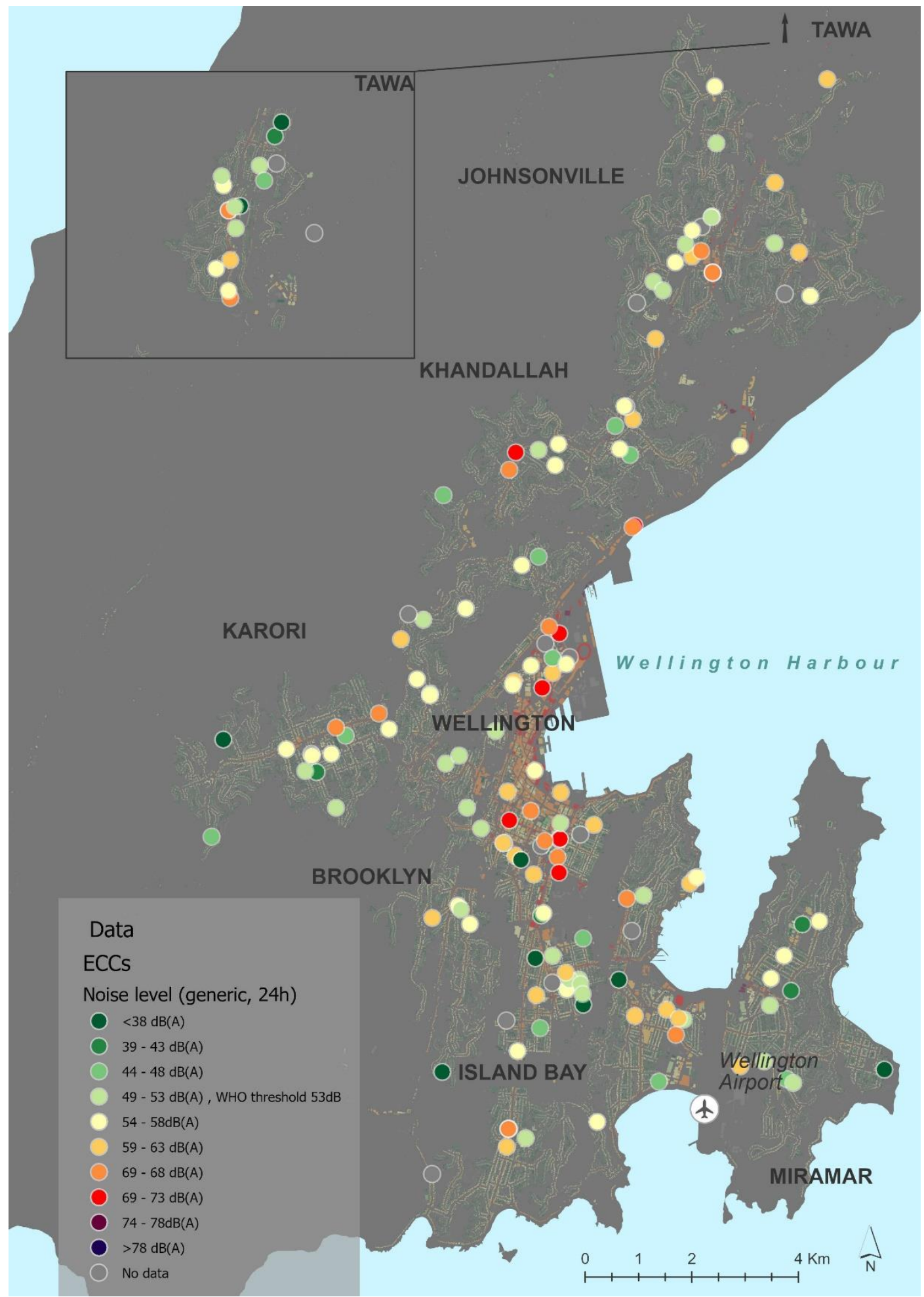

Figure 7: Building size weighted mean noise level for ECCs in Wellington Territorial Authority 


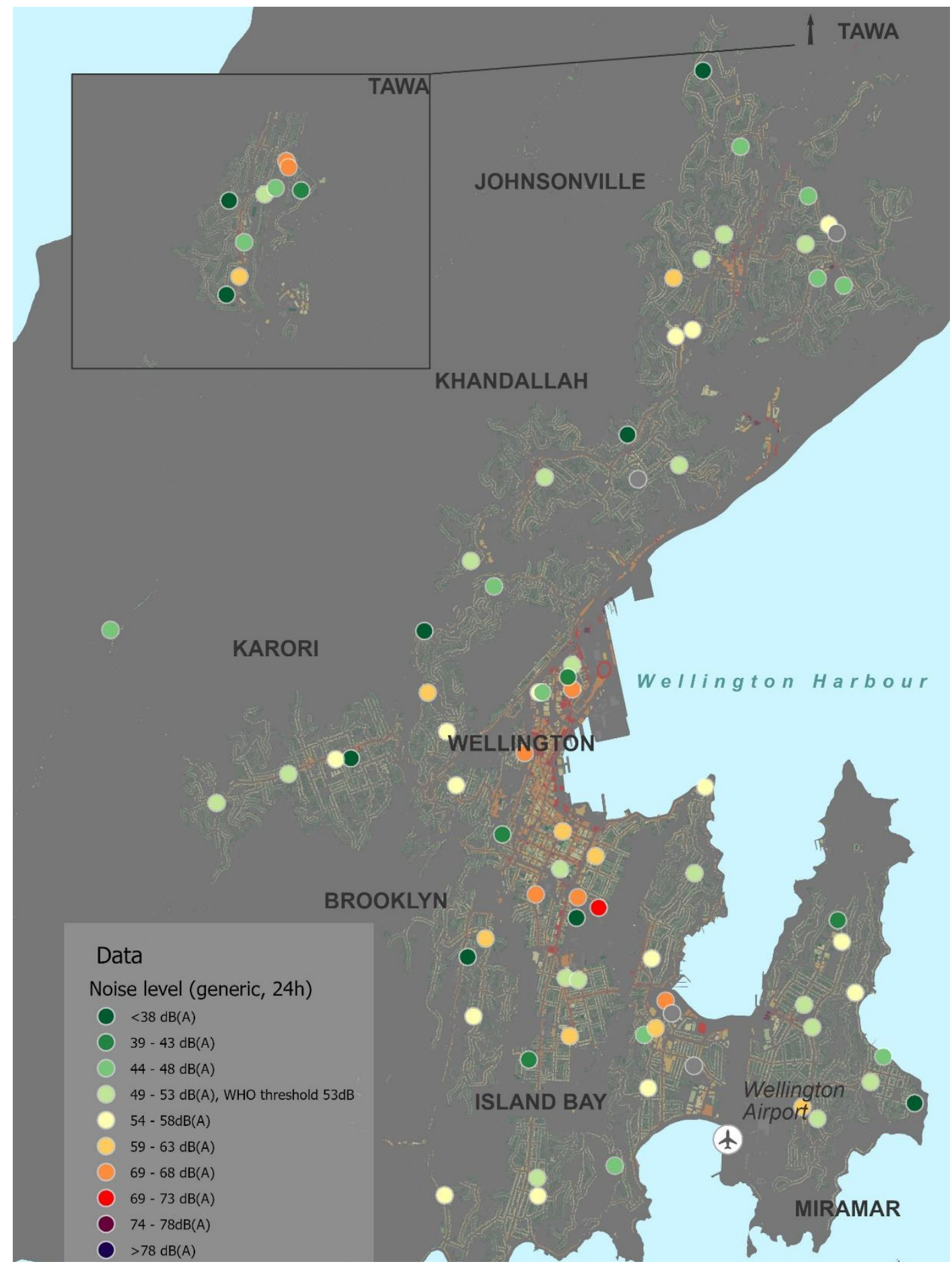

Figure 8:Building size weighted mean noise level for schools in Wellington Territorial Authority 
Comparison by building-use

ECC buildings, School buildings, and all remaining 'Other buildings' (residential housing, industrial, retail etc.) were found to have mean noise levels of $51.8 \mathrm{~dB}, 49.8 \mathrm{~dB}$ and $46.7 \mathrm{~dB}$ respectively. This finding suggested some differences in the central tendencies of these populations might exist, however further hypothesis testing was required to determine whether this difference was significant.

Figure 10 shows the relative frequency of noise level for each type of building use. Normality for each of the population distributions was evaluated using Shapiro-Wilk tests, under the null hypothesis that the samples came from normally distributed populations, with $\alpha=0.05$. For all three distributions, the null hypothesis was rejected, meaning there was sufficient evidence at the $95 \%$ confidence level to suggest the populations were not normally distributed $(p<0.0001)$. Q-Q plots also indicated a left skew in all three distributions. Since the data fails the assumption of normality required for Student's t tests, non-parametric methods were required to examine the differences in central tendencies between the populations.

\section{Page 84 of 182}




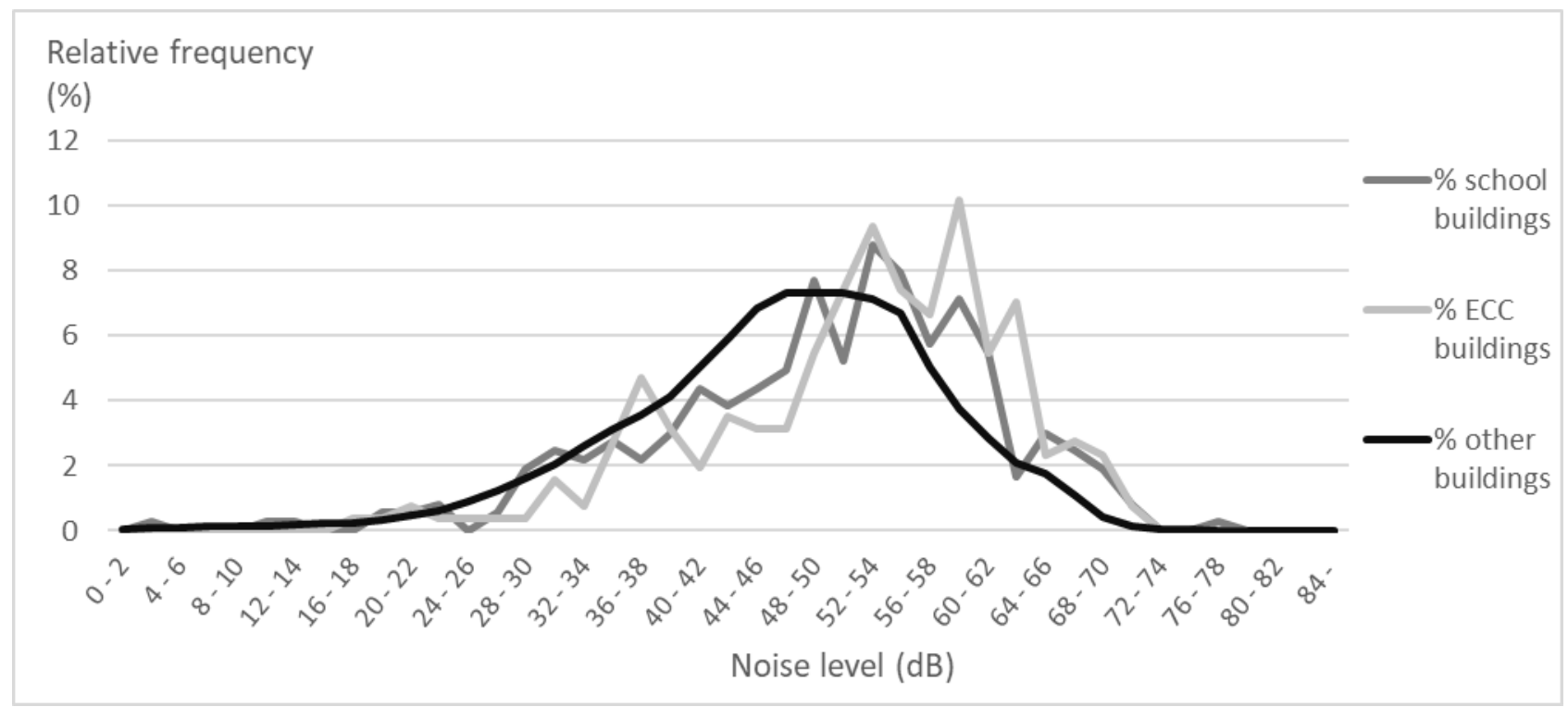

Figure 10: Relative frequency of building level noise, by building use

A Kruskal-Wallace test was performed and confirmed that at least one of the median values was not equal between some of the building-use median noise levels $(p<0.0001)$ and Mann-WhitneyWilcoxon $\mathrm{U}$ tests were required to determine where these differences laid. One tailed MannWhitney-Wilcoxon $U$ tests were performed to examine:

1. whether the median noise level for school buildings was higher compared to other buildings:

$\mathrm{H}_{0}: x_{\text {School }}-x_{\text {Other }} \leq 0$

$\mathrm{H}_{\mathrm{A}}: x_{\text {School }}-X_{\text {Other }}>0$

$\alpha=0.05$

Where: $x=$ median noise level for specific building-use 
The Mann-Whitney-Wilcoxon $U$ test returned a $p$-value of $<0.001$. Observing that the $p$-value is less than $\alpha$, there was sufficient evidence at $\alpha=0.05$ to reject the null hypothesis. Therefore, there was sufficient evidence at the $95 \%$ confidence level to suggest that median noise levels for school buildings are higher compared to other buildings.

2. whether the median noise level for the ECC buildings was higher compared to Other buildings:

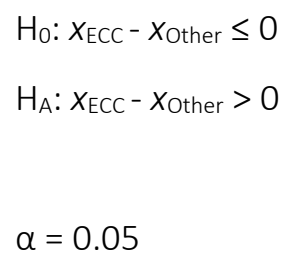

The Mann-Whitney-Wilcoxon $U$ test returned a $p$-value of $<0.001$. Observing that the $p$-value was less than $\alpha$, there is sufficient evidence at $\alpha=0.05$ to reject the null hypothesis. Therefore, there was sufficient evidence at the $95 \%$ confidence level to suggest that median noise levels for ECC buildings is higher compared to Other buildings. 
3. whether the median noise level for ECC buildings was higher compared to School buildings:

$$
\begin{aligned}
& H_{0}: x_{E C C}-x_{\text {Schools }} \leq 0 \\
& H_{A}: x_{E C C}-x_{\text {Schools }}>0 \\
& \alpha=0.05 \\
& \text { Where: } x=\text { median noise level for specific building-use }
\end{aligned}
$$

The Mann-Whitney-Wilcoxon $U$ test returned a $p$-value of 0.0071 . Observing that the $p$-value was less than $\alpha$, there was sufficient evidence at $\alpha=0.05$ to reject the null hypothesis. Therefore, there was sufficient evidence at the $95 \%$ confidence level to suggest that median noise levels for ECC buildings is higher compared to School buildings.

In addition to examining differences in central tendencies between the building-use groups, we also examined the difference in the proportion of these groups meeting the WHO standard of 53dB. $52.6 \%$ of ECC buildings and $56.4 \%$ of school buildings had, modelled noise levels below $53 \mathrm{~dB}$, compared to $70.2 \%$ of all buildings. We used Fischer's exact test to determine that the differences between each of these proportions were statistically significant at the $95 \%$ confidence level $(p<0.0001)$.

\section{Page 87 of 182}




\subsection{Socio-demographic}

In this section we describe the relationship between noise levels at schools and ECCs by sociodemographic variables.

Early Childhood Centres (ECCs)

For ECCs, socio-demographic variables included facility type, ethnicity, equity index, and roll size.

\section{Facility type}

The building-size weighted mean noise level was highest for Education and Care Services (55.4dB), followed by Free Kindergartens (51.1dB), Playcentres (50.4dB) and Te Kōhanga Reo (50.1dB). At the 95\% confidence level these differences were not statistically significant (Table 8).

Community-based facilities comprise of Playcentres, Te Kōhanga Reo, Free Kindergartens, Homebased networks and some Education and Care Services. Privately owned facilities include some Education and Care Services. There were 89 community-based facilities and 48 privately owned facilities included in the study. At the 95\% confidence level, the building-size weighted mean noise level was higher for privately owned facilities compared to community-led facilities. The mean noise level for privately owned facilities was 57.0dB (54.9 dB $-59.2 \mathrm{~dB}$ ), while the mean noise level for community-led facilities was 52.3dB (50.4dB - 54.2 dB) (Table 8).

Overall, differences in noise levels lie within authority (ownership model), rather than institution type. Different authority types could have different drivers when site selecting. Community-led 
facilities could be in quieter areas, close to communities where people live. Site selection may be more restricted to cheaper land values in the fringes of cities. Privately run ECCs could be driven to open in central areas close to workplaces, driven by convenience for working parents. These are discussed further in section 5.2.

Table 8: Mean noise level by ECC facility type (institution and authority)

\begin{tabular}{|c|c|c|c|c|}
\hline Facility type & Count & $\begin{array}{c}\text { Mean } \\
\text { noise } \\
\text { level }(\mathrm{dB})\end{array}$ & $\begin{array}{c}\text { Lower } \\
\text { confidence } \\
\text { interval (95\%) }\end{array}$ & $\begin{array}{c}\text { Upper } \\
\text { confidence } \\
\text { interval (95\%) }\end{array}$ \\
\hline \multicolumn{5}{|l|}{ Institution } \\
\hline \multicolumn{5}{|l|}{ Service } \\
\hline Free Kindergarten & 27 & 51.1 & 47.6 & 54.7 \\
\hline Homebased Network & 0 & - & - & - \\
\hline Playcentre & 11 & 50.4 & 44.4 & 56.5 \\
\hline Te Kōhanga Reo & 6 & 50.1 & 40.6 & 59.6 \\
\hline \multicolumn{5}{|l|}{ Authority } \\
\hline Community based & 89 & 52.3 & 50.4 & 54.2 \\
\hline Privately owned & 48 & 57 & 54.9 & 59.2 \\
\hline
\end{tabular}




\section{Ethnicity}

Māori and Pacific people in New Zealand often have poorer health and education outcomes compared to other ethnicities (Walsh \& Grey, 2019). Therefore, it is important to examine whether any differences in noise levels between ethnicities at ECCs exists.

Of the 6,301 children enrolled at ECCs and included in the study, 707 (11.2\%) were Māori, 292 (4.6\%) Pacific, 1292 (20.5\%) Asian, 3,556 (56.4\%) European/Pākehā and 330 (5.2\%) Other. We found Māori children had the highest mean noise level 56.0dB (55.8dB - 57.1dB), this was statistically significantly higher compared to European/Pākehā, 54.6dB (54.4 - 55.0dB), Pacific and Other (Table 9). Children of Asian ethnicity also registered higher mean noise levels (55.6dB), statistically significantly higher compared to Pacific, European/Pākehā, and Other children. There were no differences in noise levels between Pacific, European/Pākehā or Other children (Table 9).

Table 9: Mean noise level by ethnicity of children attending ECCS

\begin{tabular}{lcccc} 
Ethnicity & Count & $\begin{array}{c}\text { Mean } \\
\text { noise level } \\
(\mathrm{dB})\end{array}$ & $\begin{array}{c}\text { Lower } \\
\text { confidence } \\
\text { interval (95\%) }\end{array}$ & $\begin{array}{c}\text { Upper } \\
\text { confidence } \\
\text { interval (95\%) }\end{array}$ \\
\hline Māori & 707 & 56 & 55.8 & 57.1 \\
Pacific & 292 & 52.8 & 52.7 & 54.7 \\
Asian & 1292 & 55.6 & 55.4 & 56.4 \\
European/Päkehā & 3556 & 54.6 & 54.4 & 55 \\
Other & 330 & 53.6 & 52.8 & 54.7 \\
\hline
\end{tabular}




\section{Equity index (EQI)}

Of the 137 facilities in the Wellington Territorial Authority included in the study, the majority (120 of 137) were EQI 5 (least deprived). The sample sizes for the remaining EQIs $(1,2,3,4)$ were too small to meaningfully assess whether a relationship between EQI and noise level exists. For completeness, results are presented in Table 10, however, conclusions are not drawn from these results in the discussion.

Table 10: Mean noise level by ECC equity index

\begin{tabular}{lcc} 
Equity index & Count & Mean noise level (dB) \\
\hline 1 (most deprived) & 2 & 38 \\
2 & 0 & - \\
3 & 2 & 44.6 \\
4 & 1 & 52.2 \\
5 (least deprived) & 120 & 54.3 \\
\hline
\end{tabular}

\section{ECC roll size}

Variation of noise levels at ECCs by roll size was not assessed. ECC rolls are limited to relatively small sizes, sometimes as low as 25 children, as set out by the Education (Early Childhood Services) Regulations 2008 (Ministry of Education, 2008). These restrictions can limit the number of children enrolled to as low as 25 children for very young children. The median ECC roll size for ECC in the Wellington Territorial Authority was 32.0 children, with a standard deviation 22.7. 


\section{Schools}

For schools, socio-demographic variables included facility type, ethnicity and international students, decile, school roll size, and student achievement.

\section{Facility type}

The 78 schools included in this study comprised of 31 (39.7\%) full primary, 27 (34.6\%)

contributing, 10 (12.8\%) secondary, 4 (5.1\%) composite, 3 (3.8\%) intermediate, and one each of teen parent unit, special school, and activity centre (1.3\% each). We found slightly higher mean noise levels for Secondary schools (55.9dB) compared to other facility types. Both contributing and composite schools reported slightly lower mean noise levels, $48.1 \mathrm{~dB}$ and $48.4 \mathrm{~dB}$ respectively). However, the differences in mean noise levels between any of the facility types was not statistically significantly different (Table 11).

Table 11: Mean noise levels by school type

\begin{tabular}{lcccc}
$\begin{array}{l}\text { Count } \\
\text { Facility type }\end{array}$ & $\begin{array}{c}\text { Mean noise } \\
\text { level (dB) }\end{array}$ & $\begin{array}{c}\text { Lower } \\
\text { confidence } \\
\text { interval } \\
(95 \%)\end{array}$ & $\begin{array}{c}\text { Upper } \\
\text { confidence } \\
\text { interval } \\
(95 \%)\end{array}$ \\
\hline $\begin{array}{l}\text { Secondary (Year 9-15) } \\
\text { Full Primary }\end{array}$ & 10 & 55.9 & 49.6 & 62.2 \\
Intermediate & 31 & 51.1 & 47.8 & 54.3 \\
Contributing & 3 & 52.4 & 30.4 & 74.5 \\
Composite & 27 & 48.1 & 44.6 & 51.6 \\
\hline
\end{tabular}




\section{Ethnicity and international students}

In addition to examining differences in ethnicity, it is also important to examine differences between domestic and international students. International students are more likely to speak English as a second language, resulting in greater communication difficulties at higher noise levels.

Of the 29,639 students included in the study, 16,890 (57.0\%) were European/Pākehā, 3,305 (11.2\%) were Māori, 2,139 (7.2\%) Pacific, 5,383 (18.2\%) Asian, 1,115 (3.8\%) MELAA (Middle Eastern/Latin American/African), 265 (0.9\%) Other and 542 (1.8\%) International students.

Students of Asian ethnicity had lower mean noise levels 51.0dB (50.7dB - 51.2dB) compared to MELAA 52.3dB (51.8 dB- 52.8dB), Pacific 52.6dB (52.2dB - 53.0dB), Other 52.4dB (51.3dB - 51.3 dB), and European/Pākehā 51.7dB (51.5dB - 51.8dB). Due to large sample sizes, these differences were statistically significant, however the largest clinical significance between these groups was $1.4 \mathrm{~dB}$. There were no statistically significant differences between the remaining ethnicities (Table 12). International students had statistically higher mean noise levels $54.2 \mathrm{~dB}$ $(53.2 \mathrm{~dB}-54.9 \mathrm{~dB})$ compared to domestic students $51.7 \mathrm{~dB}(51.6 \mathrm{~dB}-51.8 \mathrm{~dB})$ (Table 12). 


\begin{tabular}{lcccc} 
Ethnicity & Count & $\begin{array}{c}\text { Mean noise level } \\
(\mathrm{dB})\end{array}$ & $\begin{array}{c}\text { Lower } \\
\text { confidence } \\
\text { interval } \\
(95 \%)\end{array}$ & $\begin{array}{c}\text { Upper } \\
\text { confidence } \\
\text { interval } \\
(95 \%)\end{array}$ \\
\hline $\begin{array}{l}\text { European/Păkehā } \\
\text { Māori }\end{array}$ & 16890 & 51.7 & 51.5 & 51.8 \\
Pacific & 3305 & 51.5 & 51.2 & 51.8 \\
Asian & 2139 & 52.6 & 52.2 & 53 \\
MELAA & 5383 & 51 & 50.8 & 51.2 \\
Other & 1115 & 52.3 & 51.8 & 52.8 \\
\hline International & 265 & 52.4 & 51.3 & \\
Domestic & 542 & 54.2 & 53.4 & 54.9 \\
& 29097 & 51.7 & 51.6 & 51.8
\end{tabular}

Note: international is also counted as an ethnicity.

\section{Decile}

School counts in the Wellington Territorial Authority were skewed toward high deciles (i.e., least deprived), resulting in small sample sizes for low deciles. In Wellington City, 11/78 (14.1\%) schools were deciles 1-5. Lower decile schools were more likely to be in the neighbouring territorial authorities of Porirua City and Lower Hutt City. In Porirua City, schools were heavily skewed to low decile, 27/36 (75.0\%) were decile 1-5. While in Lower Hutt City, schools' deciles were normally distributed, 30/55 (54.5\%) of schools were deciles 1-5. 
Schools were plotted on a scatter chart comparing decile and mean noise level. The Pearson coefficient was -0.12 , revealing no linear relationship between school decile and noise level (Table 13).

Table 13: Mean noise level by school decile

\begin{tabular}{lcc} 
Decile & Count & Mean noise level (dB) \\
\hline 1 (most deprived) & 3 & 56.4 \\
2 & 0 & - \\
3 & 2 & 50.9 \\
4 & 1 & 50.9 \\
5 & 5 & 53.8 \\
6 & 3 & 44.6 \\
7 & 5 & 43.1 \\
8 & 8 & 54 \\
9 & 13 & 50.4 \\
10 (least deprived) & 30 & 50.3
\end{tabular}




\section{School decile}

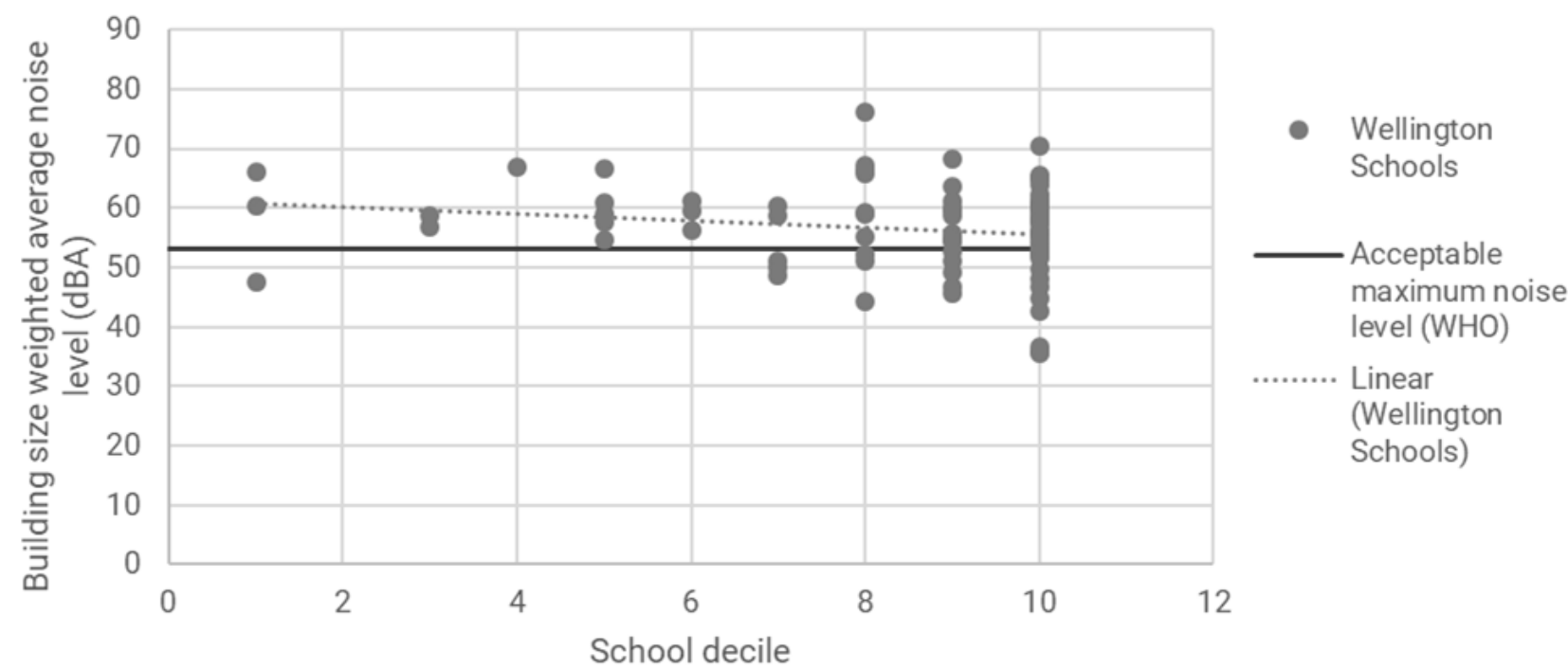

Figure 11: Scatter plot of Mean noise level versus school decile

\section{School roll size}

School roll size may be linked with noise levels. Schools with larger roll sizes may attract more traffic as they are a destination for school traffic. To test this, the relationship between school roll size and mean noise level was examined for primary and secondary schools. Low counts for the remaining school facility types (intermediate, contributing and composite) restricted this type of analysis to primary and secondary schools. The median roll size for secondary schools was higher (1,192 students) compared to primary schools (224 students). To avoid any confounding variation associated with facility type rather than roll size, primary and secondary schools were examined separately. School roll was plotted against noise level for primary and secondary schools (Figure 12). The r-squared value for the relationship between mean noise and school roll size for secondary schools was 0.0298. The Pearson coefficient for this relationship

\section{Page 96 of 182}


was 0.173 , meaning a low degree of positive correlation. This means that as secondary school roll sizes increase, noise levels increase.

For primary schools, the $r$-squared value was -0.003 and the Pearson coefficient -0.06 , meaning there was no significant correlation between mean noise level and primary school roll size.
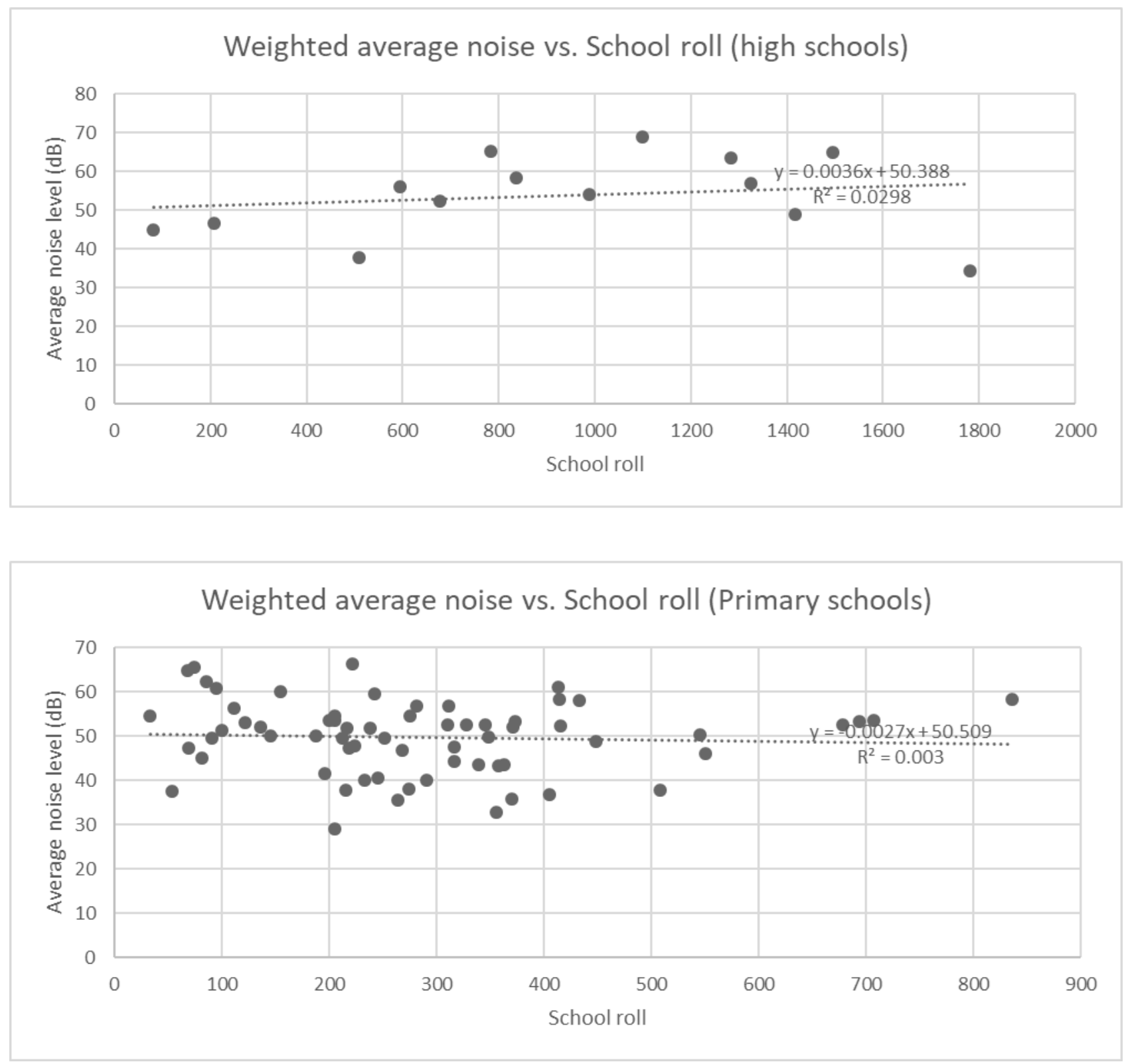

Figure 12: Scatter plots of Mean noise level v school size, high schools (top), primary school (bottom) 


\section{School achievement}

For schools with year 13 students (i.e., secondary, and composite type schools), we plotted average noise levels against the percent of year 13 students gaining university entrance in 2015 (Figure 13). The r-squared value for the relationship was 0.0851 . The Pearson coefficient of the relationship was -0.292 , meaning a low-moderate degree of negative correlation for this relationship. This means that university entrance attainment decreased as the average noise level increased.

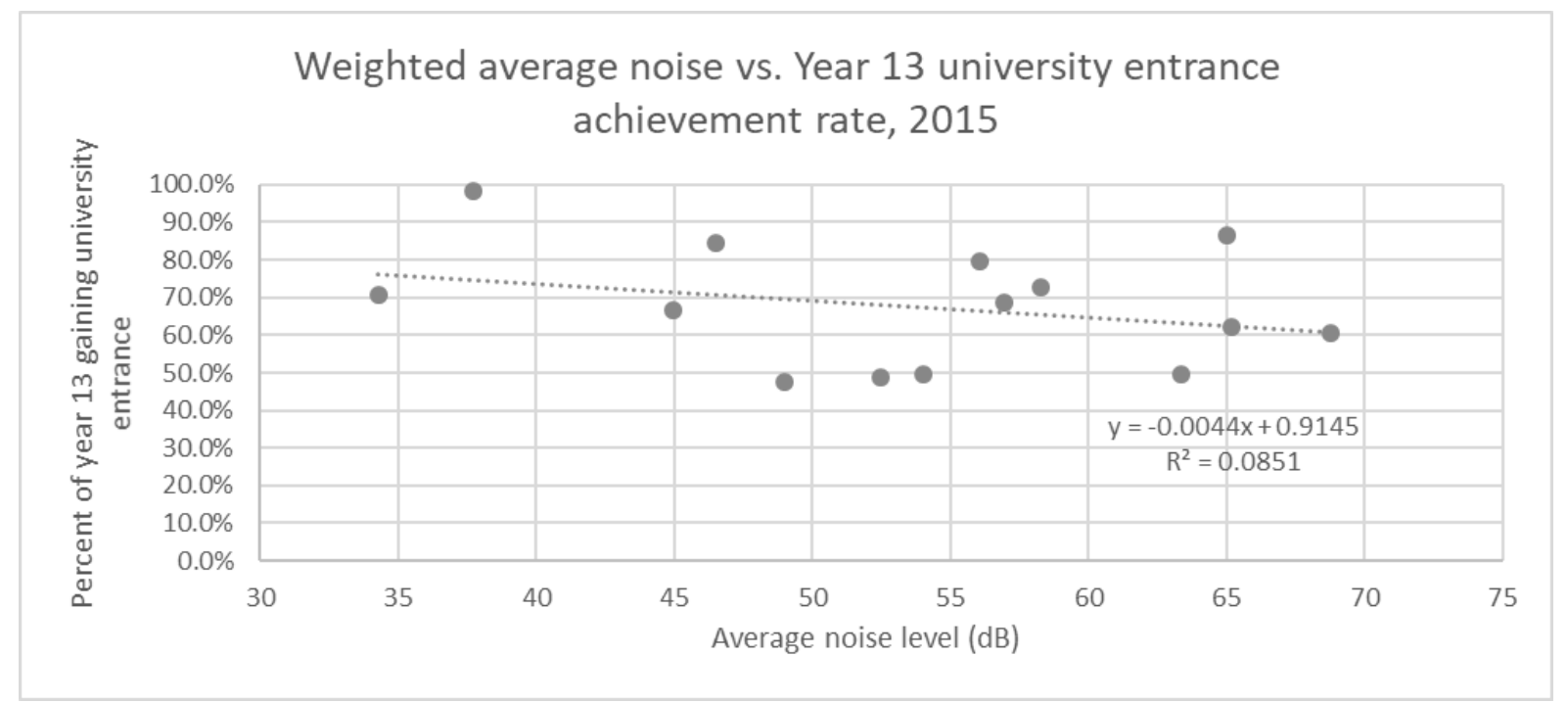

Figure 13: Scatter plot of Mean noise level vs. university entrance attainment 


\subsection{Land use and distance to roads}

This section presents the results for noise levels by land use and distance to roads.

Land use

Of the 78 schools included in the study, 54 (69.2\%) were in Outer residential areas, $13(16.7 \%)$ in Inner residential areas, while the remaining 11 (14.1\%) were in either City centre, Open space, or Other land use areas. No schools were in Industrial areas (Table 14).

Schools in the City centre, Inner residential, and Other reported the highest noise levels 53.0 53.4dB. However, based on overlapping confidence intervals (Table 14), the noise levels for schools in the City centre and Inner residential areas were not statistically significantly different to any of the remaining land uses, likely owing to small sample sizes.

Table 14: Mean noise level for schools by land use

\begin{tabular}{lcccc}
$\begin{array}{lcc}\text { Land use } \\
\text { Count }\end{array}$ & $\begin{array}{c}\text { Mean noise } \\
\text { level }(\mathrm{dB})\end{array}$ & $\begin{array}{c}\text { Lower } \\
\text { confidence } \\
\text { interval } \\
(95 \%)\end{array}$ & $\begin{array}{c}\text { Upper } \\
\text { confidence } \\
\text { interval } \\
(95 \%)\end{array}$ \\
\hline $\begin{array}{l}\text { Inner residential } \\
\text { Outer residential }\end{array}$ & 4 & 53.4 & 46.6 & 74.7 \\
$\begin{array}{l}\text { Industrial } \\
\text { Open space }\end{array}$ & 54 & 53.0 & 47.0 & 57.7 \\
Other & 0 & 50.0 & 49.5 & 54.0 \\
\hline
\end{tabular}


Of the 137 ECCs included in the study, 67 (48.9\%) were in Outer residential areas, 25 (18.2\%) in the City centre, $21(15.3 \%)$ in Inner residential areas, (6.6\%) in Open space and $8(5.8 \%)$ in Industrial areas. ECCs located in the City centre reported a mean noise level of $60.7 \mathrm{~dB}$, which is statistically significantly higher compared to ECCs located in Inner and Outer residential areas. Though the mean noise level for ECCs located in Industrial areas was high at $57.5 \mathrm{~dB}$, this was not statistically significantly higher compared with any other land use area due to the small sample size (Table 15).

Table 15: Mean noise level for ECCs by land use

\begin{tabular}{|c|c|c|c|c|}
\hline Land use & Count & $\begin{array}{c}\text { Mean noise } \\
\text { level }(\mathrm{dB})\end{array}$ & $\begin{array}{c}\text { Lower } \\
\text { confidence } \\
\text { interval } \\
(95 \%)\end{array}$ & $\begin{array}{c}\text { Upper } \\
\text { confidence } \\
\text { interval } \\
(95 \%)\end{array}$ \\
\hline City centre & 25 & 60.7 & 57.0 & 64.4 \\
\hline Inner residential & 21 & 52.4 & 48.3 & 56.5 \\
\hline Outer residential & 67 & 51.9 & 49.7 & 54.1 \\
\hline Industrial & 8 & 57.5 & 50.0 & 65.0 \\
\hline Open space & 9 & 50.5 & 43.6 & 57.4 \\
\hline Other & 7 & 51.2 & 42.9 & 59.5 \\
\hline
\end{tabular}

Figure 14 shows the mean noise levels for the District plan zones as vertical bars, while the labelled horizontal lines show the mean noise level for the aggregated land use categories used in this study. Of all buildings in the Wellington Territorial Authority, mean noise levels were highest for buildings in the City centre $(61.5 \mathrm{~dB})$, followed by Industrial areas $(56.9 \mathrm{~dB})$. In

\section{Page 100 of 182}


addition, when examined by District Plan zones, Open space A (i.e., recreation grounds, sports fields) and institutional precinct (i.e., Universities) reported relatively high noise levels, 56.9dB and $55.8 \mathrm{~dB}$ respectively. The District Plan zones with the lowest mean noise levels were the Airport (note: excludes air traffic noise) (26.6dB), Rural (43.2dB) and Conservation (34.6 dB) areas.

Noise level (dB)

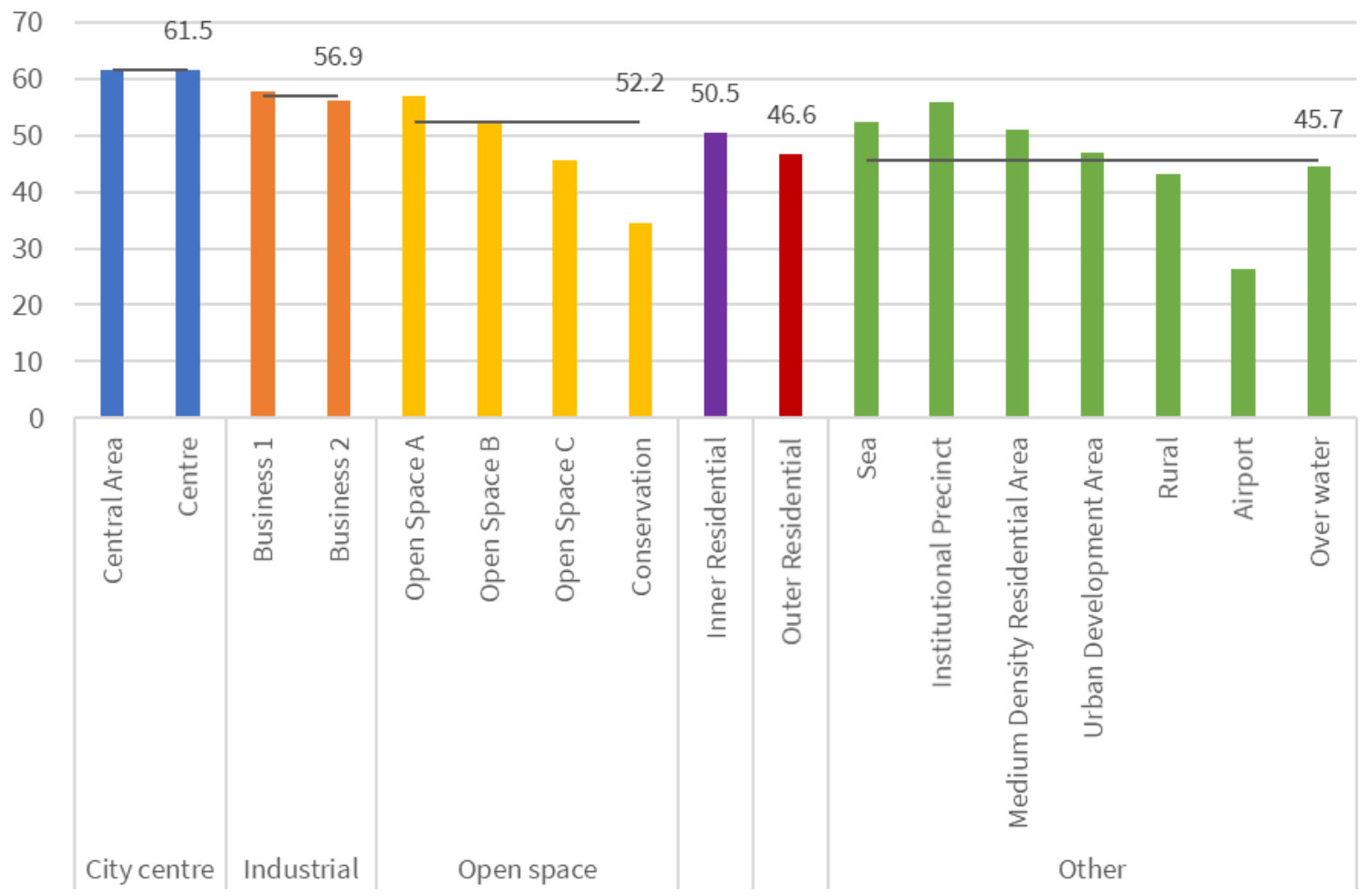

Figure 14: Mean noise levels by land use and District Plan zones (weighted by building size) 


\section{Distance to road results}

The mean distance from all building centroids to the nearest road in Wellington Territorial Authority was $24.4 \mathrm{~m}$. This compared to $34.0 \mathrm{~m}$ for buildings on school grounds (Table 17) and 18.5m for buildings on ECC grounds (Table 16). For both schools and ECCs, the shortest distances between building centroids and roads were for facilities in the City centre: $18.3 \mathrm{~m}$, and $11.8 \mathrm{~m}$ respectively. The land use with the largest mean distances were Open space, with a mean distance of $24.8 \mathrm{~m}$ for ECCs and $51.4 \mathrm{~m}$ for schools. Because sample sizes were relatively low, many of the differences in distances were not statistically significant. However, for ECCs, the mean distance to roads in the City centre were significantly lower compared to Outer residential areas at the $95 \%$ confidence level.

Table 16: Mean distance to roads for ECCs, by land use

\begin{tabular}{|c|c|c|c|c|}
\hline Land use & Count & $\begin{array}{c}\text { Mean } \\
\text { distance }(\mathrm{m})\end{array}$ & $\begin{array}{c}\text { Lower } \\
\text { confidence } \\
\text { interval } \\
(95 \%)\end{array}$ & $\begin{array}{c}\text { Upper } \\
\text { confidence } \\
\text { interval } \\
(95 \%)\end{array}$ \\
\hline City centre & 25 & 11.8 & 6.8 & 16.7 \\
\hline Inner residential & 21 & 15.3 & 9.8 & 20.8 \\
\hline Outer residential & 67 & 20.6 & 17.7 & 23.6 \\
\hline Industrial & 8 & 23.3 & 13.3 & 33.4 \\
\hline Open space & 9 & 24.8 & 15.6 & 34.1 \\
\hline Other & 7 & 20.5 & 9.4 & 31.6 \\
\hline Total & 137 & 18.5 & 16.4 & 20.5 \\
\hline
\end{tabular}




\begin{tabular}{|c|c|c|c|c|}
\hline Land use & Count & $\begin{array}{c}\text { Mean } \\
\text { distance }(\mathrm{m})\end{array}$ & $\begin{array}{c}\text { Lower } \\
\text { confidence } \\
\text { interval } \\
(95 \%)\end{array}$ & $\begin{array}{c}\text { Upper } \\
\text { confidence } \\
\text { interval } \\
(95 \%)\end{array}$ \\
\hline City centre & 4 & 18.3 & 0 & 50.0 \\
\hline Inner residential & 13 & 29.2 & 17.1 & 41.2 \\
\hline Outer residential & 54 & 35.8 & 30.4 & 41.2 \\
\hline Industrial & 0 & - & - & - \\
\hline Open space & 2 & 51.4 & 0 & 230.4 \\
\hline Other & 5 & 33.3 & 8.6 & 58.1 \\
\hline Total & 78 & 34.0 & 29.6 & 38.5 \\
\hline
\end{tabular}

The mean distance from all building centroids to the nearest major road in the Wellington Territorial Authority was $251.3 \mathrm{~m}$. This result compared to $142.4 \mathrm{~m}$ for buildings on school grounds (Table 18) and $106.7 \mathrm{~m}$ for buildings on ECC grounds (Table 19). Again, for both schools and ECCs, facilities in the City centre had the shortest mean distance to major roads. The mean distance to major roads for schools in the City centre was $42.6 \mathrm{~m}$ and $25.5 \mathrm{~m}$ for ECCs. Because sample sizes were relatively low, the differences in distances were statistically insignificant. 


\begin{tabular}{|c|c|c|c|c|}
\hline Land use & Count & $\begin{array}{c}\text { Mean } \\
\text { distance }(\mathrm{m})\end{array}$ & $\begin{array}{c}\text { Lower } \\
\text { confidence } \\
\text { interval } \\
(95 \%)\end{array}$ & $\begin{array}{c}\text { Upper } \\
\text { confidence } \\
\text { interval } \\
(95 \%)\end{array}$ \\
\hline City centre & 4 & 42.6 & 0 & 537.0 \\
\hline Inner residential & 13 & 75.7 & 0 & 263.5 \\
\hline Outer residential & 54 & 116.6 & 31.8 & 201.4 \\
\hline Industrial & 0 & - & - & - \\
\hline Open space & 2 & 315.3 & 0 & 3107.0 \\
\hline Other & 5 & 604.7 & 218.9 & 990.6 \\
\hline Total & 78 & 142.4 & 72.3 & 212.4 \\
\hline
\end{tabular}

Table 19: Mean distance to major roads for ECCS, by land use

\begin{tabular}{|c|c|c|c|c|}
\hline Land use & Count & $\begin{array}{c}\text { Mean } \\
\text { distance }(\mathrm{m})\end{array}$ & $\begin{array}{c}\text { Lower } \\
\text { confidence } \\
\text { interval } \\
(95 \%)\end{array}$ & $\begin{array}{c}\text { Upper } \\
\text { confidence } \\
\text { interval } \\
(95 \%)\end{array}$ \\
\hline City centre & 25 & 25.5 & 0 & 82.1 \\
\hline Inner residential & 21 & 96.5 & 34.0 & 158.9 \\
\hline Outer residential & 67 & 144.6 & 111.1 & 178.1 \\
\hline Industrial & 8 & 33.6 & 0 & 148.3 \\
\hline Open space & 9 & 159.4 & 53.9 & 264.9 \\
\hline Other & 7 & 112.7 & 0 & 239.6 \\
\hline Total & 137 & 106.7 & 83.6 & 129.9 \\
\hline
\end{tabular}


Relationship between distance to road and noise levels

We examined the relationship between distance to major roads and modelled noise levels

(Figure 15). The R-squared value for the relationship was 0.021, meaning that for the Wellington Territorial Authority, distance to roads explained just $2 \%$ of noise levels in the model. The remainder was explained by other factors in the model, such as traffic volume, slope, and the effect of buildings acting as barriers among others.

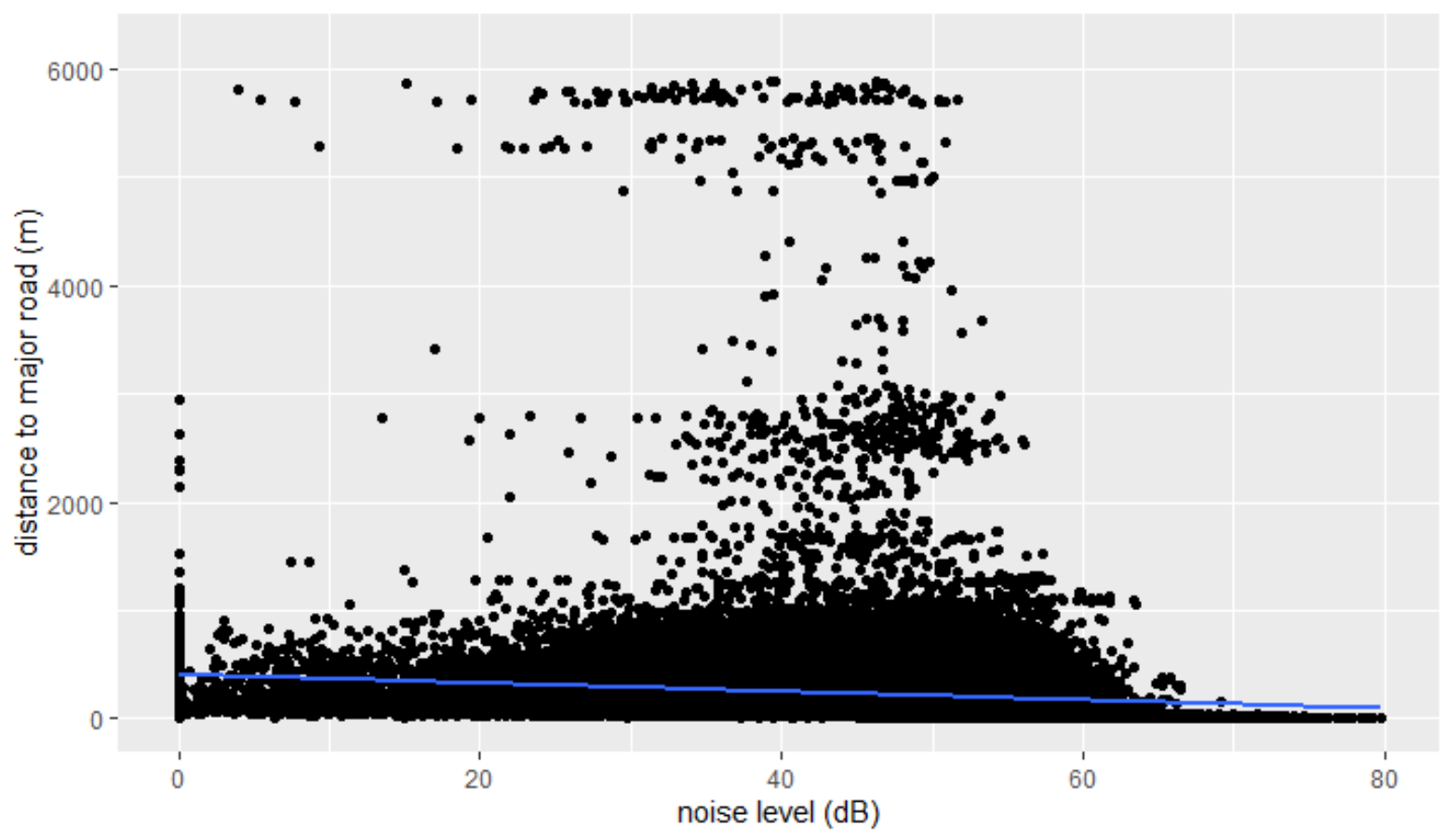

Figure 15: Relationship between distance to major road (arterial routes and greater) and modelled noise levels (R-squared = 0.02111)

We also examined the relationship between distance to roads of any hierarchy and modelled noise levels (Figure 16). The R-squared value for this relationship was 0.27 , higher compared to 
major roads. This means that distance to any road explained $27 \%$ of the modelled noise level and was a better predictor compared to distance to major roads.

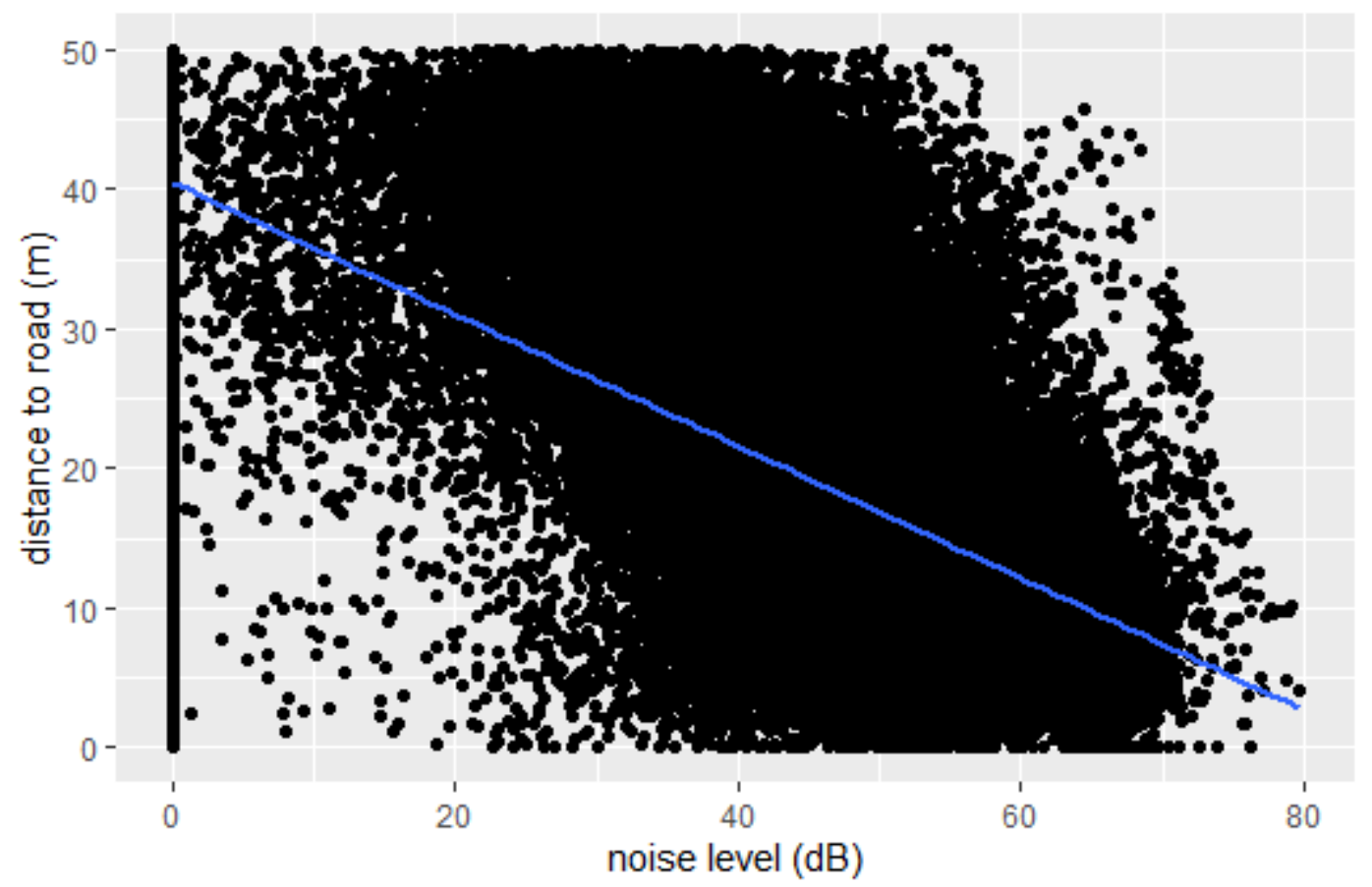

Figure 16: Relationship between distance to roads of any hierarchy and modelled noise levels (R-squared $=0.2697)$. 


\subsection{Model validation}

Results from the linear model which compared modelled and volunteered noise data are presented in Table 20. These results assume unbiased sampling methods, however, we found evidence of bias sampling for volunteered data, whereby the collection of in situ noise measurements favoured areas of high noise levels. While the R-squared values indicate a moderate to poor fit of the linear models around the data points (depending on land use), the validity of these results should be interpreted conservatively. We found Open space and Outer residential areas had the highest $\mathrm{R}$-squared values, 0.18 and 0.14 respectively (Table 20), indicating a moderate fit. The R-squared value for Industrial land use areas was higher (0.24) (Table 20), however the gradient of the linear model indicated a negative relationship between volunteered and modelled data (i.e., as modelled noise levels increased volunteered noise levels decreased). R squared values for Inner residential areas and the City centre were 0.0 , this indicates the data do not fit tightly around the linear model.

\section{Page 107 of 182}


Table 20: Summary statistics for the linear model: volunteered (measured) vs. modelled noise levels, by land use area

\begin{tabular}{|c|c|c|c|c|c|}
\hline Land use area & R-squared & $\begin{array}{r}\text { Linear model } \\
\text { gradient }\end{array}$ & Y intercept & $\begin{array}{r}\text { Median } \\
\text { measured } \\
\text { noise } \\
\text { level }(\mathrm{dB})\end{array}$ & $\begin{array}{r}\text { Median } \\
\text { modelled } \\
\text { noise } \\
\text { level (dB) }\end{array}$ \\
\hline City centre & 0.00 & -0.01 & 67.58 & 68.24 & 64.62 \\
\hline Inner residential & 0.01 & 0.09 & 60.43 & 66.71 & 64.40 \\
\hline Outer residential & 0.14 & 0.30 & 48.17 & 64.24 & 57.60 \\
\hline Industrial & 0.24 & -0.85 & 125.90 & 69.41 & 65.65 \\
\hline Open space & 0.18 & 0.44 & 40.62 & 66.06 & 64.00 \\
\hline All & 0.14 & 0.30 & 48.17 & 64.24 & 57 \\
\hline
\end{tabular}

The loose fit between modelled and volunteered data could be due to other sources of noise measured in the environment such as air traffic and rail, which are not included in the model. However, we also found evidence of bias sampling for volunteered data; the mean modelled noise level for buildings where a volunteered value was obtained was significantly higher (64.2 $\mathrm{dB}$ ), compared to the mean modelled noise level of $46.7 \mathrm{~dB}$ for all buildings in the Wellington Territorial Authority. This difference was significant at the 95\% confidence level. In the scatterplots (Figure 18: $\mathrm{a}-\mathrm{j}$ ), the bias presents as clusters of points in the upper right quadrant

\section{Page 108 of 182}


(i.e., data only present for high-volunteered, high-modelled values) this pattern is consistent for all land use types (Figure 18: a-j). Fitting a linear model to an incomplete sample is difficult and is likely not to be telling of the actual relationship between volunteered and modelled noise. This sampling bias will be discussed in more detail in section 5.4. To compensate for the lack of low noise level data, we fitted a linear model restricted to passing through the origin. The results from the origin restricted scatterplots help to better imagine the true model performance in the absence of low noise level data (Figure 18: b, d, e, j).

To summarise how closely volunteered and measured points matched, we examined absolute differences in noise levels for each building. We found $66 \%$ of modelled measurements fell within $10 \mathrm{~dB}$ of volunteered data, rising to $81 \%$ within $15 \mathrm{~dB}$ (Figure 17). We can conclude, that in areas of high noise levels, the model returns high modelled noise levels and the differences between volunteered and modelled noise levels is reasonable (i.e., $81 \%$ within $15 \mathrm{~dB}$ ). However, not enough volunteered data was captured at low noise levels to draw conclusions on model performance at these levels.

\section{Page 109 of 182}




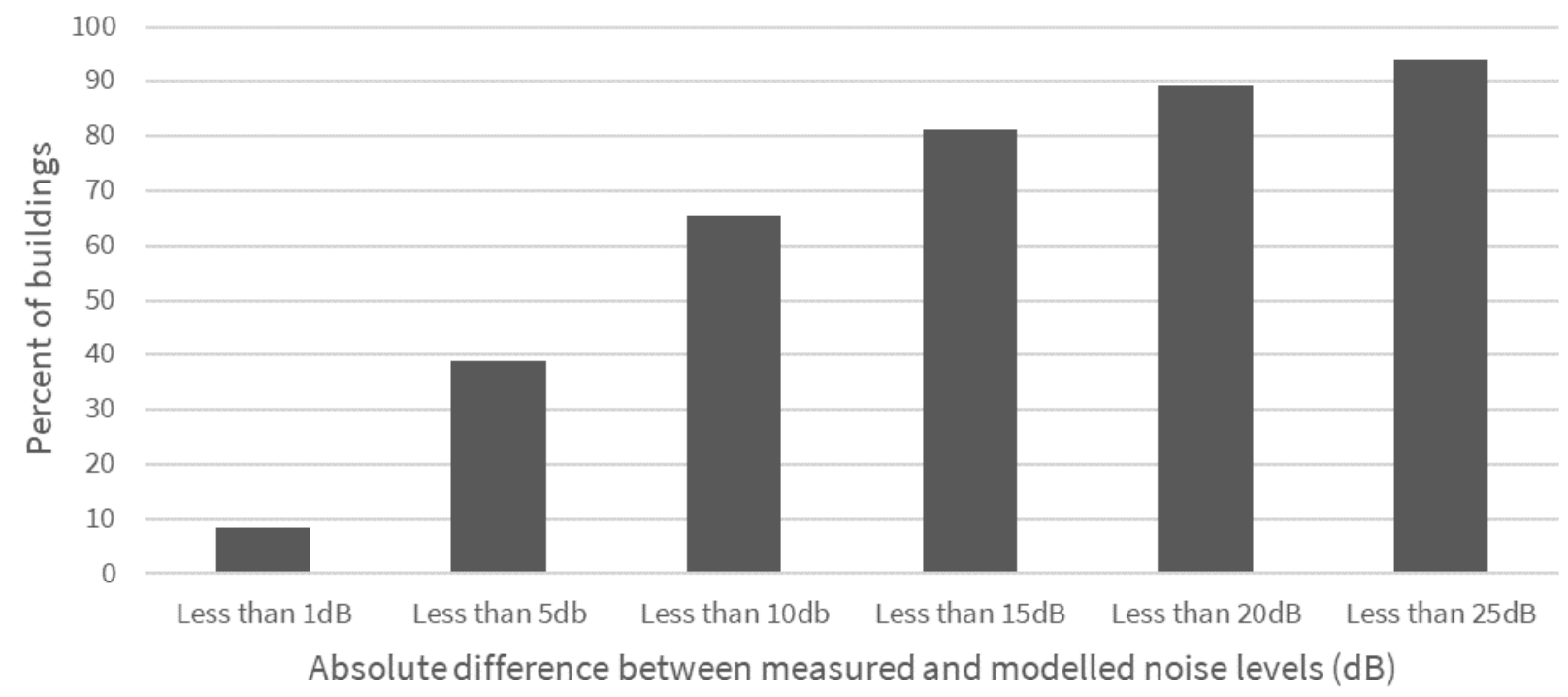

Figure 17: Percent of buildings with absolute differences between volunteered (measured) and modelled noise values 
Figure 18 (a-j): Scatterplots comparing volunteered (measured) and modelled noise levels, by land use. Left linear fit, right origin constrained fit. Notice that axes are identical between charts and begin at the origin, helping to highlight areas where data are missing.

\section{All areas}

(a) linear

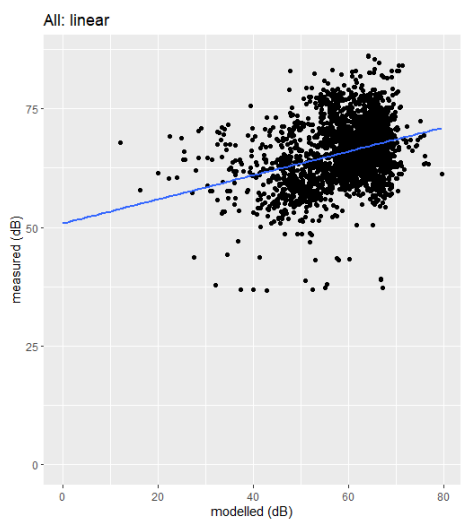

\section{City centre}

(c) linear

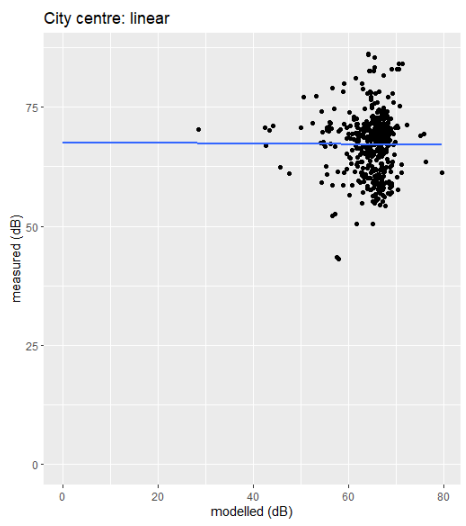

(b) linear, origin constrained

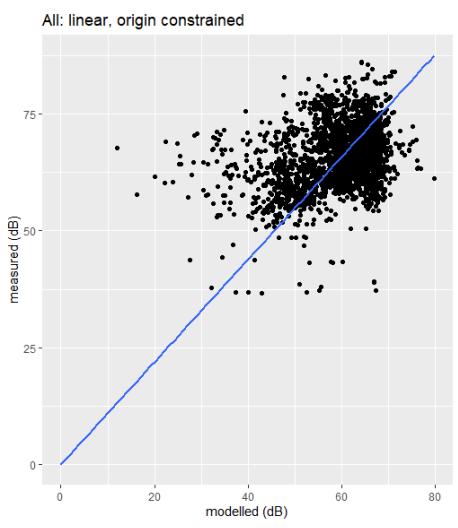

(d) linear, origin constrained

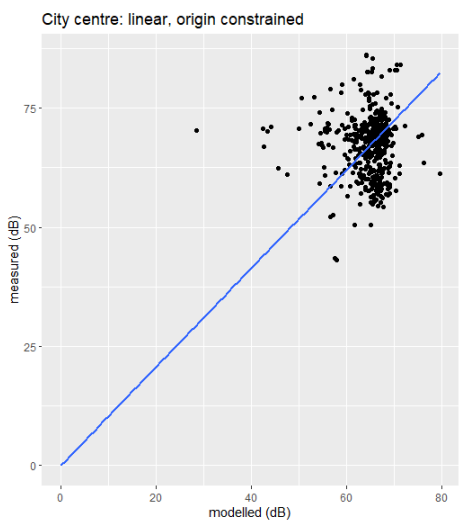

Industrial 
(d)

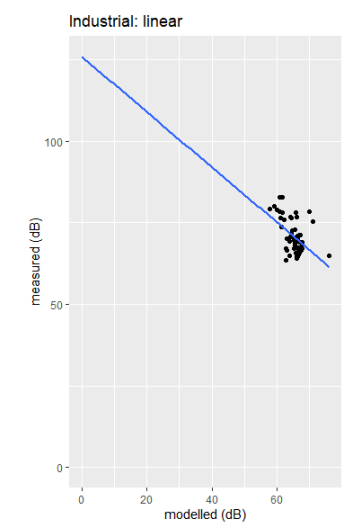

Inner residential

(e) linear

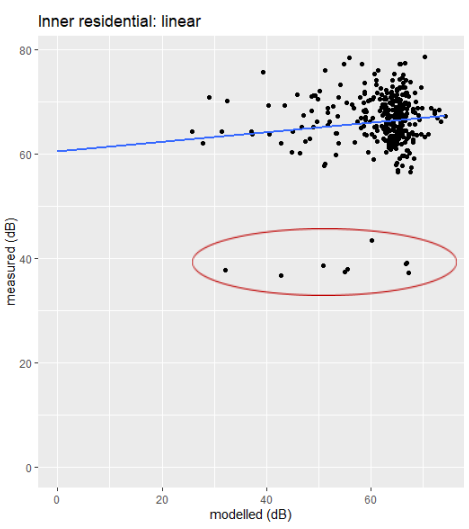

Note: Paterson Street outliers circled (e) linear, origin constrained

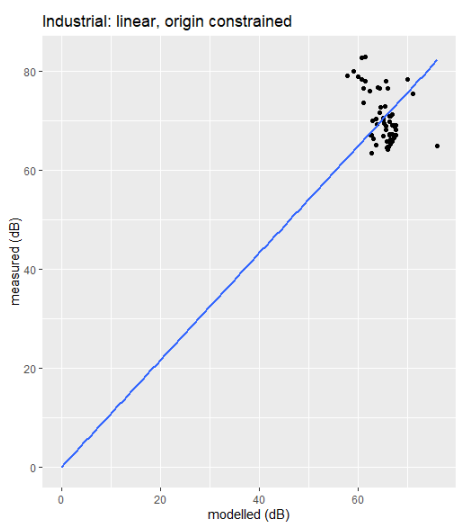

(f) linear, origin constrained

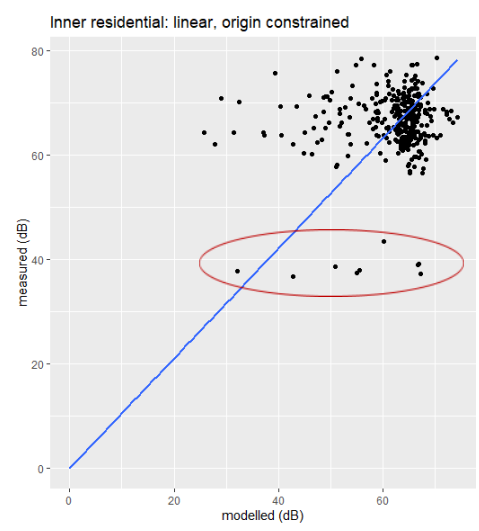


Open space

(g) linear

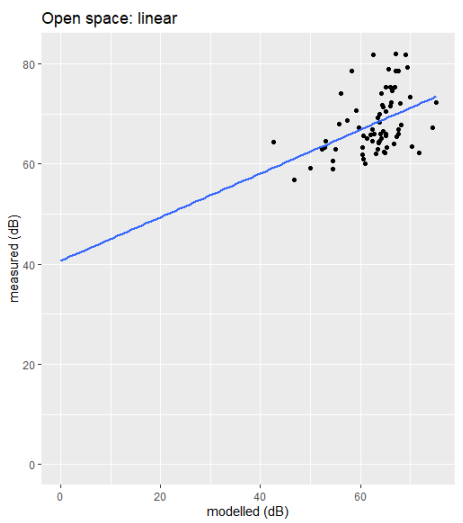

(h) linear, origin constrained

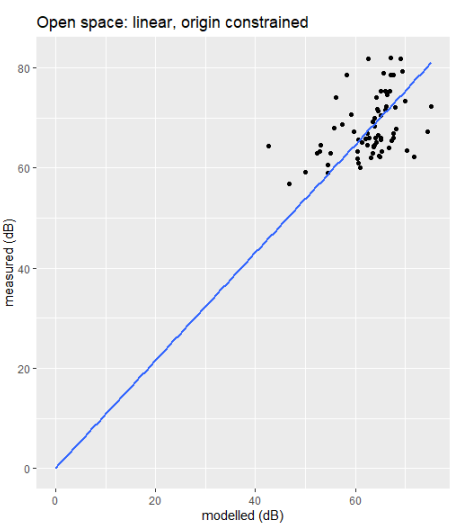

(j) linear, origin constrained

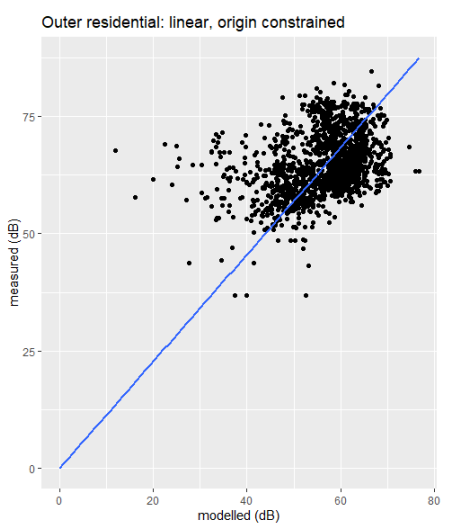




\section{Outlier areas}

For the inner residential area, there were 9 outlier points where the volunteered values were all low (36.6-43.4dB), contrasting the higher modelled values of 32-67dB. On closer examination, the buildings were located on a street (Paterson Street) which runs parallel to, but elevated above State Highway 1 as it enters the Mount Victoria tunnel (Figure 19). This section of State Highway 1 is flanked by concrete retaining walls, forming a 'canyon' before entering the tunnel. The retaining walls likely act as noise barriers reducing the noise measured by volunteers at the buildings along Paterson Street. The CNSOSS-EU model neither accounts for the additional vertical distance from the road to the buildings, which would dissipate noise, nor the retaining wall barriers, which would reflect noise away from the buildings. These two factors may explain why the volunteered values are lower than the modelled values for these outlier points. For other areas in this study where there is significant vertical distance, we expect the model would have similarly over-predicted actual noise levels. Additional vertical distance and noise barriers likely occur in many places in Wellington, and indeed in most built areas of the world.

\section{Page 114 of 182}




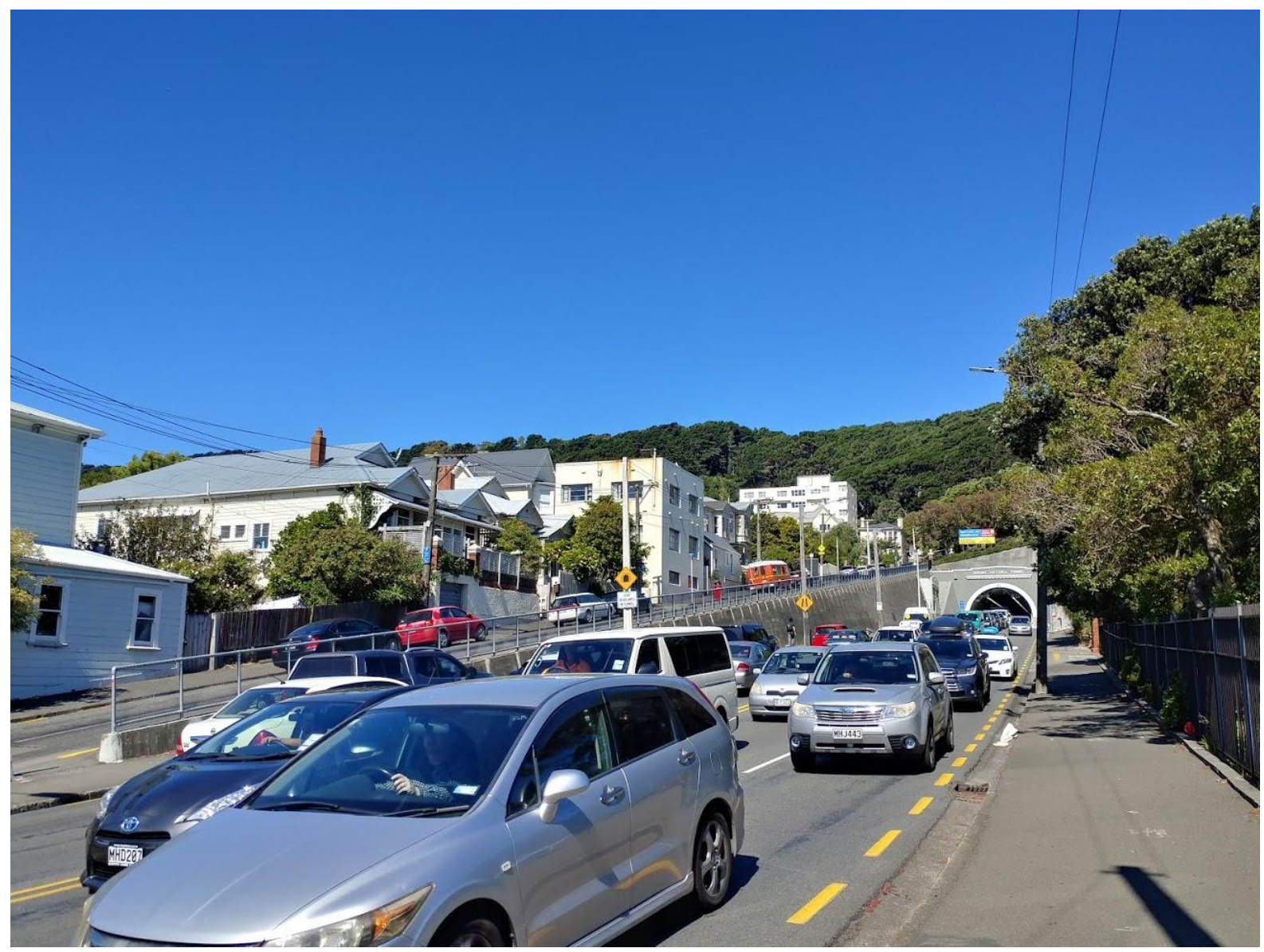

Figure 19: State Highway 1 approaching Mount Victoria tunnel from the west. State Highway 1 forms a canyon, while Paterson Street is elevated to the left. Source: Authors own. 
Areas where the absolute difference exceeded $25 \mathrm{~dB}$ typically occurred when volunteered values were much higher than modelled values. This suggests that other sources of noise could play a more substantial role in these areas, and in many of these areas, a plausible source of significant noise other than traffic can often be found. We explore three such areas here.

The Wellington Waterfront (Figure 20) is zoned as a Central Area. The land use is variable, including recreation, dining, retail, events, and contains Wellington's commuter ferry terminus. Buildings located on the waterfront could therefore be exposed to several other sources of noise including from boats, restaurants, bars (music, chatter), and events. These other sources could increase measured noise levels by volunteers compared to modelled values. 


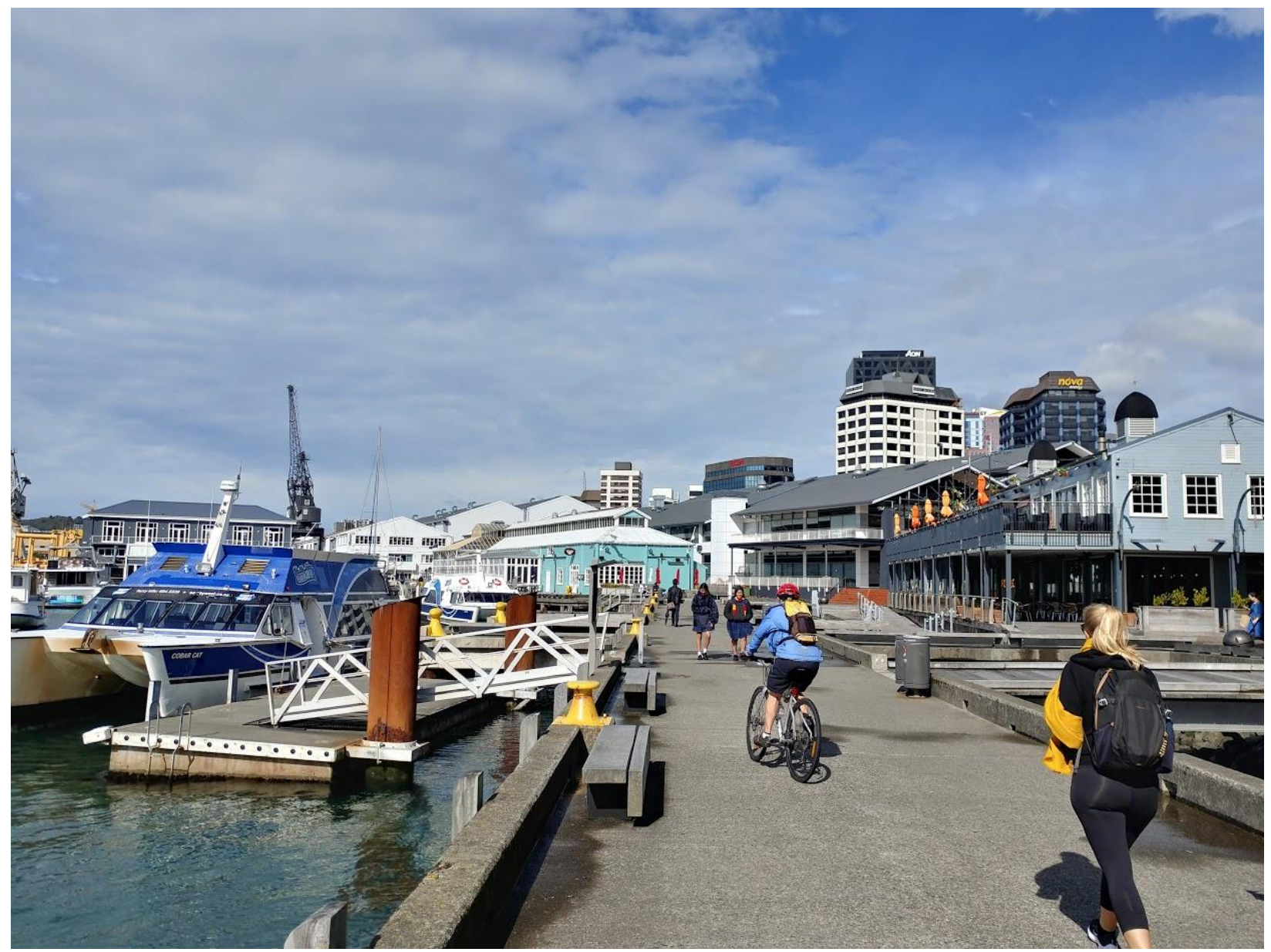

Figure 20: Wellington Waterfront has multiple sources of noise including, the commuter ferry terminus (pictured left), and al fresco dining areas (pictured right)

Source: Author's own work

Volunteered noise measurements located at Victoria University of Wellington Kelburn Campus

(Figure 21) may be boosted by noise from education related activities, such as chatter and

student events, resulting in measured noise levels higher than modelled noise levels. 


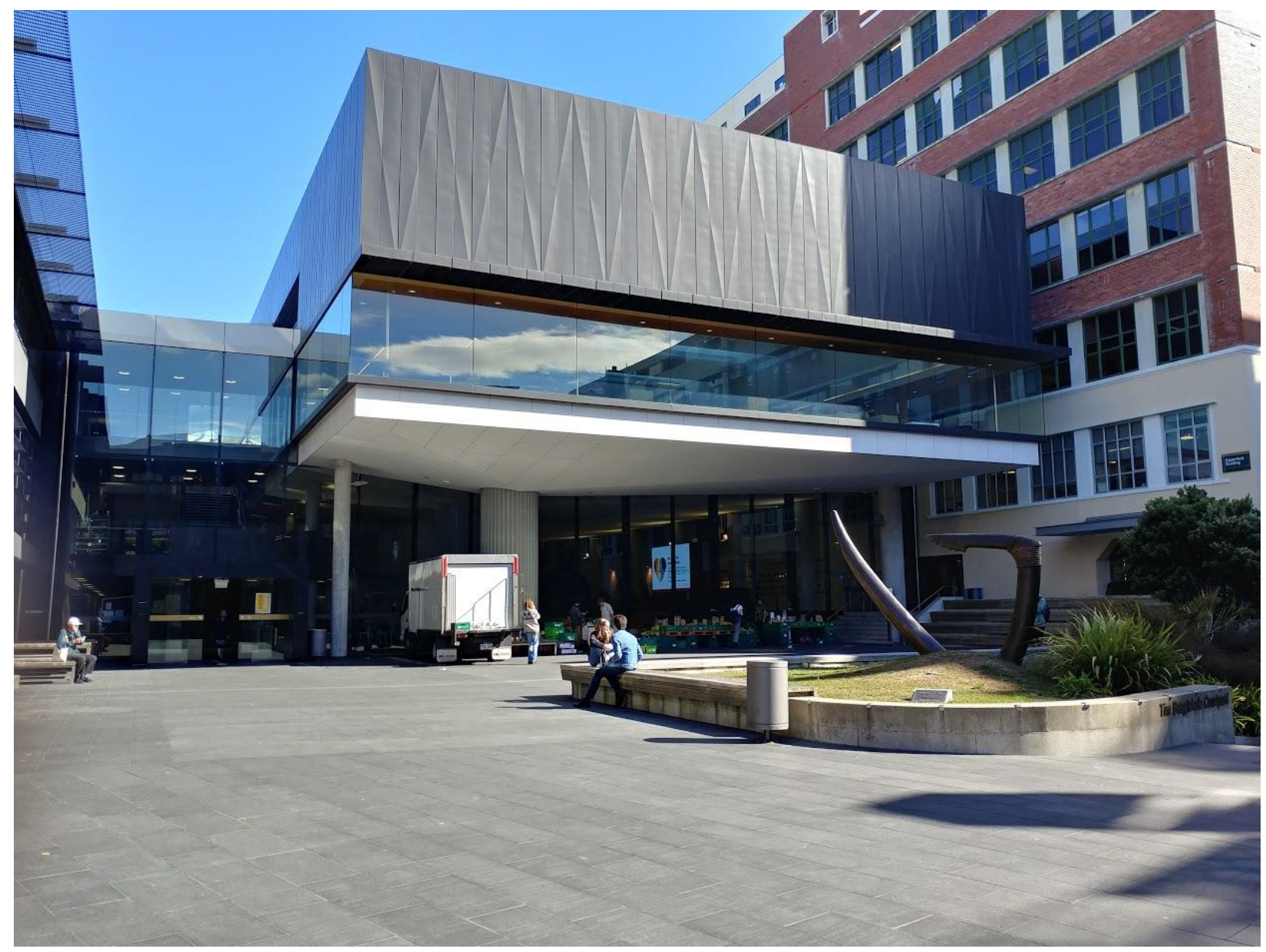

Figure 21: Victoria University of Wellington, Kelburn Campus. Outdoor areas host student events such as a pop-up farmers' market (pictured).

Waipapa Terrace is a cul-de-sac located on hilly terrain, with a low traffic volume. There are no high-volume roads nearby and it is in a residential area. Modelled values were low at 22.4dB34.4dB, while volunteered values were much higher $64.2 \mathrm{~dB}-69.9 \mathrm{~dB}$. For this group of buildings, there is no clear reason for volunteered values to be constantly high. Though one can expect that one-off high-noise events occur from time to time in otherwise quiet areas, e.g., road works, construction, machinery (e.g., from refuse truck compactors), or private gatherings. It is 
conceivable that such an event could have been captured in Waipapa Terrace, though there is no evidence to support this claim. 


\section{Chapter 5: Discussion}

The aims of this research were to assess exposure to traffic generated noise at schools and ECCs, examine the interaction between noise pollution and socio-demographic indicators at schools and ECCs, and assess how land use and distance to roads compares to noise levels. In this chapter, we discuss the significance of the research findings for each of the three objectives inturn, address the limitations of the study, explore what can be done to ameliorate noise levels, and interpret the significance of the findings in a regulatory context.

\subsection{Spatial patterns of noise levels}

Our results presented in section 4.1, showed that for all buildings across the Wellington Territorial Authority, including schools and ECCs, the noise levels generated by motor vehicle traffic were typically higher around Central Wellington and high traffic roads compared to suburban areas. This pattern is expected, and echoes soundscapes measured in other cities. Urban-suburban differences have been reported for noise measurements across Curitiba, Brazil (Paz \& Zannin, 2008), and multiple cities in Italy (Alías \& Socoró, 2017), while Toronto, Canada reported a relationship with proximity to high volume roads (Zuo et al., 2014). Central areas are destinations for work, shopping, and leisure. These areas attract high traffic volumes from suburbs, fed through a number of arterial roads. The elevated noise levels in central Wellington, largely reflects the volume of vehicles passing through and the high density of buildings in central areas. Space is a scarce resource in central areas, so buildings tend to be densely filled, with little room between roads and building facades. Noise propagation paths are short, with

\section{Page 120 of 182}


little distance for noise to dissipate. Main arterial routes to and through Wellington City have high traffic flows, and often higher speeds, contributing to higher noise levels in adjacent areas. Although this study did not capture sources of noise pollution beyond traffic generated noise, it is expected that other sources would compound urban noise pollution and increase the urbansuburban difference. Other noise sources (such as music, people talking, horns, and sirens from ambulances, fire trucks, and police) are all more likely to be more prevalent in urban areas (Alías \& Socoró, 2017).

Well established links exist between noise levels and health effects on the population (World Health Organization, 2018). WHO's Environmental Noise guidelines for the European Region suggest that for traffic noise, noise above $53 \mathrm{~dB}$ is associated with adverse health effects (World Health Organization, 2018). We can hypothesise that health effects are, in general, more widely felt in central Wellington where noise levels are higher, compared to the suburbs.

Of all buildings in the Wellington Territorial Authority, 33.7\% exceeded the 53dB threshold. For schools in the Wellington Territorial Authority, 55 schools (67.1\%), or 21,209 (67.1\%) students exceed this threshold, along with 79 ECCs (57.7\%), or 3,288 children (60.1\%). This result indicates that excessive noise levels at both schools and ECCs is a widespread issue in the Wellington Territorial Authority. A large proportion of students and children may be at risk of the health effects associated with elevated noise levels at schools and ECCs.

In addition to the 53dB threshold, the WHO also recommends night-time noise levels of below $45 \mathrm{~dB}$. Noise levels above this threshold are associated with negative effects on sleep (World

\section{Page 121 of 182}


Health Organization, 2018). For ECCs, this lower threshold may also be applicable, as young children often have sleep patterns which include sleep during the day, i.e., 'naptime'. The $45 \mathrm{~dB}$ threshold was exceeded at 116 ECCs (84.7\%), with 4,633 children (84.7\%) affected. High noise levels lead to sleep disturbance, multiple awakenings, and poorer cardiac and blood pressure outcomes (World Health Organization, 2018). These health impacts are likely to be a causal pathway to cardiovascular disease (World Health Organization, 2018). Our results indicate that noise levels at ECCs in the Wellington Territorial Authority are often too high to facilitate quality naptime and the issue is generally widespread.

Adverse effects of poor sleep quality at ECCs may be moderated by nocturnal sleep in the home environment. There is evidence to suggest that total daily sleep time remains uniform, regardless of the breakdown of daytime and nocturnal sleep, i.e. children who sleep less in ECCs will have longer nocturnal sleep times, while children who spend more time sleeping in ECCs will have shorter nocturnal sleep times (Ward, Gay, Anders, Alkon, \& Lee, 2008). Whether sleep quality is better at home compared to an ECC depends on the noise environment at home. We found Outer residential areas typically have buildings with the lowest noise levels, as detailed further in section 5.3. As many homes are in suburban environments, it is likely nocturnal sleep will, in many cases, be of better quality than ECC nap time. Though, if children attend ECCs in high noise areas also live inside high noise areas, then there may be little opportunity for quality sleep time. Assessing noise levels in residential areas in future research would therefore be valuable.

\section{Page 122 of 182}




\subsection{Socio-demographic indicators}

In this section, we discuss the interaction between modelled noise levels for schools and ECCs and socio-demographic indicators.

\section{Early childhood centres: facility type and authority}

This study found that for ECCs differences in noise levels predominantly lie within the authority type (i.e., ownership model), rather than the institute type (e.g., Te Kōhanga Reo, kindergarten, playcentre). No statistically significant difference in noise levels were found between any of the institute types. Whereas, broken down by authority type, noise levels were statistically significantly higher in privately owned facilities compared to community led facilities. Research into the dynamics of different ownership models suggests there could be a few drivers for this difference. First, it could be driven by different values the authority types place on managing aspects of their service, such as spending on building and equipment. Second, it may also be driven in part by different convenience desires between working and stay-at-home parents.

Mitchell (2002) examined the differences in the quality of education between community-led and privately run ECCs in New Zealand, Canada, and the United States. The study determined that community led facilities tend to prioritise aspects of the service, such as quality, and involving parents in decision making, while privately run facilities must weigh in profitability (i.e., cost/benefit) into decisions and parents are less involved. When examining budget cuts, privately owned facilities tend to neglect equipment and buildings maintenance whereas community owned centres looked for cutbacks which keep conditions unchanged. Hence, it appears

\section{Page 123 of 182}


community led facilities place higher value on aspects which relate to facility environment compared to privately run facilities. Differing values and spending could mean that community led facilities put more emphasis on site location in terms of environment, such as road noise, air pollution and risk of traffic injuries outside the facility compared to privately owned facilities.

At the same time, community led facilities also tend to have more qualified staff, pay staff more, and have lower fees (Mitchell, 2002). Because community facilities pay staff more, and charge lower fees, they may need to cut costs elsewhere, and space is a large expense for most ECCs. In monocentric urban areas, such as Wellington, land prices typically reduce from the central city to the outer suburbs (Grimes \& Liang, 2009), hence savings might be found in outer suburbs compared to central Wellington. This land value pattern also approximately matches the soundscape found in this study, with typically higher noise levels in the more expensive central Wellington compared to the suburbs. Hence, seeking cost savings for space may result in selecting an area with lower noise levels. How the space is attained (rented, mortgaged, and wholly owned) influences the actual costs placed on the facility, which in turn could influence where a facility can afford to open. However, it seems there is a mixture of rented, mortgaged, or wholly owned, regardless of ownership type in New Zealand (Mitchell, 2002).

A second explanation for the difference between authority type and noise levels is the desire for parents' convenience influencing the location selection for both privately run and community led facilities. Privately run facilities may be more likely to accommodate the needs of working parents who have little time to be involved in a community led ECC. For these working parents, having children located in ECCs close to parents' places of work in the central city, or en route on

\section{Page 124 of 182}


a busy road may be a desirable factor parents seek out when selecting an ECC as it minimises travel costs. In contrast, community-led facilities are more likely to accommodate parents who have time to engage with the facility and may not travel into work. For parents remaining at home during the day, the most convenient facility will likely be near the home. In addition to convenience in terms of minimising travel costs, being physically close provides security to parents, for example, quick access during unpredictable emergencies (e.g., earthquake), if a child becomes ill, or simply for visits during the day.

Identifying ideal locations for ECC facilities based on minimising travel costs for parents has previously been examined using a location-allocation model in the city of Edmonton, Canada (Hodgson, 1981). The model minimised parents' travel costs for three different journey types; the 'home to daycare to work journey', the 'work to daycare journey', and 'home to daycare journey', and found different patterns for ideal day-care centres for the journey types. When the location-allocation model was configured to minimise travel costs on the 'work to daycare' journey or to minimise travel costs on the 'home to daycare to work' journey, ideal locations of day-care centres concentrated in central areas. While for trips from the 'home to day care', ideal locations were dispersed across the city, (Hodgson, 1981). If ECCs in Wellington are distributed in a way that minimises travel costs for parents, then locating facilities in central locations and around busy roads could provide the most convenience for working parents, however, result in higher noise levels for children. While, for parents remaining at home, ECCs dispersed throughout the suburbs may provide the most convenient locations for parents and result in lower noise levels for children.

\section{Page 125 of 182}


The finding that road traffic noise levels are higher in privately owned facilities compared to community led facilities adds to recent concerns about the quality of ECC environments. The 2020 Child Forum survey (Alexander, 2020) of 4000 ECC teachers found $26 \%$ of respondents did not endorse the quality of the centre they worked at. Concerns around the quality of service are long standing with the quality endorsement rate remaining unchanged since 2014.

Environmental issues were raised by survey respondents, including, concerns about the lack of space, greenspace, and excessive noise levels. Respondents also had concerns about centres cutting corners and putting profits ahead of children. No breakdown of community versus privately owned facilities was provided in the survey.

\section{Ethnicity}

Our study found that for schools, Pacific students had higher noise levels ( $52.6 \mathrm{~dB}$ ) compared to European/Pākehā students $(51.7 \mathrm{~dB})$. There was no significant difference in noise levels for Māori students compared to European/Other students. Students of Asian ethnicity had the lowest noise levels (51.0dB) and were significantly lower than European/Pākehā students. For ECCs, Māori had the highest mean noise levels (56.0dB), statistically significantly higher than European/Pākehā students (54.6dB). No other ethnic group had noise levels significantly higher or lower than European/Pākehā children.

Throughout both education levels, there appears to be an inconsistent pattern between noise levels and ethnicity between schools and ECCs. Both Māori and Pacific children experience higher noise levels, however this is limited to either at ECCs (Māori children), or school (Pacific

\section{Page 126 of 182}


students), and while the differences are statistically significant, they are also relatively small in magnitude especially compared to other differences in this study.

Disparities in health outcomes between different ethnicities, particularly for Māori, are important in a New Zealand setting. The New Zealand government has a duty under the Treaty of Waitangi to ensure the protection of Māori, and in a health setting this means ensuring Māori have equal levels of health compared to non-Māori (Ministry of Health, 2014). Unfortunately, equal levels of health are often not met, and it is common for both Māori and Pacific to have poorer than average health outcomes (Walsh \& Grey, 2019). This has resulted in life expectancies of up to 7.7 years lower for both Māori and Pacific people compared to nonMāori/non-Pacific people (Walsh \& Grey, 2019). The most significant of these are in health statistics, such as premature death caused by avoidable cancers, coronary disease, and diabetes in Māori and Pacific people (Walsh \& Grey, 2019). Both diabetes and cardiovascular health are associated with exposure to high noise levels (World Health Organization, 2018). Disparities also exist in the broader transport environment, with land transport injuries decreasing life expectancies for Māori and Pacific by more years compared to non-Māori/non-Pacific (Walsh \& Grey, 2019).

While the over representation of Māori and Pacific people in health statistics is often common, it is not always true across all aspects. A few examples exist where Māori or Pacific people have about the same or better health outcomes compared to non-Māori/non-Pacific. While genetic factors can explain some of these cases, such as the lower rates of skin cancer in Māori, and Pacific people (Sneyd \& Cox, 2009), there are also cases where cultural values can play a

\section{Page 127 of 182}


protective role. Finding these areas where Māori achieve equal or better outcomes is as important as finding disparities since it can help identify and preserve the sorts of structures that are required to achieve at least the same levels of health for Māori compared to non-Māori. Previous research has found that Māori are possibly more resilient to natural hazards due to the social networks across whanau, hapū and iwi, cultural values, physical structures (such as Marae) and leadership structures (Mason, 2019).

Te Kohanga Reo are a type of ECC institute unique to Māori which supports full expression of Māori language, customs and values (kohangareo.ac.nz, n.d.). We found that for ECCs, Māori children had the highest noise levels, however we also found that there was also no difference in noise levels between Te Kohanga Reo facilities and other facility types, such as playcentres and kindergartens. This suggests that Māori in Te Kohanga Reo may have lower noise levels compared to Māori children outside Te Kohange Reo. An explanation for this is that Te Kohanga Reo empower Māori in decision making, allowing them to practise core values, such as kaitiakitanga (a sense of responsibility for the people in the area), which improve the environment and the health outcomes of their people. Nonetheless, having less resources can result in less flexibility, making it difficult to deal with issues relating to adverse environmental conditions (Mason, 2019).

As discussed in the limitations section, it must be noted that because the study area was limited to the Wellington Territorial Authority, the sample size of Kohanga Reo was small (6 facilities), which resulted in a large confidence interval. However, in future, expanding the research area beyond the Wellington Territorial Authority would increase the number of Kohanga Reo in the

\section{Page 128 of 182}


study. A larger sample size would provide more evidence to determine whether there are differences in noise levels between facility types. Increasing spatial coverage of data, such as road traffic and building (Land Information New Zealand, 2019), will allow for this analysis at a national scale.

\section{International versus domestic students}

This study found that international students had significantly higher modelled noise levels at schools compared to domestic students. The average noise level for international students was $54.2 \mathrm{~dB}$, compared with a mean noise level of $51.7 \mathrm{~dB}$ for domestic students. One explanation for the division between international and domestic students is that international students or parents of international students may be more likely to select schools in central areas, which incidentally, tend to have the most elevated noise levels.

The selection of centrally located schools by international students or students' parents finds agreement with more general concepts around immigration patterns, whereby recent immigrants tend to form geographically concentrated patterns, particularly in urban areas (Damm, 2009; Maré, Morten, \& Stillman, 2007). Economic factors, such as job opportunities initially play a significant role in the nucleation of the clustering of immigrants in central areas (Hugo, 1995), but further clustering in particular areas may later also become self-perpetuating as immigrants tend to select regions where there is a high proportion of people of the same ethnicity (Hugo, 1995; Maré et al., 2007), and this is particularly true for uneducated migrants. Less educated individuals and individuals with poor English language skills may lack access to

\section{Page 129 of 182}


information and networks to learn about alternative locations in a city (Smart, Grimes, \& Townsend, 2018). In New Zealand specifically, about $78 \%$ of recent migrants initially select New Zealand's three largest urban areas (Auckland, Wellington and Christchurch) as places to settle (Maré et al., 2007). Observing the Wellington Territorial Authority in greater detail, data from the 2018 census show the highest proportion of recent immigrants (0-1 years) were in central city area units, where up to $15.6 \%$ of the resident population were recent immigrants to New Zealand within the past year (Figure 22). 


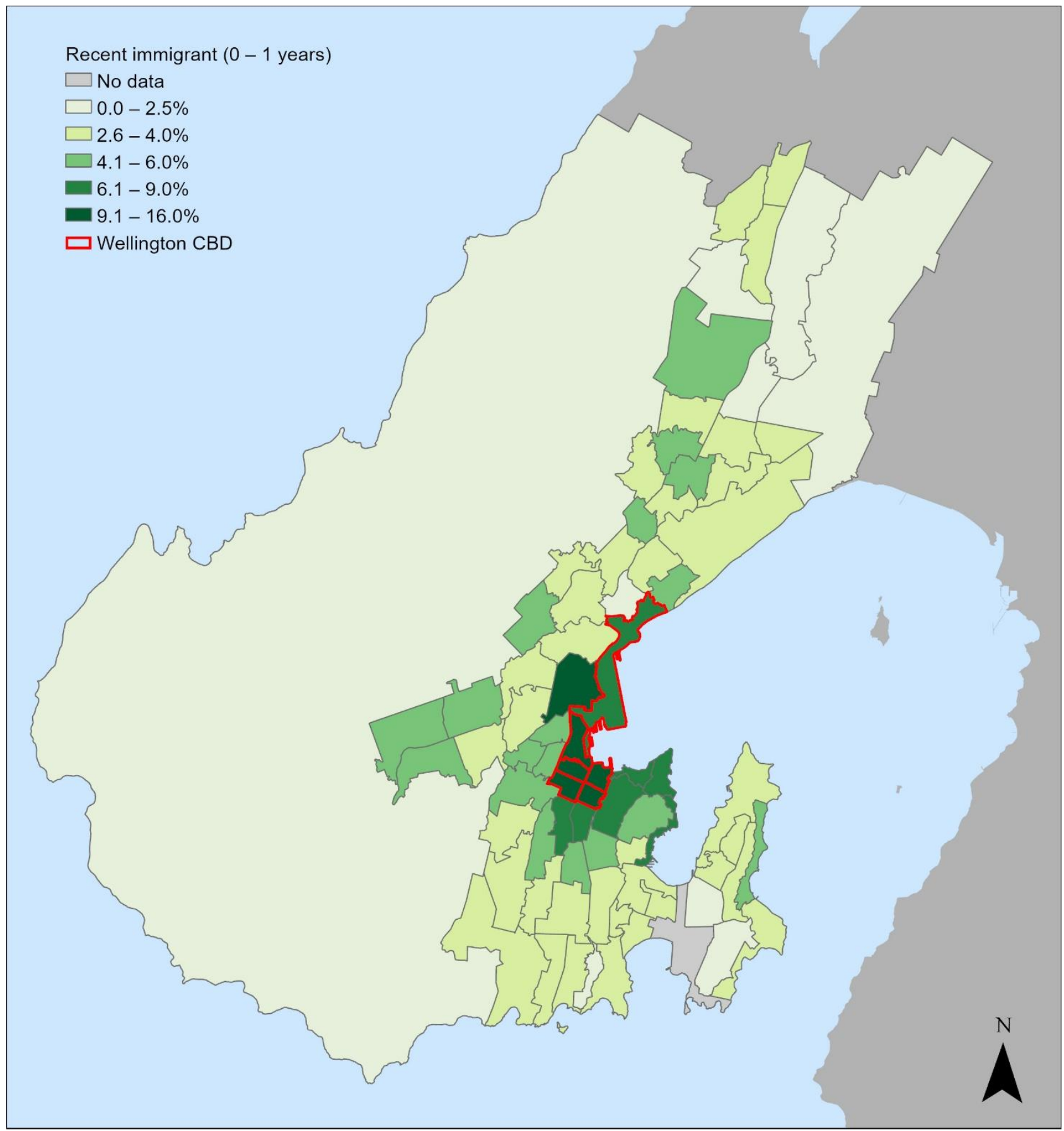

Figure 22: Location of recent ( 0 - 1 years since arrival) migrant population and Central Business District (CBD), Wellington Territorial Authority, 2018

Data source: Statistics New Zealand (2018) 
For international students, their parents/caregivers might not have access to the sorts of networks required to gain the knowledge of the lay of an unfamiliar city, speak English, or not necessarily be well educated, measures which are needed to make informed decisions about school selection based on environment. They may, instead, be making decisions from abroad without having visited the selected city. If they have migrant contacts in their selected city, these contacts may be more likely to recommend the central areas with which they are more familiar. Since central locations in Wellington tend to have higher noise levels, it may explain why international students have on average higher noise levels compared to domestic students.

The finding that international students are exposed to, on average higher traffic noise levels compared to domestic students, is particularly important given there is also evidence to suggest that international students are more sensitive to elevated noise levels compared to their domestic peers. The majority of international students in New Zealand are drawn from countries where English is not the main spoken language (Ministry of Education, 2013). A high proportion of English as a second language (L2) students exposed to high levels of noise is of concern as L2 students are more affected by elevated noise levels in the classroom compared to English-onlyspeaking (EO) students. Differentiation between words with similar pronunciation (e.g. lake v. rake, ten $\mathrm{v}$. tan) decreases for both EO and L2 students at elevated classroom noise levels, however L2 students have a much more marked decrease in word differentiation at higher noise levels compared to EO students (Nelson et al., 2005). If L2 international students struggle to understand speech in the classroom, they are likely to struggle to understand concepts taught verbally in the curriculum, resulting in poorer educational outcomes.

\section{Page 132 of 182}


Providing more information to parents about school environments may help international students and their parents/caregivers make better informed decisions about the school they select. Better informed decisions about school choice may, in turn, reduce the disparity in noise exposure between domestic and international students. However, providing this information lends itself to ranking schools based on noise, which could have unintended consequences. By publicising that one school has a better environment to another to international students, a preference is made for one school over another for all students and parents/caregivers. Ranking in New Zealand's school decile system has resulted in 'white-flight' from low decile schools to high decile schools. Between 1996-2013, low decile schools (most deprived) saw a reduction in the number of European students and an increase in the number of Māori and Pacific students, simultaneously, high decile schools (least deprived) saw an increase in European students (Vester, 2018). So, while informing international students of potential environmental issues with schools may reduce the disparity in noise levels between domestic and international students, it may drive disparities between factors such as ethnicity and deprivation as seen with the decile system.

There are alternative solutions to reduce the disparity between international and domestic students such as taking steps to reduce noise levels at all schools. This addresses the issue without having unintended consequences on particular groups of students/children. By reducing noise levels at all schools to acceptable levels, there will be no preferential choice and it eliminates the need for international students and parent/caregivers to have local knowledge.

\section{Page 133 of 182}


There are several actions that can be taken to reduce overall noise near schools. These are discussed further in section 5.5 .

Roll size

This study found that for secondary schools, noise levels tend to increase with roll size. However, for primary schools there was no relationship between roll size and noise levels. Secondary schools tend to have larger rolls than primary schools and are, therefore, a significant destination for travel within their neighbourhood. Staff, parents driving children to school (i.e., 'the school run'), children driving themselves to school, as well as other secondary service workers required to support staff and students (canteen staff, ground staff, cleaners), all have the school as their daily commuting destination. In the Wellington Territorial Authority, there are approximately 2,299 teachers employed by schools (Education Counts, 2020), a further 29,639 students (Education Counts, n.d.), and an unknown number of additional support staff. Teaching staff, support staff, and students represent over $15 \%$ of the population in the Wellington Territorial Authority. It stands to reason that the larger the school roll, the more teachers, students, and support staff we can expect to travel to it, generating more traffic and therefore, more noise near the school. The travel mode to school is an important variable. Some forms of transport generate less noise than others; active transport, such as walking or cycling, generates insignificant noise pollution compared to vehicular transport, while vehicles used for public transport (e.g., buses) produce more noise individually, but can greatly reduce the volume of vehicles on the road. In New Zealand, the breakdown for trips to school is $67 \%$ vehicular (private vehicle or public transport) compared to 32\% active transport (walking, cycling) (Lindberg, 2019).

\section{Page 134 of 182}


However, children's travel mode to school has not remained constant over time. In the last 50 years, students have shifted away from active forms of transport and towards vehicular transport (as a passenger). This pattern is true for many developed countries, including the United States (McDonald, 2005), Australia and the United Kingdom (Marten \& Olds, 2004), and New Zealand (Lindberg, 2019). The shift will have contributed to an increase in traffic near schools, and a subsequent increase in noise levels. Further, schools near busy roads also become less desirable for students to walk to (Giles-Corti et al., 2011). Hence, if more students travel to school by car, walking becomes less desirable for the remaining walking students which further encourages more vehicular transport.

A pattern of increasing noise level with increasing school roll was not present in primary schools in this study. School rolls in primary schools are typically much smaller, so traffic around primary schools is more likely to be influenced by people travelling to other destinations, rather than the school itself.

We also note that traffic associated with the school run occurs mostly before and after school (Kingham et al., 2011). If elevated noise is present before and after learning, it's effect on learning is unknown, as studies have focussed on noise levels in the classroom during lessons (Shield \& Dockrell, 2008). Nonetheless, traffic noise can induce a stress response (Riedel et al., 2018) which may indirectly affect concentration, learning, and academic outcomes.

The effect of noise pollution is rarely considered in studies focusing on the effects of active transport to schools on health. The main considerations for active transport are the health

\section{Page 135 of 182}


benefits of reduced obesity, cardiovascular disease, and physical injury through motor vehicle traffic crashes (Kingham et al., 2011). However, the results of this study show that associated reduction of noise of increased active transport to schools should be another factor in future research.

\section{Deprivation: Equity index and school deciles}

We found no relationship between school decile and noise, while data for ECCs was insufficient to examine the relationship between noise and equity index. Overall, the analysis of noise levels by deprivation level were restricted by a low number of high deprivation schools and ECCs in the Wellington Territorial Authority. This resulted in small sample sizes of low decile schools and especially ECCs. The greater Wellington metropolitan area consists of Wellington City and two surrounding territorial authorities: Hutt City and Porirua City, the latter two having higher proportions of deprived schools and ECCs. Expanding the study beyond the case study area, and into the neighbouring territorial authorities or across the whole of New Zealand, would increase the sample size of lower deprivation schools and ECCs, enabling a much better understanding of the relationship between noise and deprivation. Coverage of spatial data, such as traffic counts and building outline data, is likely to expand in future to meet the sample sizes needed.

In general, both in New Zealand and overseas, higher levels of deprivation are associated with poorer health outcomes. Some poor health outcomes in high deprivation populations may be linked to lifestyle rather than environment e.g. smoking or obesity (Adams et al., 2009). However, deprivation and health can be linked through environment as well. More deprived

\section{Page 136 of 182}


populations are often located in lower quality environments, for example, areas of higher air pollution (Walker, Mitchell, Fairburn, \& Smith, 2005) or flood risk (Walker \& Burningham, 2011), which lead to poorer health outcomes. When moving residence, more deprived populations are more likely to move for negative reasons (negative move), while less deprived people are likely to move to positive reasons (positive move) (Crowley, 2003). Since areas with poor environments are likely to be less-desirable places to live, those with enough means may move away (i.e., positive move) to a more desirable area. Whereas deprived people living in a poor environment are less likely to have the same means to move away. In addition, more deprived people may move into a lower quality environment in order to save money (i.e., negative move).

Despite established relationships between measures of environmental quality, such as air pollution and flood risk, only weak evidence exists of a relationship between deprivation and noise levels (Brainard, Jones, Bateman, \& Lovett, 2004). It has been hypothesised that the benefits of living close to transport may outweigh the disadvantages of elevated noise levels (Brainard et al., 2004). For the Wellington Territorial Authority, this study identified a central pattern where the highest noise levels are in areas located centrally. Therefore, a desire to live/attend school centrally might lead people to compromise on living in areas with poor environmental noise quality. If this is true, it is quite likely that there is no association between noise level and deprivation. Expanding the research beyond the case study areas will allow this hypothesis to be investigated further.

\section{Page 137 of 182}




\section{Academic performance}

This study found academic performance decreases as noise levels increase. For every 10dB increase in noise level, university entrance rates decreased by 4.4 percentage points. In New Zealand, we believe no research exists on the relationship between classroom noise levels and academic performance. However, this result is consistent with research abroad looking at the relationship between academic performance (UK: standard attainment tests, 'SAT', scores) and noise levels, as well as concepts into how noise levels affect learning processes (Shield \& Dockrell, 2008). Elevated noise levels negatively affect, memory, reading, motivation, and attention (Shield \& Dockrell, 2008), which drives academic performance downwards. On the surface, the evidence of this theory appears to be weaker in this study, compared to other studies (Shield \& Dockrell, 2008). However, this may be expected since this study only explains the effect of traffic generated noise on academic results. Studies, such as Shield and Dockrell (2008), compared all measured internal and external noise sources, e.g. traffic, babble, air conditioning systems. The aggregate effect of all noise sources would likely have a stronger relationship with academic performance. Modelling for the effect of traffic-related noise also does not occur in isolation of human behaviour. If the ambient noise level in the classroom is raised, for example by traffic generated noise, then children often raise their voices to outcompete the ambient noise (Garnier \& Henrich, 2014), further increasing noise levels inside the classroom.

The result that for every $10 \mathrm{~dB}$ increase in noise level, university entrance rates decreased by 4.4 percentage points, requires further investigation. Many other factors are also known to affect

\section{Page 138 of 182}


academic performance, including parental educational attainment, socioeconomic status, ethnicity, and housing types (Considine \& Zappalà, 2002). It is likely that such factors could confound the relationship between academic performance and noise levels found in this study.

In addition, peak noise levels caused by interrupting noises, such as sirens and horns, also have negative effects on academic performance. For older children, these interrupting noises appear to have the greatest impact on academic achievement (Shield \& Dockrell, 2008), more so than background ambient noises modelled in this study. While interrupting noises are more likely to occur on busy roads, this might not always be the case. Sirens might be concentrated around ambulance depots and fire stations, and horns around intersections. As far as we know, no methodology has been developed to examine interrupting noises produced from roads, nor assess the effects on children's ability to learn.

In this study, we did not examine the academic performance of younger children at primary schools or ECCs since academic performance is not tested for very young children, nor are standardised tests for primary school children in New Zealand used. However, based on research abroad, we can postulate that the effects of noise on learning observed for high school students may extend to younger ages. In studies abroad, noise levels affected the academic performance of primary school aged children. There are several reasons we might expect the burden of traffic noise to be greater on younger children's academic performance compared to high school students in Wellington. In the Wellington Territorial Authority, we found ECCs had a higher mean noise level compared to schools, hence they are more likely to be exposed to higher noise levels. In addition, younger children also tend to be more affected by ambient levels of background

\section{Page 139 of 182}


external noise (e.g. traffic noise) compared to older children who are more affected by maximum noise levels (i.e. sirens, horns) (Shield \& Dockrell, 2008). 


\subsection{Noise levels by land use and proximity to roads}

In this section, we discuss the relationship between noise levels and distance to land use and

busy roads. Examining the role land use plays in noise levels and assessing the suitability of using distance to roads and major roads as indicators of noise levels.

Noise levels by land use

This study found that for the Wellington Territorial Authority, noise varied by land use for buildings. The highest noise levels were in the City centre $(61.5 \mathrm{~dB})$ and the Industrial area (56.9 $\mathrm{dB}$ ). The lowest noise levels were in the airport (note: excludes aircraft noise), conservation, and rural areas. The variation in noise levels across the Wellington Territorial Authority is expected and follows noise patterns in other cities (Alías \& Socoró, 2017; Paz \& Zannin, 2008). Though, for schools, there was no difference in noise levels when examined by their land use zone. Most schools were in Outer residential areas (69.2\%), leaving relatively few schools in other land use zones. The relatively small number of schools in these other land use zones led to results with relatively large confidence intervals, hence noise levels between schools in different land use categories were not statistically significantly different.

However, there are also a few reasons why we may expect to see no or low variation in noise levels between schools within different land uses. Schools are often placed early in the development of cities and occupy larger tracts of land, often with open green space and larger distances from streets, allowing road noise to dissipate. The larger tracts of open land contrasts to the remainder of the central city which becomes intensified over time, reducing distance

\section{Page 141 of 182}


between roads and building façades, resulting in higher noise levels. Examples of schools in the central city include St Mary's, and Sacred Heart Cathedral School in the City centre. Both schools were founded early in the settlement of Wellington, in 1850 (Sacred Heart Cathedral School, n.d.; St Mary's College, n.d.). Relative to the surrounding central city, both schools are less intensively developed, lending to larger distances between streets and school buildings.

In contrast to schools, noise levels at ECCs were statistically significantly higher in the City centre $60.7 \mathrm{~dB}(57-64.4 \mathrm{~dB})$ when compared to the Outer residential areas $50.0 \mathrm{~dB}(49.5-54.0 \mathrm{~dB})$. ECCs are more recent features in New Zealand cities. The rise of ECCs was tied to gradual societal changes as women's roles went from domestic duties to the workforce (Mutch, 2004). The first kindergarten in New Zealand opened in 1889, creches joined in 1903, play centres in 1941, and Kohanga Reo in the 1980s (Mutch, 2004). ECCs are therefore more likely to have become components of cities later in the urban intensification compared to schools. In addition, because of their smaller roll size, ECCs can fit into smaller premises within an already intensified city. We examined the mean distance between road centrelines and buildings for schools and ECCs in the City centre to find evidence of whether schools were set back further from road centrelines compared to ECCs. We found schools had a mean distance of $18.3 \mathrm{~m}$, compared to $11.8 \mathrm{~m}$ for ECCs. Though we note this difference was not statistically significant due to the relatively few schools (4) in the City centre.

For ECCs, the greatest proportion were in Outer residential areas (48.9\%), and in contrast to schools, a greater proportion of ECCs occupied other land use zones, particularly the City centre (18.2\%). Also, of note, 5.8\% of ECCs were in Industrial areas while no schools were in Industrial

\section{Page 142 of 182}


areas. Central city and Industrial land use areas reported the highest road traffic noises in this study, but these land use zones are likely to also experience greater noise from other sources, e.g., horns, sirens, music (Alías \& Socoró, 2017), factories, hammers, and drills (Gupta et al., 2018). This result may also suggest that locating ECCs in inappropriate areas is more of an issue compared to schools.

Indicator measures for noise levels: distance to major roads

Indicators can measure and monitor environmental health problems which are otherwise difficult to quantify (Briggs, 2003). Indicators are commonly used in quantifying exposure to the health effects of the road environment, with the WHO suggesting proximity to 'heavily trafficked' roads as an indicator of respiratory health and physical injury (Briggs, 2003) and researchers have used proximity to major roads to assess exposure to noise and air pollution for schools and ECCs (Amram et al., 2011; Appatova et al., 2008; Chakraborty \& Zandbergen, 2007; Green et al., 2004; Wu \& Batterman, 2006). Quantifying noise can be considered difficult; in this study, modelling noise required an assortment of rich road traffic flow data (e.g., speed, vehicle count, slope, vehicle class), information about the built environment (e.g., digitized building footprints), and computing power to run the calculation. Whereas, proximity to roads only requires a relatively simple road to buildings distance calculation, readily available in GIS software, such as ArcGIS: Nearest tool (ESRI, 2020) or QGIS: NNJoin (QGIS.org, 2021). If distance to road could be used as an indicator of noise it would provide a simpler 'indicator' alternative to modelling noise levels. This would be advantageous where rich road data (i.e., traffic flow, speed, slope etc.) are not available. At the time of this study, for example, road traffic flow data for New Zealand did

\section{Page 143 of 182}


not have complete coverage, which would limit extending the study area. In developing countries, costs associated with collecting rich road data required to model traffic noise, are likely to be prohibitively high, if such data does not already exist. However, building-road distance calculations are more likely to be possible, especially with humanitarian mapping effort such as OpenStreetMap, pushing for building and road outline data to become increasingly available in the developing world (Herfort, Lautenbach, de Albuquerque, Anderson, \& Zipf, 2021).

To assess the suitability of using road-building distances as an indicator for noise levels, we examined the difference between distance from buildings to major roads (main arterial routes, regional and national roads) and the distance from buildings to roads of any hierarchy. We then compared this with the modelled noise levels with this study to examine the relationship. We found that distance to major roads explained only about $2 \%$ of the modelled road noise level, while distance from buildings to roads of any hierarchy explained a much greater proportion of modelled noise, about $27 \%$. So, while distance to major roads appears to be a poor indicator of road noise, distance to any road is a much more reasonable indicator.

However, modelling road traffic noise still has advantages, and distance to roads should not be used in place of modelled noise levels if data is available to model noise levels. While a significant proportion (27\%) of the modelled data is explained by distance to roads, $73 \%$ is explained by other variables included in the model (speed, traffic count, etc). Modelled noise levels also provide an output in a decibel scale which can be directly compared to health guidelines, and health outcomes. Measures such as distance to roads of any hierarchy are still

\section{Page 144 of 182}


relatively crude and cannot be compared to health guidelines nor health outcomes. However, they may be of reasonable use where it is not possible to model noise levels.

\subsection{Limitations}

In this section we discuss the study limitations including those arising from the model design, and case study area.

\section{Model limitations}

\section{Temporal changes in noise levels}

This study was limited to modelling a 24-hour equivalent continuous noise level (Leq24h). This limitation originated from traffic count data, which is collected as a 24-hour average traffic count. The model output could therefore not isolate variation in noise over time scales such as hours, weekdays, or months. The ability to isolate variation over different time scales is useful since children are only at school between certain hours of the day (8am-4pm), days of the week (Mon-Fri) and months of the year (school terms). We also know that traffic volumes change markedly across these time scales. Peaks in traffic volumes tend to match times where children would be at schools and ECCs. Waka Kotahi (the New Zealand Transport Agency) collects temporal traffic flow data for selected main highways in New Zealand. In Wellington, this data includes Ngauranga (State Highway 1) northbound and southbound lanes. Table 21 compares traffic volumes for 'school periods' with 'outside school periods', across different time scales. It shows increases in traffic volumes coinciding periods of times when children and students are at school across time scales from hourly $(+88 \%)$, weekday $(+16 \%)$ and monthly $(+11 \%)$.

\section{Page 145 of 182}


Table 21: Traffic volumes for school periods compared to outside school period, State Highway 1 (north and south bound lanes), Ngauranga, Wellington, 2018

$\begin{array}{llll} & \text { School period* } & \text { Outside school } & \text { Difference, school period- outside school } \\ \text { Time scale } & \text { volume } & \text { period** volume } & \text { period. Volume (percent) }\end{array}$

Hour (Vehicles per

hour)

3,023

1606

+1417 (+88\%)

Week (Vehicles per

day)

50,183

43,269

$+69,14(+16 \%)$

Month (Vehicles per

day)

48,711

43,890

$+4,821(+11 \%)$

Source: (NZTA, 2018)

Note:

*School period definition:

- Hour: 8am-4pm

- Week: Mon-Fri

- Month: Feb-Dec
** Outside school period definition:

- Hour: Before 8am, after 4pm

- Week: Sat- Sun

- Month: Jan, NZ holidays

\section{Page 146 of 182}


We know that higher traffic volumes when children are scheduled to be at school will correspond to higher noise levels than the model predicts using a 24-hour equivalent. The magnitude of the underprediction depends on the variation of traffic volume across that period, which is unknown.

Other research can be used as a gauge of the magnitude of some of these differences. For example, a study in Messina, Italy measured noise levels and traffic volumes during the day and night for 6 sites. On average, the noise levels were $10 \mathrm{~dB}$ higher during the day compared to night (Piccolo, Plutino, \& Cannistraro, 2005). In New York, Ross et al. (2011) measured and analysed noise levels at both the hourly and weekday temporal scales. For the weekday period (Tuesday-Friday), noise levels were $2.9 \mathrm{~dB}$ higher compared to the weekend period (Saturday and Sunday). The weekday rush period was 3dB higher compared to the weekday non rush period.

Although these studies give an indication of the scale expected between different time periods, the results are highly site-specific, and not suited for extrapolation to this study. Further research is required to determine the impact more generally and assess relevance for studies such as ours.

\section{Speed}

We used the posted speed limit to approximate the speed travelled by vehicles on roads. The actual average speed travelled on the road segment can be lower or higher than the posted speed limit, especially in heavy traffic, and on roads which are windy. Using the posted speed

\section{Page 147 of 182}


limit will have led to in an over prediction in noise level, where actual vehicle speeds are lower than the posted speed limit and an under prediction where actual vehicles speeds are faster than the posted speed limit. This particularly affects the rolling noise component.

\section{Existing noise barriers in the environment}

In this study, we only modelled the effect of buildings as noise barriers and assumed tunnels produced no surface noise. In urban areas, buildings are likely the most common sound barrier. However, other sound barriers, including fences, hedges, and engineered barriers, designed specifically to block traffic noise also exist. If more data becomes available for different noise barriers in the environment, these could be added to better represent the real world and improve the accuracy of the results.

\section{Limitations of volunteered geographic information for model validation}

We identified a spatial bias of volunteered noise levels, whereby measured values were skewed toward high noise level areas. Measured noise levels were gathered by means of volunteer geographic information (VGI). VGI has become an increasingly prominent source of geographic data, enabling researchers to benefit from access to geospatial big data, community knowledge (Flanagin \& Metzger, 2008), and is often low cost and can continually be updated (Zhang \& Zhu, 2019). For this study, VGI data provided a large sample of spatial noise data which would otherwise be unobtainable. However, previous studies have identified several issues with VGI relating to the credibility of the gathered data (Flanagin \& Metzger, 2008; Quattrone, Capra, \&

\section{Page 148 of 182}


De Meo, 2015; Sullivan et al., 2009), including the lack of specialised knowledge and opportunistic collection methods.

A lack of specialised knowledge about the data collected may mean volunteers have poor data collection technique resulting in inaccurate data. This phenomena was observed by Sullivan et al. (2009) for bird sighting VGI, whereby some bird watchers were unable to differentiate some bird species. For spatial noise data, a lack of knowledge about acoustics may lead volunteers to operate the NoisePlanet app incorrectly. There is the potential to inaccurately gather noise readings from inside vehicles, buildings or outside but with mobile devices located in pockets. While anyone can contribute VGI, those who volunteer large amounts of information are more likely to be experts in the field, educated, and with high income (Basiri, Haklay, Foody, \& Mooney, 2019). The large amount of data volunteered by experts might mitigate poor data collection technique for a substantial proportion of the data.

The opportunistic nature of collection often leads to spatial biases in sampling. Sullivan et al. (2009) reported this credibility issue, where bird sightings were concentrated around populated areas, and fewer sightings were reported in areas where human populations were low. Volunteers may also seek to measure phenomena they are interested in or volunteer data to fulfil their specific agendas. OpenStreetMap contains a significant amount of this interest-bias, whereby users contribute to points nearby and of their own interest. Volunteered data is often produced by a small number of "power volunteers", following the $80: 20$ rule, where $80 \%$ of the data is collected by just $20 \%$ of the volunteer population (Quattrone et al., 2015).

\section{Page 149 of 182}


For noise data, spatial bias is likely to lead to users to collect nose data in high noise level areas. High density areas are places where more people are located, which may lead to volunteers measuring these areas, which also have the highest noise levels. For example, volunteers are more likely to walk along main roads with high noise levels, compared to private alleyways, where noise is likely to be lower. Volunteers' interest in noise levels is likely to vary, both spatially and temporally. When volunteers are bothered by a particularly noisy area, they might be more likely to have a greater interest measuring these peak noise levels. Noise levels are typically lower at night compared to during the day, while volunteers' interest in collecting noise data overnight is likely to be low compared to daytime.

Volunteered noise data collect noises from all sources which limits the validity of the comparison.

Not acknowledging spatial bias has serious scientific and possibly political consequences (Flanagin \& Metzger, 2008). Hence, we have recognised the bias and made modifications to the analysis; restricting linear models to pass through the origin and noted that while the model performs reasonably well at high noise levels (i.e., $81 \%$ of modelled data was within $15 \mathrm{~dB}$ of volunteered data) we cannot draw conclusions about the model performance at low noise levels. We also note that the impacts of spatial bias are restricted to the model validation with volunteered data. Modelled noise levels methods used in the remainder of the study are not affected by spatial bias.

\section{Page 150 of 182}




\section{Limitations of the case study areas}

Wellington has the lowest vehicle ownership per capita compared to other regions of New Zealand; 65 light vehicles per 100 people, compared to 77 light vehicles per 100 across New Zealand (Ministry of Transport, 2018). As traffic volumes contribute to higher noise levels, we would expect New Zealand's reliance on motor vehicles to raise the noise generated by road traffic more so compared to other countries. In Wellington, noise levels might be slightly subdued compared to the remainder of the country due to a lower vehicle ownership rates, though rates have continued to rise in recent years (Ministry of Transport, 2018), Figure 23, meaning traffic generated noise could still be rising.

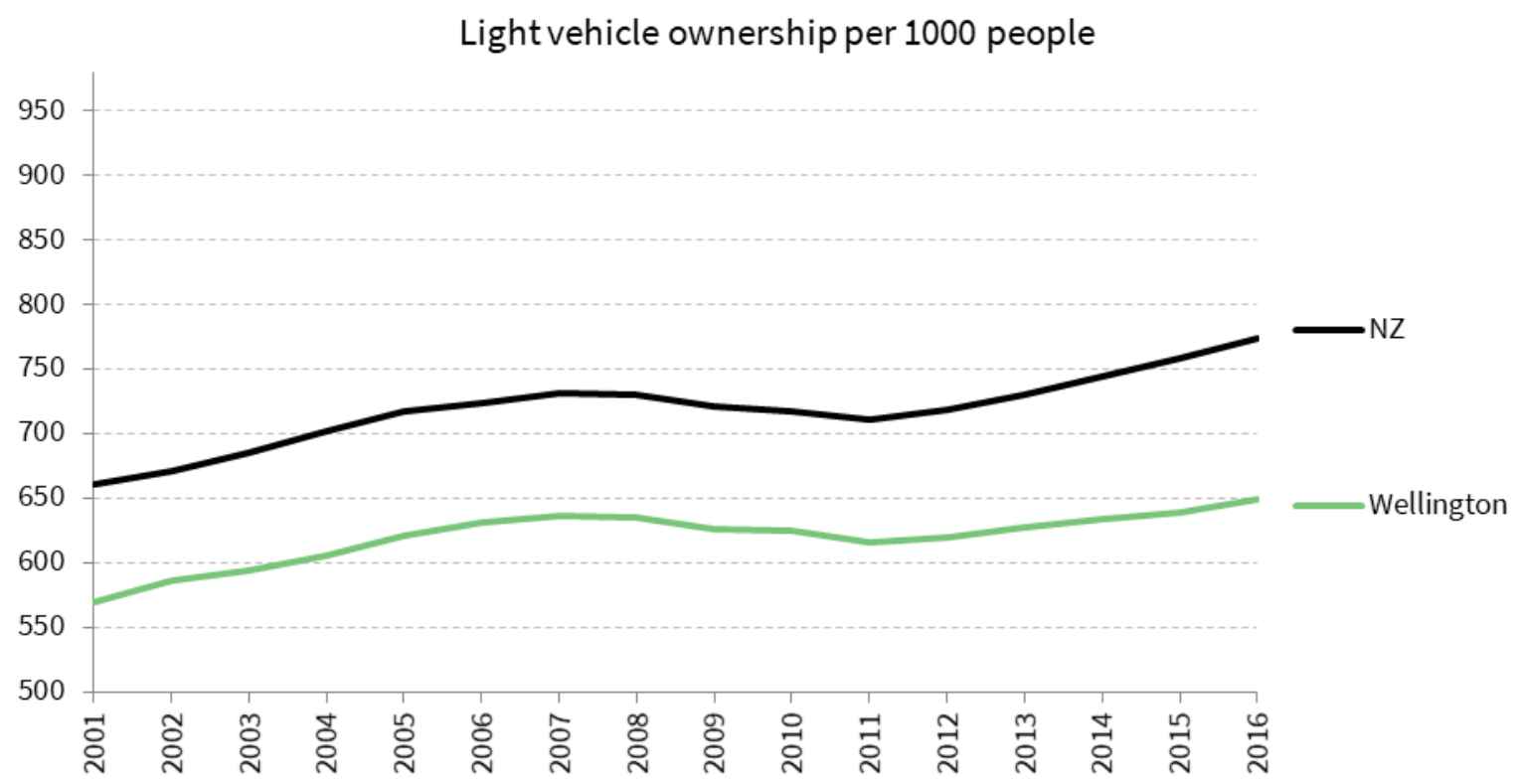

Figure 23: Light vehicle ownership per 1000 people, in Wellington and New Zealand, 2018

Densely populated areas are likely to have less distance between roads and building façades and to have high concentration of traffic. Wellington City is a relatively densely populated area, it is

\section{Page 151 of 182}


comparable only to Auckland in New Zealand. The remainder of New Zealand comprises of less dense cities, towns, and rural areas. These areas are likely to have less traffic and more space between roads and building facades, resulting in lower noise levels, however rural areas experience higher traffic speeds which increases noise levels. Further research into noise levels at schools and ECCs in rural areas and smaller towns is needed to assess differences between urban schools and ECCs.

Concerning demographics, the Wellington Territorial Authority is somewhat atypical compared to other territorial authorities in New Zealand. The Wellington metropolitan area is distributed across four territorial authorities (Wellington City, Porirua City, Hutt City and Upper Hutt City) which form an almost contiguous metropolitan area centred upon Wellington City. The outer areas of Porirua, Hutt City and Upper Hutt City contain most of the deprived populations of the Wellington metropolitan area, while Wellington City is relatively less deprived. By comparison, the Auckland and Christchurch urban areas are each almost entirely contained within a single territorial authority, and therefore contain a fuller mix of deprivation deciles. By only examining the Wellington Territorial Authority in isolation, it is possible this study overlooks some typical patterns of noise of larger metropolitan areas. The lack of mixed deprivation also hindered analysis between deprivation deciles and noise, as there were few low decile schools and low equity index ECCs to establish the relationship between.

Wellington's topography is hilly compared to other cities, such as Auckland and especially Christchurch. Road gradient affects engine thrust, increasing propulsion noise in areas with steep gradients. Hills also act as natural barriers, blocking noise in some situations. When validating the

\section{Page 152 of 182}


model against measured noise levels, we found an example of this where State Highway 1 enters Mount Victoria Tunnel from the west. Measured noise values for buildings in this area were lower than modelled noise values due to noise being blocked by concrete walls flanking the road on each side. These barriers were not factored into the model. While these effects may not be so apparent elsewhere in New Zealand, it is noteworthy that steep terrain can restrict model performance. In future, including terrain barriers could improve the model performance.

Despite limitations on the model and case study area, the study was able to assess noise levels at schools against guideline values and by socio-demographic variables. The methodology offers an improvement on assessing noise levels using proximity indicators and limitations discovered in the case study area offer areas to improve study designs in future. 


\subsection{Improving noise levels}

This study has highlighted that exposure to elevated noise levels in Wellington schools and ECCs is a widespread issue, with a considerable proportion of schools and ECCs experiencing noise levels which are potentially detrimental to health. There are, however, measures which can be taken to reduce noise levels and ameliorate the current situation. In this section we discuss modifications to the environment, vehicles, and human behaviour which can reduce noise levels at existing facilities, and spatial planning and site selection, which can help avoid high noise levels when planning sites for new facilities.

\section{Noise barriers}

Noise barriers, acoustic insulation, and altering the composition of road surfaces are examples of how modifying the environment surrounding schools and ECCs could mitigate exposure to harmful levels of noise. Noise barriers block or reflect noise propagation paths away from sensitive facilities. To be effective, barriers need to be designed to account for how noise will be reflected, diffracted, and transmitted through the barrier (Kotzen \& English, 2014). Thought needs to be taken into material, angle, and leakage though gaps. As a result, barriers often need to be tall and extend past the features they are protecting as diffraction occurs over the top edge and ends of the barrier. Noise barriers are therefore often a visually intrusive solution and difficult to implement in built up areas where space is valuable. Though passive designs, such as earth mounds and disguising barriers with climbing vegetation, can be effective at reducing intrusiveness (Kotzen \& English, 2014). Noise barriers constructed around schools and ECCs may

\section{Page 154 of 182}


be an effective tool to reduce student exposure to harmful noise levels, though thought should also be given to aesthetics to ensure designs are not visually intrusive.

Noise reduction within the classroom is another solution to reducing noise levels for students and children. Insulation in classrooms is another quasi-noise barrier whether it is wall insulation, double-glazed windows, window shutters or acoustic foam. These indoor measures are only beneficial while students and children are inside, and not during, for example, lunch breaks. Noise barriers are still effective at lowering noise levels both inside and outside the classroom.

\section{Road surface}

Road surface type and surface features can modify noise levels generated by traffic. Selecting appropriate surface types and the placement of surface features around schools and ECCs can reduce noise levels. The road surface type affects noise produced from the interaction between the tyre and road (i.e., rolling noise). Adding pores to the surface allows air to flow into the road surface, absorbing noise, while having a smooth texture and less stiff surface lessens the impact of tyres on the road (Waka Kotahi, 2014). Typical roads in New Zealand are chip seal (89\%) (Waka Kotahi, 2014) which does not have optimal acoustic performance. Other road surface types such as porous asphalt and stone mastic asphalt offer better acoustic performance (Waka Kotahi, 2014). Research into new even quieter road surface types continues: poro-elastic rubber surfaces, using rubber crumb or rubberised bitumen can provide substantial noise reductions of 10dB (Waka Kotahi, 2014). Since rolling noise is dominant at faster speeds, the greatest benefits would be gained from schools and ECCs adjacent to roads with high speeds. Ensuring roads are

\section{Page 155 of 182}


well maintained around schools will also reduce noise, as potholes and other impurities in the road surface can increase impact and road noise. If the road surface is porous, keeping the pores clean is important. This can be maintained by regular vacuum cleaning or spray cleaning roads to ensure road pores remain open (Waka Kotahi, 2014).

The placement of features on the road surface can affect the noise output. Fire hydrants and manholes can generate impact noise with tyres (Waka Kotahi, 2014). Placing or re-placing these away from wheel paths around schools or ECCs may reduce noise levels. Speed humps could have a mixed impact. Any bumps in roads generate impact noise with tyres (Waka Kotahi, 2014), however speed humps also work to reduce speed, which lowers propulsion and rolling noise generated by vehicles.

\section{Modifications of driver behaviour}

Modifications to drivers' speed along the road can be useful for reducing noise. Reduction in speed can be achieved through 'hard' approaches such as lowering speed limits (New Zealand Transport Agency, 2011), or 'soft' approaches, which encourage drivers to choose lower speeds (Elliott, McColl, \& Kennedy, 2003). Many of these solutions are originally designed for reducing speed for road safety but could be adapted to reduce noise pollution around sensitive areas, such as schools and ECCs. An example is variable speed limits around schools, where electronic signage alerts drivers of a change in speed limit during certain times of the day. Variable speed limits for school zones have been in place at some New Zealand schools from 2000 onwards but are currently only intended for improving road safety for motor vehicle traffic crashes. The current guidelines allow

\section{Page 156 of 182}


for speeds to be reduced at times when students are likely to be present on roads, i.e. 35 minutes before school commences and 20 minutes after school concludes (New Zealand Transport Agency, 2011). Extending these speed restrictions to cover all times children are at school could achieve a reduction in noise generated near schools. Variable speed limits are currently only mandated for use outside schools; however, extending use to outside ECCs could also reduce noise levels and increase safety. Though driver compliance with variable speed signs are generally high on highways (Hawkins, Wainwright, \& Tignor, 1999), they are restricted to use during rush hour periods. Drivers may find all-day lower speed limits outside schools and ECCs tiring, so a concern for variable speed limits is driver compliance. Speed cameras, used to identify those speeding may help to improve compliance to variable speed limits (Hawkins et al., 1999).

Soft approaches to reducing speed give drivers a psychological push to drive slower. Narrowing road widths, increasing footpath width, pinch point narrowing, and adding traffic islands are all examples of features which can encourage drivers to reduce speed without enforcing hard limits (Elliott et al., 2003). Many suggested soft approaches to reducing speed come from a background of reducing speed for road safety rather than noise reduction, and as a result, not all solutions are appropriate for reducing noise. Increasing the roughness of the road surface, rumble strips, and speed humps are examples of soft approaches to reduce speed. These approaches reduce speed by creating vibrations, which cause driver discomfort at higher speeds. These vibrations, however, also generate noise, meaning these types of solutions may not be effective for reducing noise levels near schools and ECCs (Elliott et al., 2003).

\section{Page 157 of 182}


In addition to reducing the speed of drivers, offsetting drive times relative to school/ECC operating hours could also help to reduce traffic noise by reducing traffic volumes. Pushing school times back, for example, starting later in the morning might avoid noise produced the morning rush hour. Though, in this study we found that noise levels increased as school roll size increased for high schools. We reasoned this was likely due to a significant amount of traffic around schools deriving from people commuting to schools for work or study. If this is the case, the impact of offsetting school start times to avoid peak travel times may be lessened, particularly for large schools. Later start times have been studied for teenage students and found it fits natural sleep cycles for teenagers resulting in less sleepiness and greater school attendance (Wahistrom, 2002).

\section{Electric vehicle uptake}

Electric vehicle (EV) usage has increased in many countries over the past decade (2010 - 2020) (Rietmann, Hügler, \& Lieven, 2020). In New Zealand, light electric vehicle registrations were 161 in 2013, and had grown to 18,500 by 2019 (Environmental Health Indicators, 2020). The worldwide vehicle fleet is expected to comprise 30\% electric vehicles by 2032, growing to almost 50\% by 2035 (Rietmann et al., 2020). Although the trend is driven primarily to reduce greenhouse gas emissions, it is fortuitous that it also has the potential to reduce vehicle noise. Compared to internal combustion engines (ICE), electric engines generate much less noise and as a result, the propulsion component of noise is significantly reduced for EVs compared to traditional ICE vehicles. The noise difference is greatest at idle speeds and gradually reduces to near-zero at high speeds. At low speeds, the propulsion component (e.g., engine) dominates total noise, while at higher speeds the rolling noise component (e.g., interaction between the tyres and road) dominates total noise. At

\section{Page 158 of 182}


idle (i.e. zero rolling noise component), EVs are $15 \mathrm{~dB}$ quieter compared to ICE vehicles, at city speed (15-50 km/h), EVs are 5-6dB quieter compared to ICE vehicles and at speeds greater than $50 \mathrm{~km} / \mathrm{h}$ the difference is negligible (Jabben, Verheijen, \& Potma, 2012). Therefore, any reduction in noise from the uptake of electric vehicles would be largely limited to schools and ECCs located near roads with speed limits less than $50 \mathrm{~km} / \mathrm{h}$. EVs could consequently widen in differences in noise levels. Schools/ECCs located near city roads (>50 km/h) will benefit from EV uptake, while schools/ECCs located near high-speed roads $(<50 \mathrm{~km} / \mathrm{h})$ will not benefit from this. Compounding the issue for schools/ECCs near high speed roads is the growth in the total number of vehicles, which have grown year on year both in real terms and per capita (Environmental Health Indicators, 2020) and state highway traffic volumes have also increased in Wellington (NZTA, 2018). If these trends continue, noise generated at high-speed motorways will also likely increase due to traffic volume, despite the future uptake of EVs.

\section{Reducing vehicle volumes}

Reducing traffic volumes would also be an effective strategy for reducing noise around schools and ECCs, which could be accomplished by encouraging alternative forms of transport to the private car, such as public and active transport. The use of public and active transport is especially important as a method of travelling to school. For secondary schools, we noticed a positive relationship between noise levels and school roll size. As secondary school increased, noise levels increased. This trend could be as a result of schools being a destination for traffic attracting higher traffic volumes.

\section{Page 159 of 182}




\section{Location planning for new facilities}

Mitigation techniques can only reduce noise levels by so much. When initially planning the location for a new school or ECC, much more weight should be given to the expected noise level at the

facilities. Setting maximum noise levels as been suggested by Canterbury District Health Board (CDHB) (Canterbury District Health Board, 2017) and ARPHS (Auckland Regional Public Health Service, 2013). 


\subsection{Regulatory context}

In New Zealand, no official legislation exists around the placement of ECCs or schools relative to noise levels or as a proxy, road traffic. However, two agencies, the CDHB and ARPHS have issued unofficial guidance on siting ECCs and schools in locations with appropriate noise levels. CDHB advised noise levels should not exceed WHO Environmental Noise Guidelines (i.e. 53dB) in ECCs (Canterbury District Health Board, 2017). ARPHS suggested limits of 30dB for sleeping (preschools), 35dB for school classrooms, and 55dB for school grounds/playgrounds (Auckland Regional Public Health Service, 2013). These limits were based on the older WHO guidelines, Guidelines for community noise, published in 1999 (Berglund et al., 1999). While this study only covered the Wellington Territorial Authority as a study area, we found evidence that many ECCs and schools exceed the WHO guidelines for noise. Noise levels for ECC buildings were on average higher compared to all other buildings, and higher than buildings used for schools.

$\mathrm{CDHB}$ stated that planning restrictions were encouraging centres to consider inappropriate locations (Canterbury District Health Board, 2017). Based on the evidence of this study, CDHB likely has well founded concerns about noise levels at schools and ECCs. However, the issue is likely to be more complex than planning restrictions alone. In this study we have explored alternative explanations of as to why ECCs and schools may have higher noise levels compared to other buildings. These include convenience for parents, costs-benefit decisions for privately owned and community led facilities as well as the role of larger roll sizes which could drive up traffic volumes and road noise.

\section{Page 161 of 182}




\section{Chapter 6: Conclusions}

In this study, we used GIS methods to model noise levels at schools and ECCs, validating modelled results against volunteered noise measurements, and examining differences in noise levels by socio-demographic variables, land use, and proximity to roads. We found excessive noise levels were common across Wellington, with $29.5 \%$ of all buildings examined in the case study area exceeding the WHO Environmental Noise guidelines 2018 (53dB daytime). Buildings in the central and industrial areas had the highest mean noise levels, $61.5 \mathrm{~dB}$ and $56.9 \mathrm{~dB}$, respectively. In addition, buildings located on school and ECC grounds had higher modelled noise levels and exceeded the WHO's Environmental Noise guidelines more frequently compared to other buildings. Around $67 \%$ of schools and $58 \%$ of ECCs exceeded WHO guidelines ( $53 \mathrm{~dB}$ daytime). In general, the current locations of many schools and ECCs are likely to expose children and students to excessive noise levels, with implications for health, wellbeing, and learning. In addition, for ECCs, the proportion exceeding the nighttime guideline value of $45 \mathrm{~dB}$ rises to $85 \%$, meaning very few facilities are likely to be able to provide quality naptime.

We found excessive noise levels were not evenly spread across schools of different sociodemographic groups either. Examining noise levels for schools and ECCs by socio-demographic variables, we found evidence that some vulnerable groups of children and students experienced higher noise levels compared to others. International students had higher modelled noise levels (54.2dB) compared to domestic students $(51.7 \mathrm{~dB})$. This is of particular concern, as there is evidence L2 language comprehension deteriorates at lower noise levels compared to native

\section{Page 162 of 182}


English-speakers, meaning more vulnerable L2 international students may also be exposed to higher noise levels.

We found noise levels for ECCs differed by ownership type. Privately run facilities experienced higher noise levels compared to community led facilities. Drivers for this could be differences in the most convenient locations for parents, and different values the facility types place on aspects such as profitability and involving parents in decision making.

We also found noise levels at secondary schools increased as roll sizes increased. We propose that this could be because larger roll sizes attract more traffic, generating higher noise levels. The total teaching staff, support staff, and children who are likely to have schools as commuting destinations is considerable, about $15 \%$ of the case study population. The choice of transport mode to and from school for this population likely impacts noise levels around schools. In the last 50 years, transport modes to school have trended toward favouring private vehicles over active transport, likely contributing to higher noise levels.

Distance to major roads has previously been used as a proxy or indicator measure of environmental noise. However, in this study, we found distance to major roads was a poor indicator of noise levels and explained just $2 \%$ of modelled noise levels, and distance to roads of any hierarchy explained $27 \%$ of modelled noise levels. Distance to major roads may have some applications in areas where sufficient data to model road noise is not available, such as in the developing world, however, where data permits, modelled noise levels should be favoured.

\section{Page 163 of 182}


When comparing modelled noise levels in this study to volunteered in situ noise measurements, the results of the model were reasonable for high modelled noise levels ( $81 \%$ within $15 \mathrm{~dB}$ ). However, due to bias sampling of volunteered noise data we were not able to comment on the models performance at lower noise levels.

The findings of this study are likely to be of interest to decision makers participating in the urban planning, transport, education, and health sectors. The findings could help to form better policy to mitigate exposure to excessive noise levels around schools and ECCs. For example, better selecting where new schools and ECCs can be located with respect to noise levels, and identifying which facilities need additional interventions to ensure noise levels are safe for children and students. For researchers interested in environmental health at school and ECC environments, this study improves our understanding of noise pollution exposure, its relationship with socio-demographic factors and offers an improvement on indicator methods such as land use and distance to roads.

\subsection{Future research}

This study also leads the way for future research in a number of related areas, including adjusting model parameters to answer questions about the future, expanding the research to additional exposure sources and sites, and examining the relationship between noise pollution and other environmental factors.

\section{Page 164 of 182}




\section{Adjusting model parameters to predict future noise levels}

The effects of noise pollution are often not included in studies assessing the benefits of increasing active transport to and from schools, with reduced obesity, cardiovascular disease, and physical injury through motor vehicle traffic crashes being the main benefits considered (Kingham et al., 2011). Increasing active transport to schools would result in a reduction in the number of vehicles travelling around schools, which is linked to road traffic noise. The methodology used in this study could be adjusted to answer questions such as what the impact of decreasing traffic around schools would have on noise levels. Future iterations of the CNSOSSEU standard are also likely to incorporate the effects of EVs on noise generation (Pallas et al., 2016). Including the effects of an increasing composition of EVs could begin to answer questions around which schools and ECCS are most likely to benefit from a reduction in noise levels caused by future EV uptake.

\section{Additional sources of noise pollution exposure}

While this research focussed on the effects of traffic generated noise pollution, there are other significant sources of noise within urban areas, including air traffic and rail. Incorporating multiple noise sources into a noise model would gauge the full impact of noise pollution. In addition to multiple exposure sources, it would be beneficial to examine different sites of exposure as well. Increasing the study beyond the school and ECC environments to include, for example residential buildings, would increase our understanding of the cumulative time exposed to noise pollution.

\section{Page 165 of 182}


Relationship between noise and other environmental factors

Noise pollution exposure is one of several environmental factors which impacts children's health at schools and ECCs. Other environmental factors which impact children's health include air pollution and injuries from motor vehicle traffic crashes. Little research has accounted for the combined health effects of noise and air pollution, and motor vehicle traffic crashes around schools. However, studying these factors together is important in understanding the total impact busy roads have on children's health. 


\section{References}

Adams, R. J., Howard, N., Tucker, G., Appleton, S., Taylor, A. W., Chittleborough, C., .. Wilson, D. H. (2009). Effects of area deprivation on health risks and outcomes: a multilevel, cross-sectional, Australian population study. International journal of public health, 54(3), 183-192.

Aguilera, I., Foraster, M., Basagaña, X., Corradi, E., Deltell, A., Morelli, X., . . Thomasson, A. (2015). Application of land use regression modelling to assess the spatial distribution of road traffic noise in three European cities. Journal of Exposure Science \& Environmental Epidemiology, 25(1), 97-105.

Alexander, S. (2020). Is Our Publicly-Funded Early Childhood Education Good Enough for Children? Results from the 2020 Survey of Teaching Staff. Retrieved from https://www.childforum.com/reports/1901-quality.html

Alías, F., \& Socoró, J. C. (2017). Description of anomalous noise events for reliable dynamic traffic noise mapping in real-life urban and suburban soundscapes. Applied Sciences, 7(2), 146.

Amram, O., Abernethy, R., Brauer, M., Davies, H., \& Allen, R. W. (2011). Proximity of public elementary schools to major roads in Canadian urban areas. International journal of health geographics, 10(1), 68.

Andringa, T. C., \& Lanser, J. J. L. (2013). How pleasant sounds promote and annoying sounds impede health: A cognitive approach. International journal of environmental research and public health, 10(4), 1439-1461.

Anfosso-Lédée, F., \& Pichaud, Y. (2007). Temperature effect on tyre-road noise. Applied Acoustics, 68(1), 1-16.

Annual Fleet Statistics. (2016). Wellington: Minsitry of Transport

Antoniou, V., Capineri, C., \& Haklay, M. M. (2017). VGI and beyond: From data to mapping. In The Routledge Handbook of Mapping and Cartography (pp. 475-488): Routledge.

Appatova, A. S., Ryan, P. H., LeMasters, G. K., \& Grinshpun, S. A. (2008). Proximal exposure of public schools and students to major roadways: a nationwide US survey. Journal of Environmental Planning and Management, 51(5), 631-646.

Auckland Regional Public Health Service. (2013). Health \& Safety Guidelines for Early Childhood Centres. Auckland

Basiri, A., Haklay, M., Foody, G., \& Mooney, P. (2019). Crowdsourced geospatial data quality: Challenges and future directions. In: Taylor \& Francis. 
Berglund, B., \& Lindvall, T. (1995). Community Noise. Stockholm: Center for Sensory Research: Stockholm University and Karolinska Institute.

Berglund, B., Lindvall, T., \& Schwela, D. H. (1999). Guidelines for community noise. World Health Organization.

Bocher, E., Petit, G., Picaut, J., Fortin, N., \& Guillaume, G. (2017). Collaborative noise data collected from smartphones. Data in brief, 14, 498-503.

Brainard, J. S., Jones, A. P., Bateman, I. J., \& Lovett, A. A. (2004). Exposure to environmental urban noise pollution in Birmingham, UK. Urban Studies, 41(13), 2581-2600.

Briggs, D. (2003). Making a difference: Indicators to improve children's environmental health. WHO

Briggs, D., Mason, K., \& Borman, B. (2015). Rapid assessment of environmental health impacts for policy support: The example of road transport in New Zealand. International journal of environmental research and public health, 13(1), 61.

Bueno, M., Luong, J., Viñuela, U., Terán, F., \& Paje, S. (2011). Pavement temperature influence on close proximity tire/road noise. Applied Acoustics, 72(11), 829-835.

Canterbury District Health Board. (2017). Early childhood centre information. Christchurch: Canterbury District Health Board

CDC. (2016). 10 Leading Causes of Injury Deaths by Age Group Highlighting Unintentional Injury Deaths, Unite States - 2016. In C. f. D. C. a. Prevention (Ed.). cdc.gov.

Chakraborty, J., \& Zandbergen, P. A. (2007). Children at risk: measuring racial/ethnic disparities in potential exposure to air pollution at school and home. Journal of Epidemiology \& Community Health, 61(12), 1074-1079.

Chappell, P. (2014). The climate and weather of Wellington. NIWA Science and Technology Series(65).

Christchurch City Council. (n.d.). Traffic count data. Retrieved from https://ccc.govt.nz/transport/transport-projects/traffic-count-data

Considine, G., \& Zappalà, G. (2002). The influence of social and economic disadvantage in the academic performance of school students in Australia. Journal of sociology, 38(2), 129-148.

Crowley, S. (2003). The affordable housing crisis: Residential mobility of poor families and school mobility of poor children. Journal of Negro Education, 22-38.

Damm, A. P. (2009). Determinants of recent immigrants' location choices: quasi-experimental evidence. Journal of population Economics, 22(1), 145-174.

Dargay, J., Gately, D., \& Sommer, M. (2007). Vehicle ownership and income growth, worldwide: 19602030. The Energy Journal, 143-170. 
DataKustik. (n.d.). CadnaA - Computer Aided Noise Abatement. Retrieved from https://www.datakustik.com/products/cadnaa/cadnaa/

de Lisle, S. (2016). Comparison of road traffic noise prediction models: CoRTN, TNM, NMPB, ASJ RTN. Acoustics Australia, 44(3), 409-413.

Department of Transport Welsh Office. (1988). Calculation of Road Traffic Noise. Wales: HMSO Books Retrieved from http://programmeofficers.co.uk/Preston/CoreDocuments/LCC389.pdf

Dragutinovic, N., \& Twisk, D. (2006). The effectiveness of road safety education: A literature review. SWOV Institute for Road Safety Research.

Dutta, J., Pramanick, P., \& Roy, S. (2017). NoiseSense: Crowdsourced context aware sensing for real time noise pollution monitoring of the city. Paper presented at the 2017 IEEE international conference on advanced networks and telecommunications systems (ANTS).

Dzhambov, A. M. (2015). Long-term noise exposure and the risk for type 2 diabetes: a meta-analysis. Noise \& health, 17(74), 23.

Education Counts. (2020). Teacher Numbers by School (2008-2019). Retrieved from https://www.educationcounts.govt.nz/statistics/teacher-workforce\#6

Education Counts. (n.d.). Directories. Retrieved from https://www.educationcounts.govt.nz/directories

education.govt.nz. (n.d.-a). Equity Index Assessment. Retrieved from https://www.educationcounts.govt.nz/data-services/collecting-information/collectionforms/equity-index-assessment

education.govt.nz. (n.d.-b). School deciles. Retrieved from https://www.education.govt.nz/school/funding-and-financials/resourcing/operationalfunding/school-decile-ratings/\#How

Elliott, M., McColl, V., \& Kennedy, J. V. (2003). Road design measures to reduce drivers' speed via'psychological'processes: a literature review: TRL.

Environmental Health Indicators. (2020). Average age of vehicle fleet. Factsheet, Wellington: Environmental Health Indicators Programme, Massey University.

Environmental Protection Agency of Piedmont Italy. (2019a). opeNoise (Version Version 1.3).

Environmental Protection Agency of Piedmont Italy. (2019b). OpeNoise-Map. Retrieved from https://github.com/Arpapiemonte/openoise-map

ESRI. (2020). ArcGIS Pro 2.6.0. Redlands, CA: Environmental Systems Research Institute. 
European Comission. (2002). The Environmental Noise Directive. Retrieved from https://ec.europa.eu/environment/archives/noise/directive.htm

Flanagin, A. J., \& Metzger, M. J. (2008). The credibility of volunteered geographic information. GeoJournal, 72(3-4), 137-148.

Garnier, M., \& Henrich, N. (2014). Speaking in noise: How does the Lombard effect improve acoustic contrasts between speech and ambient noise? Computer Speech \& Language, 28(2), 580-597.

Gauderman, W. J., Avol, E., Gilliland, F., Vora, H., Thomas, D., Berhane, K., . . Rappaport, E. (2004). The effect of air pollution on lung development from 10 to 18 years of age. New England Journal of Medicine, 351(11), 1057-1067. Retrieved from https://www.nejm.org/doi/pdf/10.1056/NEJMoa040610

Giles-Corti, B., Wood, G., Pikora, T., Learnihan, V., Bulsara, M., Van Niel, K., . . Villanueva, K. (2011). School site and the potential to walk to school: The impact of street connectivity and traffic exposure in school neighborhoods. Health \& place, 17(2), 545-550.

Green, R. S., Smorodinsky, S., Kim, J. J., McLaughlin, R., \& Ostro, B. (2004). Proximity of California public schools to busy roads. Environmental health perspectives, 112(1), 61. Retrieved from https://www.ncbi.nlm.nih.gov/pmc/articles/PMC1241798/pdf/ehp0112-000061.pdf

Grimes, A., \& Liang, Y. (2009). Spatial determinants of land prices: Does Auckland's metropolitan urban limit have an effect? Applied Spatial Analysis and Policy, 2(1), 23-45.

Gulliver, J., Morley, D., Vienneau, D., Fabbri, F., Bell, M., Goodman, P., ... Fecht, D. (2015). Development of an open-source road traffic noise model for exposure assessment. Environmental Modelling \& Software, 74, 183-193.

Gupta, A., Gupta, A., Jain, K., \& Gupta, S. (2018). Noise pollution and impact on children health. The Indian Journal of Pediatrics, 85(4), 300-306.

Gurley, T., \& Bruce, D. (2005). The effects of car access on employment outcomes for welfare recipients. Journal of urban Economics, 58(2), 250-272.

Hawkins, H., Wainwright, W. S., \& Tignor, S. C. (1999). Innovative traffic control practices in Europe.

Herfort, B., Lautenbach, S., de Albuquerque, J. P., Anderson, J., \& Zipf, A. (2021). The evolution of humanitarian mapping within the OpenStreetMap community. Scientific reports, 11(1), 1-15.

Hétu, R., Truchon-Gagnon, C., \& Bilodeau, S. A. (1990). Problems of noise in school settings: A review of literature and the results of an exploratory study. Journal of Speech-Language Pathology and Audiology.

Hodgson, M. J. (1981). The location of public facilities intermediate to the journey to work. European Journal of Operational Research, 6(2), 199-204. 
Houston, D., Ong, P., Wu, J., \& Winer, A. (2006). Proximity of licensed child care facilities to nearroadway vehicle pollution. American journal of public health, 96(9), 1611-1617. Retrieved from https://cloudfront.escholarship.org/dist/prd/content/qt7zt576cn/qt7zt576cn.pdf?t=nhxlf5

Hugo, G. (1995). Understanding where immigrants live: Australian Government Publishing Service.

Hygge, S. (2003). Classroom experiments on the effects of different noise sources and sound levels on long-term recall and recognition in children. Applied Cognitive Psychology: The Official Journal of the Society for Applied Research in Memory and Cognition, 17(8), 895-914.

Jabben, J., Verheijen, E., \& Potma, C. (2012). Noise reduction by electric vehicles in the Netherlands. Paper presented at the INTER-NOISE and NOISE-CON Congress and Conference Proceedings.

Jeon, J. Y., Lee, P. J., You, J., \& Kang, J. (2010). Perceptual assessment of quality of urban soundscapes with combined noise sources and water sounds. The Journal of the Acoustical Society of America, 127(3), 1357-1366.

Kephalopoulos, S., Paviotti, M., \& Anfosso-Lédée, F. (2012). Common noise assessment methods in Europe (CNOSSOS-EU). In (pp. 180 p): Publications Office of the European Union.

Kim, J., Smorodinsky, S., Lipsett, M., Singer, B., Hodgson, A., \& Ostro, B. (2004). Traffic-related air pollution near busy roads: the East Bay Children's Respiratory Health Study. American journal of respiratory and critical care medicine, 170(5), 520-526.

Kim, M., Chang, S. I., Seong, J. C., Holt, J. B., Park, T. H., Ko, J. H., \& Croft, J. B. (2012). Road traffic noise: annoyance, sleep disturbance, and public health implications. American journal of preventive medicine, 43(4), 353-360.

Kingham, S., Sabel, C. E., \& Bartie, P. (2011). The impact of the 'school run'on road traffic accidents: A spatio-temporal analysis. Journal of transport geography, 19(4), 705-711.

kohangareo.ac.nz. (n.d.). Te Kohanga Reo. Retrieved from https://www.kohanga.ac.nz/en/

Kotzen, B., \& English, C. (2014). Environmental noise barriers: a guide to their acoustic and visual design: CRC Press.

Kruskal, W. H., \& Wallis, W. A. (1952). Use of ranks in one-criterion variance analysis. Journal of the American statistical Association, 47(260), 583-621.

Land Information New Zealand. (2017). Wellington LiDAR Im DEM (2013-2014). Retrieved from: https://data.linz.govt.nz/layer/53621-wellington-lidar-1m-dem-2013-2014/metadata/

Land Information New Zealand. (2019). An open building outlines dataset for New Zealand. Retrieved from https://medium.com/on-location/an-open-building-outlines-dataset-for-new-zealandeef8b558ef7a 
Land Information New Zealand. (2020). NZ Primary Parcels. Retrieved from: https://data.linz.govt.nz/layer/50772-nz-primary-parcels/metadata/

Lindberg, K. (2019). Active transport to and from school [Factsheet]. In M. U. Environmental Health Intelligence (Ed.).

LINZ. (n.d.). NZ Buildings Data Dictionary. Retrieved from https://nzbuildings.readthedocs.io/en/latest/index.html

Lucas, K. (2012). Transport and social exclusion: Where are we now? Transport policy, 20, 105-113.

Lwin, K., \& Murayama, Y. (2009). A GIS approach to estimation of building population for micro-spatial analysis. Transactions in GIS, 13(4), 401-414.

Lynch, S. M. (2006). Explaining life course and cohort variation in the relationship between education and health: The role of income. Journal of Health and Social Behavior, 47(4), 324-338.

Maher, A., Wilson, N., \& Signal, L. (2005). Advertising and availability of'obesogenic'foods around New Zealand secondary schools: a pilot study. The New Zealand Medical Journal (Online), 118(1218).

Maisonneuve, N., Stevens, M., Niessen, M. E., \& Steels, L. (2009). NoiseTube: Measuring and mapping noise pollution with mobile phones. In Information technologies in environmental engineering (pp. 215-228): Springer.

Mann, H. B., \& Whitney, D. R. (1947). On a test of whether one of two random variables is stochastically larger than the other. The annals of mathematical statistics, 50-60.

Maré, D. C., Morten, M., \& Stillman, S. (2007). Settlement patterns and the geographic mobility of recent migrants to New Zealand. New Zealand Economic Papers, 41(2), 163-195.

Marten, N., \& Olds, T. (2004). Physical activity: patterns of active transport in 11-12 year old Australian children. Australian and New Zealand journal of public health, 28(2), 167-172.

Mason, L., Haenfling, Schori, Thomas, Popovich, Faulkner, Beban, Gunnel, Marsters, Read, Borman. (2019). ocial vulnerability indicators for flooding in Aotearoa New Zealand: Research report. Retrieved from Wellngton:

McCarthy, T., \& Ratcliffe, J. (2005). Garbage in, garbage out: geocoding accuracy and spatial analysis of crime. In Geographic information systems and crime analysis (pp. 45-59): IGI Global.

McDonald, N. C. (2005). Children's travel: patterns and influences. University of California, Berkeley.

McLaren, S. J. (2008). Noise in early childhood education centres: the effects on the children and their teachers: a thesis presented in partial fulfilment of the requirements for the degree of Doctor of Philosophy at Massey University, Wellington, New Zealand. Massey University, 
Education (Early Childhood Services) regulations 2008, § Schedule 3 (2008).

Ministry of Education. (2011). Ministry of Education Statenment of intent 2011/12-2016/17. Retrieved from https://www.education.govt.nz/assets/Documents/Ministry/Publications/Statementsof-intent/SOI2011Web.pdf

Ministry of Education. (2013). INTERNATIONAL STUDENT ENROLMENTS IN NEW ZEALAND 2006-2012.

Ministry of Education. (n.d.). Different kinds of early learning services. Retrieved from https://parents.education.govt.nz/early-learning/early-childhood-education/different-kindsof-early-childhood-education/

Ministry of Health. (2014, 6 June 2014). Treaty of Waitangi principles. Retrieved from https://www.health.govt.nz/our-work/populations/maori-health/he-korowaioranga/strengthening-he-korowai-oranga/treaty-waitangi-principles

Land Transport Rule Setting of Speed Limits 2017 Rule 54001/2017, 54001/2017 C.F.R. (2017).

Ministry of Transport. (2018). RD027 Vehicle ownership per capita. Retrieved from https://www.transport.govt.nz/mot-resources/transport-dashboard/2-road-transport/rd027vehicle-ownership-percapita/\#: :text=There\%20were\%200.79\%20light\%20passenger,in\%20New\%20Zealand\%20in \%202017.\&text=(1)\%20www.itf\%2D,\%2Fstatistics\%2Dand\%2Ddata\%3F

Ministry of Transport. (n.d.). Fleet statistics. Retrieved from https://www.transport.govt.nz/statisticsand-insights/fleet-statistics/sheet/vehicle-fleet

Mitchell, L. (2002). Differences between community owned and privately owned early childhood education and care centres: A review of evidence (Vol. 12): NZCER Wellington, NZ.

Morley, D., De Hoogh, K., Fecht, D., Fabbri, F., Bell, M., Goodman, P., .. . Gulliver, J. (2015). International scale implementation of the CNOSSOS-EU road traffic noise prediction model for epidemiological studies. Environmental pollution, 206, 332-341.

Mutch, C. (2004). The rise and rise of early childhood education in New Zealand. Citizenship, Social and Economics Education, 6(1), 1-11.

Nelson, P., Kohnert, K., Sabur, S., \& Shaw, D. (2005). Classroom noise and children learning through a second language. Language, Speech, and Hearing Services in Schools.

New Zealand Qualification Authority. (2015). Secondary Statistics Consolidated Files Retrieved from: https://catalogue.data.govt.nz/dataset/secondary-statistics-consolidated-files

New Zealand Transport Agency. (2011). 40km/h variable speed limits in school zones - guidelines. Retrieved from https://www.nzta.govt.nz/assets/resources/traffic-notes/docs/traffic-note-37rev2.pdf 
NIWA. (n.d.). Mean monthly temperatures $\left({ }^{\circ} \mathrm{C}\right)$. Retrieved from: https://niwa.co.nz/education-andtraining/schools/resources/climate/meanairtemp

Land Transport Rule: Tyres and Wheels Amendment, 2 C.F.R. (2009).

NZTA. (2018). National telemetry site profiles. Retrieved from https://www.transport.govt.nz/resources/road-safetyresources/roadcrashstatistics/motorvehiclecrashesinnewzealand/motor-vehicle-crashes-innew-zealand-2016/

NZTA. (2019). National Road Centreline data. Retrieved from: https://www.nzta.govt.nz/aboutus/open-data/national-road-centreline-data-request

OECD. (2013). Environment at a Glance (Figure 2.11. Motor vehicle ownership, 2011 or latest available). In.

Oftedal, B., Krog, N. H., Pyko, A., Eriksson, C., Graff-Iversen, S., Haugen, M., . . Aasvang, G. M. (2015). Road traffic noise and markers of obesity-a population-based study. Environmental research, 138, 144-153.

OpenStreetMap. (2019). OpenStreetMap Data Extracts. Retrieved from: https://download.geofabrik.de/

Pallas, M.-A., Berengier, M., Chatagnon, R., Czuka, M., Conter, M., \& Muirhead, M. (2016). Towards a model for electric vehicle noise emission in the European prediction method CNOSSOS-EU. Applied Acoustics, 113, 89-101.

Pampalon, R., Hamel, D., Gamache, P., \& Raymond, G. (2009). A deprivation index for health planning in Canada. Chronic Dis Can, 29(4), 178-191.

Passchier-Vermeer, W., \& Passchier, W. F. (2000). Noise exposure and public health. Environmental health perspectives, 108(suppl 1), 123-131.

Paz, E. C., \& Zannin, P. H. T. T. (2008). Perception of Noise in suburban and urban areas. Journal of the Acoustical Society of America, 123(5), 3821.

Pearson, K. (1900). X. On the criterion that a given system of deviations from the probable in the case of a correlated system of variables is such that it can be reasonably supposed to have arisen from random sampling. The London, Edinburgh, and Dublin Philosophical Magazine and Journal of Science, 50(302), 157-175.

Peng, J., Kessissoglou, N., \& Parnell, J. (2017). Evaluation of Calculation of Road Traffic Noise in Australia. Paper presented at the INTER-NOISE and NOISE-CON Congress and Conference Proceedings.

Peng, J., Parnell, J., \& Kessissoglou, N. (2019). Comparison of equivalent continuous noise levels and day-evening-night composite noise indicators for assessment of road traffic noise. Paper presented at the Proceedings of ACOUSTICS. 
Piccolo, A., Plutino, D., \& Cannistraro, G. (2005). Evaluation and analysis of the environmental noise of Messina, Italy. Applied Acoustics, 66(4), 447-465.

Poulikakosa, L., Mayer, R., Heutschia, K., Soltica, P., Leesc, A., \& Van Lood, H. (2016). Defining road and rail vehicles with a low environmental footprint. Transportation Research Procedia, 14, 830839.

Poulton, E. C. (1978). A new look at the effects of noise: A rejoinder.

QGIS.org. (2021). QGIS Geographic Information System. http://www.qgis.org/

Quattrone, G., Capra, L., \& De Meo, P. (2015). There's no such thing as the perfect map: Quantifying bias in spatial crowd-sourcing datasets. Paper presented at the Proceedings of the 18th ACM Conference on Computer Supported Cooperative Work \& Social Computing.

R Core Team. (2021). R: A language and environment for statistical computing (Version 4.1.1). Boston, MA. Retrieved from https://www.R-project.org/

Ragettli, M. S., Goudreau, S., Plante, C., Fournier, M., Hatzopoulou, M., Perron, S., \& Smargiassi, A. (2016). Statistical modeling of the spatial variability of environmental noise levels in Montreal, Canada, using noise measurements and land use characteristics. Journal of Exposure Science \& Environmental Epidemiology, 26(6), 597-605.

Rajakumara, H., \& Gowda, R. M. (2008). Road traffic noise prediction models: A Review. International Journal of Sustainable Development and Planning, 3(3), 257-271.

Riedel, N., Köckler, H., van Kamp, I., Scheiner, J., Erbel, R., Loerbroks, A., . . Bolte, G. (2018). Perceived noise control and its value in the association of road traffic noise with noise annoyance. European Journal of Public Health, 28(suppl_4), cky213.317.

Rietmann, N., Hügler, B., \& Lieven, T. (2020). Forecasting the trajectory of electric vehicle sales and the consequences for worldwide CO2 emissions. Journal of Cleaner Production, 261, 121038.

Ross, Z., Kheirbek, I., Clougherty, J. E., Ito, K., Matte, T., Markowitz, S., \& Eisl, H. (2011). Noise, air pollutants and traffic: continuous measurement and correlation at a high-traffic location in New York City. Environmental research, 111(8), 1054-1063.

Sacred Heart Cathedral School. (n.d.). Our History Sacred Heart Cathedral School. Retrieved from https://www.sacred-heart.school.nz/our-school/history/

Sanz, S. A., García, A. M., \& García, A. (1993). Road traffic noise around schools: a risk for pupil's performance? International Archives of Occupational and Environmental Health, 65(3), 205-207.

Sargent, J., Gidman, M., Humphreys, M., \& Utley, W. (1980). The disturbance caused to school teachers by noise. Journal of Sound and Vibration, 70(4), 557-572.

SAS Institute Inc. (2020). SAS 9.4,. Cary, NC. 
Shapiro, S. S., \& Wilk, M. B. (1965). An analysis of variance test for normality (complete samples). Biometrika, 52(3/4), 591-611.

Shield, B., \& Dockrell, J. (2008). The Effects of classroom and environmental noise on children's academic performance. Paper presented at the 9th International Congress on Noise as a Public Health Problem (ICBEN), Foxwoods, CT.

Shield, B., \& Dockrell, J. E. (2004). External and internal noise surveys of London primary schools. The Journal of the Acoustical Society of America, 115(2), 730-738.

Smart, C., Grimes, A., \& Townsend, W. (2018). Ethnic and economic determinants of migrant location choice. In New frontiers in interregional migration research (pp. 181-204): Springer.

Sneyd, M. J., \& Cox, B. (2009). Melanoma in Maori, Asian, and Pacific peoples in New Zealand. Cancer Epidemiology and Prevention Biomarkers, 18(6), 1706-1713.

SoundPlan. (n.d.). SoundPlan - SoundPlan. Retrieved from https://www.soundplan.eu/en/

St Mary's College. (n.d.). St Mary's College - History/Values. Retrieved from https://www.stmw.school.nz/About-1/Special-Character/HistoryValues

Standards New Zealand. (2010). Road traffic noise. Retrieved from https://www.standards.govt.nz/news/media-releases/2010/may/road-traffic-noise

Stansfeld, S., \& Clark, C. (2015). Health effects of noise exposure in children. Current environmental health reports, 2(2), 171-178.

Statistics New Zealand. (2018). 2018 Census. Retrieved from: https://www.stats.govt.nz/2018-census/

Sullivan, B. L., Wood, C. L., Iliff, M. J., Bonney, R. E., Fink, D., \& Kelling, S. (2009). eBird: A citizen-based bird observation network in the biological sciences. Biological conservation, 142(10), 22822292.

Takagi, K., Miyake, T., Yamamoto, K., \& Tachibana, H. (2000). Prediction of road traffic noise around tunnel mouth. Paper presented at the Proc. InterNoise.

Ulf Sandberg, L. G. (2017). ROSANNE: Reference tyres and road surfacesfor skid resistance, noise and rolling resistance measurements. Retrieved from Vienna, Austria:

Vester, A. (2018). Removing the decile label. Ministry of Education

Wahistrom, K. (2002). Changing times: Findings from the first longitudinal study of later high school start times. Nassp Bulletin, 86(633), 3-21.

Waka Kotahi. (2014). Guide to state highway road surface noise. Retrieved from https://www.nzta.govt.nz/assets/resources/road-surface-noise/docs/nzta-surfaces-noiseguide-v1.0.pdf 
Waka Kotahi. (n.d.). One network road classification - functional classification. Retrieved from https://www.nzta.govt.nz/assets/Road-Efficiency-Group/docs/functional-classification.pdf

Walker, G., \& Burningham, K. (2011). Flood risk, vulnerability and environmental justice: evidence and evaluation of inequality in a UK context. Critical social policy, 31(2), 216-240.

Walker, G., Mitchell, G., Fairburn, J., \& Smith, G. (2005). Environmental Quality \& Social Deprivation Phase II: National Analysis of Flood Hazard, IPC Industries \& Air Quality.

Walker, R. E., Keane, C. R., \& Burke, J. G. (2010). Disparities and access to healthy food in the United States: A review of food deserts literature. Health \& place, 16(5), 876-884.

Walsh, M., \& Grey, C. (2019). The contribution of avoidable mortality to the life expectancy gap in Māori and Pacific populations in New Zealand-a decomposition analysis. NZ Med J, 132(1492), 4660.

Wang, F., McLafferty, S., Escamilla, V., \& Luo, L. (2008). Late-stage breast cancer diagnosis and health care access in Illinois. The Professional Geographer, 60(1), 54-69. Retrieved from https://www.ncbi.nlm.nih.gov/pmc/articles/PMC2367325/pdf/nihms43763.pdf

Ward, T. M., Gay, C., Anders, T. F., Alkon, A., \& Lee, K. A. (2008). Sleep and napping patterns in 3-to-5year old children attending full-day childcare centers. Journal of pediatric psychology, 33(6), 666-672.

Warsh, J., Rothman, L., Slater, M., Steverango, C., \& Howard, A. (2009). Are school zones effective? An examination of motor vehicle versus child pedestrian crashes near schools. Injury prevention, 15(4), 226-229. Retrieved from https://injuryprevention.bmj.com/content/injuryprev/15/4/226.full.pdf

Wellington City Council. (2018). WCC District Plan Zones. Retrieved from: https://datawcc.opendata.arcgis.com/datasets/6c3aaccfdbbf470491fb688595cf5b7e 0

Wellington City Council. (n.d.-a). Building and resource consents. Retrieved from https://wellington.govt.nz/property-rates-and-building/building-and-resourceconsents/resource-consents/find-out-if-you-need-a-resource-consent

Wellington City Council. (n.d.-b). Understanding the District Plan. Retrieved from https://wellington.govt.nz/your-council/plans-policies-and-bylaws/district-plan/about-thedistrict-plan/understanding-the-district-plan

Wild, K., Woodward, A., Herbert, S., Tiatia-Seath, J., Collings, S., Shaw, C., \& Ameratunga, S. (2021). The relationship between transport and mental health in Aotearoa New Zealand.

World Health Organization. (2018). Environmental noise guidelines for the European region.

World Health Organization. (2020). Factsheet: Deafness and hearing loss. Retrieved from https://www.who.int/news-room/fact-sheets/detail/deafness-and-hearing-loss 
Wu, Y.-C., \& Batterman, S. A. (2006). Proximity of schools in Detroit, Michigan to automobile and truck traffic. Journal of Exposure Science \& Environmental Epidemiology, 16(5), 457-470.

Xie, D., Liu, Y., \& Chen, J. (2011). Mapping urban environmental noise: a land use regression method. Environmental science \& technology, 45(17), 7358-7364.

Yee Choi, C., \& McPherson, B. (2005). Noise levels in Hong Kong primary schools: Implications for classroom listening. International Journal of Disability, Development and Education, 52(4), 345360.

Yelavich, S., Towns, C., Burt, R., Chow, K., Donohue, R., Sani, H. S., . . Reeder, A. I. (2008). Walking to school: frequency and predictors among primary school children in Dunedin, New Zealand. The New Zealand Medical Journal (Online), 121(1271).

Zhang, G., \& Zhu, A.-X. (2019). A representativeness-directed approach to mitigate spatial bias in VGI for the predictive mapping of geographic phenomena. International Journal of Geographical Information Science, 33(9), 1873-1893.

Zuo, F., Li, Y., Johnson, S., Johnson, J., Varughese, S., Copes, R., ... Chen, H. (2014). Temporal and spatial variability of traffic-related noise in the City of Toronto, Canada. Science of the Total Environment, 472, 1100-1107. 


\section{Appendices}

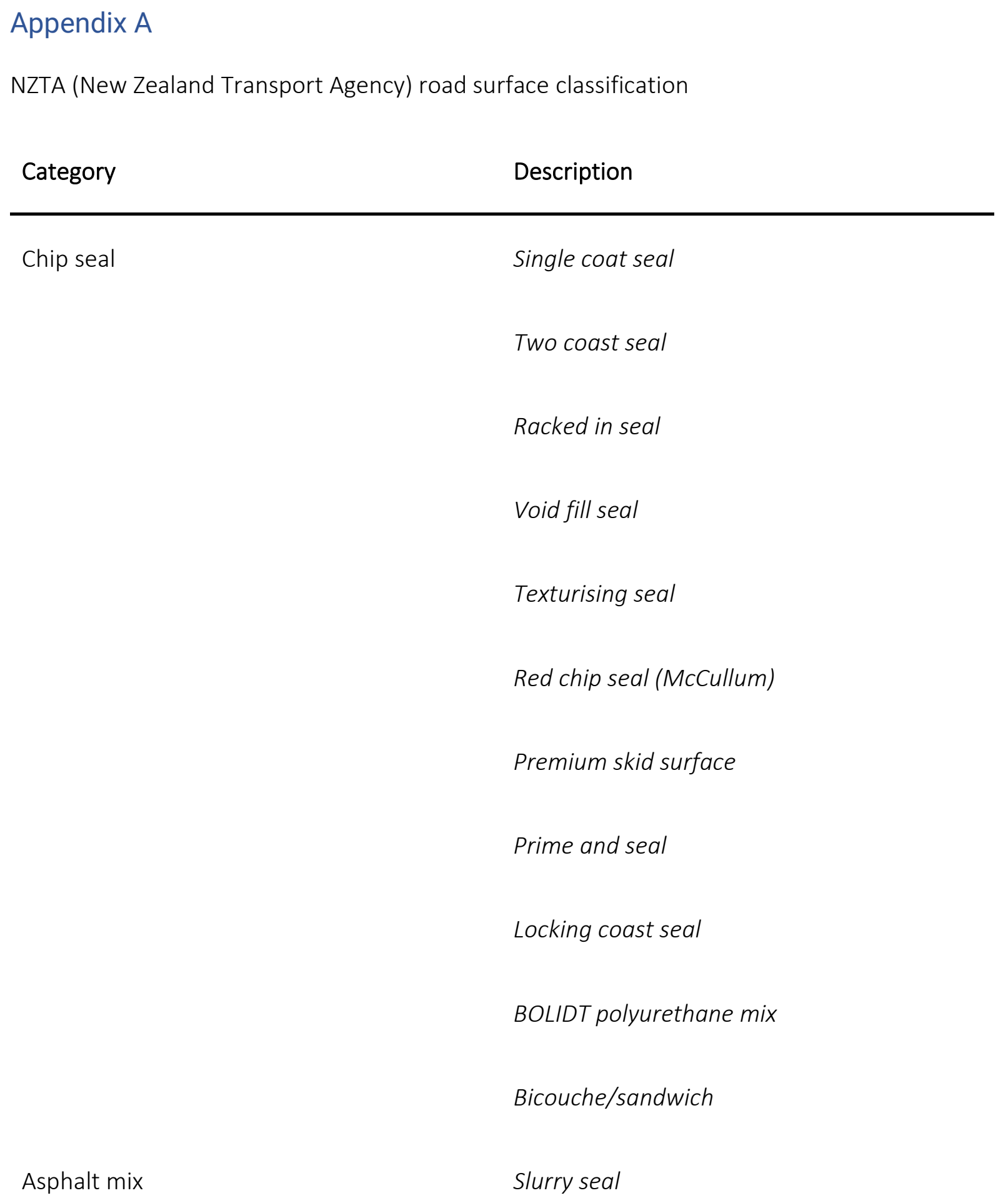

Asphalt mix

Slurry seal

\section{Page 179 of 182}


Cape seal

Asphaltic concrete

Open graded porous asphalt

Open graded emulsion mix

Stone mastic asphalt

Bitumen bound macadam

Concrete

Concrete

Metal

Metal running course

Other

Other material

Interlocking concrete blocks

Source: Waka Kotahi (2014)

\section{Page 180 of 182}


Appendix B

CNOSSOS-EU road surface classification

Code Description

NL-0 Reference road surface: consisting of an average of dense asphalt concrete 0/11 and stone mastic asphalt 0/11 between 2 and 7 years

old and in a representative maintenance condition.

NL-1 1-layer ZOAB

NL-2

2-LAYER ZOAB

$\mathrm{NL}-3$

2-LAYER ZOAB (fine)

NL-4

SMA-NL 5

NL-5

SMA- NL 8

NL-6

Brushed down concrete

NL-7

Optimized brushed down concrete

NL-8

Fine broomed concrete

NL-9

Worked surface

NL-10

Hard elements in herring-bone

NL-11

Hard elements not in herring-bone

Page 181 of 182 
$\mathrm{NL}-12$

$\mathrm{NL}-13$

$\mathrm{NL}-14$
Quiet hard elements

Thin layer $A$

Thin layer $B$

Note:

ZOAB: From Dutch, Zeer Open Asfaltbeton, meaning very open asphalt (i.e., porous concrete)

SMA: Stone Mastic Asphalt

Source: UIf Sandberg (2017)

\section{Page 182 of 182}

